XXII.

Aus dem Röntgenlaboratorium von Prof. Dr. F. de Quervain.

La Chaux-de-Fonds.

\title{
Über Manus valga oder sogenannte Madelungsche Deformität des Handgelenks. Von
}

Dr. Hans Siegrist.

(Mit 20 Abbildungen im Text und Tafel XIII.)

Unter dem Namen "Spontane Subluxation der Hand nach vorne" veröffentlichte im "Archiv für klinische Chirurgie" des Jahres 1879 Madelung die erste genaue Beschreibung einer bis dahin kaum beachteten Affektion des Handgelenks.

Wenn auch das Leiden schon lange vor Madelung bekannt war, so ist es doch erst seit diesem Autor als wohl abgegrenztes Krankheitsbild in den Beachtungskreis der Chirurgie gerïckt. Auf Grund von 1.2 von ihm selbst beobachteten Fällen hat Madelung eine umfassende Darstellung der Krankheit gegeben, als deren Kardinalsymptom er die Subluxation der Hand nach vorne betrachtet.

Da jedoch, wie wir sehen werden, in vielen Fällen eine wahre Subluxation der Hand gar nicht existiert, so gaben spätere Autoren, welche die Affektion beschrieben oder ihre Kasuistik vermehrten, derselben je nach dem Symptom, das ihnen als das wichtigste erschien, sehr verschiedene Namen, von denen folgende erwähnt sein mögen: "Subluxation progressive du poignet chez les adolescents" (Kirmisson), "Carpus curvus" (Delbet), „Luxation incomplète congénitale" (Ardouin und Jean), "Luxation progressive du poignet" (Guéry und Abadie), "Rachitisme tardif des poignets (Duplay). In der deutschen Literatur wird die Affektion meist unter der Bezeichnung "Madelungsche Deformität des Handgelenks" beschrie- 
ben. Wenn man nicht diesen Namen vorzieht, so scheint mir am passendsten die schon von Madelung gebrauchte Bezeichnung "Manus valga“ zu sein, weil die Valgus-Stellung der Hand das am meisten charakteristische Merkmal ist, wie aus den spätern Ausführungen hervorgehen wird.

Bevor ich auf die Besprechung des Leidens selbst eingehe, mag hier an Hand meiner Tabelle ein kurzer historischer Überblick folgen.

Als der erste, der die Krankheit beschrieben haben soll, wird von den meisten Autoren und auch von Madelung selbst Dupuytren genannt. Dieser macht (1832) in einem Artikel über Frakturen des untern Radiusendes, welche Luxationen im Handgelenk vortäuschen, aufmerksam auf eine „besondere Form des Handgelenks", die bisher häufig Anlaß zu Verwechslungen mit Luxation gegeben habe. Diese besondere Form des Radiocarpalgelenks beobachtete Dupuytren bei mehreren Arbeitern der Tuchfabrikation, die mit den Händen brüske, oft wiederholte Traktions- und Pressionsbewegungen ausführen müssen. Diese Berufsarbeit führt zu einer Erschluffung mit nachfolgender Überdehnung des Bandapparates, wodurch die Bewegungsausdehnung vergrößert wird. Durch das Übergewicht der Flexionsmuskeln wird der Carpus volarwärts verzogen, so daß Luxationsstellung besteht.

In diesen Fällen, die von Madelung selbst dem von ihm beschriebenen Leiden zugezählt werden, scheint es sich also um eine Berufskrankheit zu handeln, die mit unserer "Manus valga" nichts zu tun hat.

Kurze Zeit später jedoch beschrieb Malgaigne in seinem Werke über Knochenbrüche and Verrenkungen das Leiden neuerdings und reihte es in die sogenannten pathologischen Verrenkungen ein. $\mathrm{Zu}$ diesen pathologischen Luxationen des Radiocarpalgelenks rechnet er auch die Dupuytrenschen Fälle, obschon er selbst trotz eifriger Fahndung bei den Arbeitern des nämlichen Berufs während 20 Jahren keinen einzigen derartigen Fall fand, woraus er den Schluß zog, daß diese Deformität außerordentlich selten sein müsse.

Wichtiger aber ist, daß Malgaigne selbst einen einschlägigen Fall brachte, der nun als der erste Fall von echter Manus valga gelten darf, weil dabei nicht nur Banderschlaffung und Luxationsstellung bestand, sondern eine Formveränderung der Vorderarmknochen selbst, was nach späterer Auffassung das Wesentlichste ist. 
Auf eine Wiedergabe an dieser Stelle will ich verzichten, da sich das Wichtigste in der Tabelle findet.

In dem Kapitel "Angeborene Verrenkungen" erwähnt Malgaigne einen zweiten Fall, der von R. W. Smith an einer jungen Frau beobachtet wurde, die am rechten Handgelenk eine Difformität trug, die sie immer gehabt zu haben glaubte. Dieser Fall ist dadurch interessant, daß er der erste ist, der anatomisch untersucht wurde. Malgaigne läßt dabei die Frage offen, ob Pseudoluxation oder wirklich $\theta$ Verrenkung, ob Intra- oder Extrauterinluxation bestand. Ich selbst würde den Fall mit größter Wahrscheinlichkeit als einen extremen Fall der Madelungschen Deformität betrachten.

Weitere zwei Fälle wurden von Weber und Busch (1859) beschrieben. Einer dieser Fälle ist dadurch bemerkenswert, daß Busch, von der Annahme ausgehend, die Deformation sei durch Muskelkontraktion bewirkt, eine Tenotomie ausführte, die sich als wirkungslos erwies.

Von A. Nélaton und. Jean wurden (1874-1875) zwei anatomische Präparate des Musée Dupuytren beschrieben, die nichts Wesentliches brachten.

Erst durch die Mitteilungen Madelungs (1878-1879) kam Licht in das Wesen dieser bis dahin dunklen Krankheit.

Das Beobachtungsmaterial dieses Forschers umfaßt zwölf Fälle, von denen aber nur drei in seiner Abhandlung genauer beschrieben sind, worunter ein anatomisch untersuchter. Als neu erwähne ich aus den Ausführungen Madelungs in Kürze folgendes: Die Hand ist deutlich nach vorne subluxiert. Bei den einen Fällen besteht eine leichte Radial-, bei den andern Ulnarabduktion der Hand. Die untere Radiusepiphyse ist volarwärts gekrümmt. Auf diese von ihm gefundene Tatsache scheint Madelung indes zum Unterschied von späteren Autoren kein großes Gewicht zu legen, wie er sich überhaupt viel weniger mit den anatomischen Verhältnissen als mit den entwicklungsmechanischen der Deformität befaßt. In den sezierten Handgelenk einer 20 jährigen, nach einer Entbindung gestorbenen Frall, fanden sich keine Zeichen einer Knochenerkrankung. Der Effekt der Formveränderung im Handgelenk ist eine nicht unerhebliche Funktionsstörung, die auch gewissermaßen charakteristisch ist, indem sie der anatomischen Veränderung entspricht. Behindert ist die Dorsalfexion, während die Volarflexion eher vermehrt ist. In einzelnen Fällen ist die Ulnarabduktion leicht beschränkt, in andern mehr die Radialabduktion.

Während also die Symptomatologie, sowie der Entstehungsmodus 
des Leidens (letzterer ist in meiner Tabelle wiedergegeben) durch die Arbeit Madelungs in ausführlicher Weise erläutert wird, bleibt das ätiologische Moment noch unaufgeklärt. Da schon von Madelung erwähnten Krümmung des untern Radiusendes nach vorn wird in einer Abhandlung von D u play mehr Bedeutung zugeschrieben (1885), welcher in seinen zwei eigenen Fällen dieselbe Beobachtung machte und den Satz aufstellte, daß gerade hierin das primäre Moment liege. Die Verkrümmung des Knochens hinwiederum erklärte sich Duplay durch Annahme einer ihr zugrunde liegenden Spätrachitis (rachitisme tardif) und suchte diese Hypothese zu stützen durch Hinweis auf die große Ähnlichkeit der Manus valga mit dem Genu valgum, dessen Pathogenese durch die Arbeit von Mikulicz zwei Jahre vorher genau klargestellt worden war.

Ohne sich bestimmt gegen die Duplaysche Ansicht auszusprechen, findet Redard (1892), daß man mit der Annalme von Spätrachitis zur Erklärung von gewissen Deformitäten etwas Mißbrauch getrieben habe. In seinem, wie in vielen andern Fällen aus der Literatur fand er keine Zeichen von Rachitis und umgekehrt bei zahlreichen von ihm untersuchten Rachitischen in verschiedenen Lebensaltern keine Madelungsche Deformität. Deshalb nimmt Redard seine Zuffucht zu einer nenen Theorie: Die Deformation des Handgelenks ist die Folge einer Störung im Wachstum und in der Funktion der Knorpelsubstanz am untern Ende der Vorderarmknochen. Gewisse Partien dieses Knorpels erhalten durch oft wiederholte Irritationen eine Hyperfunktion, die wiederum lokale knöcherne Hypertrophie bewirkt, infolgederen sich Luxation des Handgelenks einstellt. Und zwar macht Redard darauf aufmerksam, daß die knöcheme Hypertrophie oft am untern Chnaende sitze, bei intaktem Radius, wie bei einem seiner Fälle.

In einem Aufsatz von Guépin aus demselben Jahre (1892) begegnen wir sodann zum erstenmal der Angabe, daß unsre Krankheit hereditär sein könne. Dies wird durch einen zweifellosen Fall illustriert und die Heredität von vielen spätern Beobachtern bestätigt.

Einen wichtigen Fortschritt in der Erkenntnis unseres Leidens brachte die Einführung der Radiographie in die chirurgische Diagnostik. Jagot und Guéry (1897 und 1898) sind die ersten, die ihre Fälle radiographisch untersuchten. Beide konnten dadurch eine Krümmung des untern Radiusendes nach vorne und eine Hypertrophie des untern Ulnaendes zweifellos beweisen. Es soll aber schon hier bemerkt werden, daß ein Teil der in den Radiographien 
sichtbaren Volumenzunahme des untern Ulnaendes auf optischer Täuschung beruht. Der Schatten der Ulna erscheint nämlich wegen deren weiterer Entfernung von der Platte in der Projektion auf dieselbe als zu groß. Den Duplayschen Satz, daß die Krümmung des Radius das Primäre sei, hat etwas später (1899) auch Delbet mit aller Bestimmtheitverfochten. Er macht denselben zum seinigen und fügt bei, daß der Carpus mit der Gelenkfläche des Radius in normaler Verbindung geblieben sei; Luxation bestehe nur im Ulnocarpalgelenk und zwar sei diese eine sekundäre infolge der Krümmung des Radius volarwärts. Auch Delbet nimmt als Ursache der Verkrümmung eine Spätrachitis an.

Von nun an wurden beinahe alle Fälle radiographisch untersucht und die Radiogramm meist in den betreffenden Arbeiten reproduziert, Hierbei wird von den meisten Beobachtern das Hauptgewicht auf die pathologische Verbiegung des untern Radiusendes gelegt. Besonders erwähnt muß eine Beobachtung von Kirmisson (1902) werden, weil sie die einzige ist, wo die Verhältnisse umgekehrt sind, nämlich untere Radiusepiphyse nach hinten gebogen statt nach vorn und dadurch Luxation der Ulna nach vorne. Kirmisson und nach ihm Gevaert (1902) unterscheiden wegen dieser Inkonstanz im Krankheitsbilde zwei Typen, den der Madelungschen Subluxation der Hand nach vorne and clen Typus Duplay, bei dem die Hand (gegenüber der Ulna), wie im Kirmissonschen Fall, anch nach hinten subluxiert sein kann.

Während bis jetzt alle Autoren, welche die Manus valga beschrieben liaben, die spontane Entstehung betonten, sucht für einen Fall A badie (1903) darzutun, daß genan das nämliche Krankheitsbild auch nach Trauma (Fraktur des Radius) entstehen könne. Aus dem beigegebenen Radiogramm ist mit Sicherheit zu schließen, daß der betreffende Patient eine wirkliche Madelungsche Deformität besitzt; fraglich ist nur, ob sie spontan oder traumatisch sei. Letzteres geht mit großßer Wahrscheinlichkeit hervor aus der beträchtlichen Verkürzung des Vorderarms, der brüsken, fast winkligen Biegung des Radius im Niveau seiner untern Epiphyse und aus dem Vorhandensein einer spornförmigen Exostose an derselben Stelle. Das Trauma (Sturz von einem Baume) liegt 20 Jahre zurück und die Anamnese beweist nicht mit Sicherheit eine Fraktur, da sich der Patient, der durch den Unfall bewußtlos geworden war, nur erinnert, nachher einen festen Verband getragen zu haben. Es bleibt also daningestellt, ob das vorausgegangene Trauma direkt zu der Deformität führte infolge Radiusbruches oder ob vielmehr dasselbe bloß im Sinne 
von Abadie durch Läsion des Epiphysenknorpels (Epiphyseolysis?) Anlaß gab zu einem unregelmäßigen Wachstum und dadurch Verkrümmung und Verkürzung des Radius. Bei Besprechung der Pathogenese durch Abadie fällt auf, daß in der Auswahl der zu der Deformität zu zählenden Fälle wenig kritisch vorgegangen wird, indem z. B. die Dupuytrenschen Fälle beigerechnet werden. Hierzu ist nun Abadie insofern berechtigt, als er das Leiden mit dem umfassenden Namen „Luxation progressive du poignet chez l'adolescent" belegt. Entsprechend dem seiner Ansicht nach wichtigsten Symptom, der Luxation der Ulna, welche allen Fällen gemeinsam sei, unterscheidet er verschiedene Grade und gibt folgenden Versuch einer Klassifikation (abgekürzt):

I. Der Radius behält seine Beziehungen zum Carpus.

A. Mit Verschiebung der Ulna nach hinten.

(Alle Fälle anßer dem Kirmissonschen.)

B. Mit Verschiebung der Ulna nach vorn.

(Fall von Kirmisson.)

II. Der Radius verliert seine Beziehungen zum Carpus und wird luxiert (?).

(Fälle von Dupuytren, Béguin [?], Boinet [?], Guépin [?].)

Im übrigen scheint $\mathrm{Abadie}$ das Charakteristische und die Bedentung der Affektion nicht in einer einseitigen anatomischen Läsion zu liegen, sondern er nimmt an, daß die Handgelenksgegend während des Entwicklungsalters der Sitz einer progredienten Deformation von sehr verschiedenem Ursprung sein kann, welcher Verschiedenheit er im oben angeführten Schema Ausdruck verleiht. Zu einer etwas abweichenden Klassifikation der Fälle gelangt Abadie, wenn er nicht nur den klinischen Verlauf, sondern zugleich den anatomischen Befund berücksichtigt. Er unterscheidet so folgende Formen:

a) Einfache Hyperostose der Ulna. (Immer doppelseitig, kongenital oder im frühen Kindesalter auftretend.)

b) Einfache Subluxation der UIna. (Sowohl gegenüber dem Radius als Carpus, mit Erschlaffung der Bänder, leicht reduzierbar, doppelseitig. Folgt entweder sekundär der unter a genannten Hyperostose oder ist der erste Grad einer progressiven Madelungschen Subluxation.)

c) Lageveränderung der Ulna.

(Schwer oder nicht mehr reduzierbar.)

Deutsche Zeitschrift f. Chirurgie. 81. Bd. 
d) Krümmung des Radius.

(Meist einseitig. Stellt mit c den gewọhnlichen Verlauf dar.)

Mit andern Worten: a gehört nicht zur progressiven Madelungschen Subluxation, kann nur deren Entwicklung prädisponieren; b sind Grenzfälle und c und d stellen wirkliche Fälle von $\mathrm{Ma}$ delungscher Deformität dar. Bezüglich der Pathogenese hält Abadie dafür, daß die Annahme von Spätrachitis den meisten Fällen entspreche.

Die in den nächsten Jahren folgenden Abhandlungen von Cnopf (1903), Barthès (1904), Schulze und Volkmann (1905), Schrade und Putti (1906) erwähne ich hier der Vollständigkeit halber, da sie außer Bereicherung der Statistik wenig Neues brachten. Die Diskusion dreht sich darin meist um die Frage, ob eine Subluxation im Sinne Madelungs oder eine Deformation der Handgelenksgegend im Sinne von Duplay und Delbet anzunehmen ist.

Besonders erwähnt zu werden verdienen aus neuester Zeit zwei ausführliche Arbeiten von Poulsen (1904) und von Sauer (1906). Beide werden in der klinischen Besprechung genauere Berücksichtigung erfahren.

Fasse ich alle in der Literatur verzeichneten Fälle, die meinigen nicht inbegriffen, zusammen, so erhalte ich die Zahl 55. Davon wurden anatomisch untersucht 5 Fälle und radiographisch 18 Fälle.

In Anbetracht der geringen Zahl der genau untersuchten Fälle und der Verschiedenheit der Meinungen der Autoren über die Pathogenese der Manus valga, mag daher die Mitteilung dreier sehr ausgesprochener und mehrerer leichter Fälle, die ich während meiner Assistentenzeit an der chirurgischen Privatklinik des Herrn Prof. Dr. de Quervain zu beobachten Gelegenheit hatte, berechtigt sein. Hierbei wurden zum ersten Mal stereoskopische Aufnahmen gemacht, die natürlich zur Beurteilung der Lage der einzelnen Knochen zueinander viel genaueren Aufschluß geben, als gewöhnliche Bilder.

Ich beginne mit der genauen Beschreibung der genannten drei schweren und kurzer Anführung der leichteren Fälle und lasse dann in tabellarischer Zusammenstellung die in der Literatur aufgefundenen Beobachtungen folgen.

Fall 1. Anamnese: M. J., 18 J., Tochter wohlhabender Eltern, steht seit 1 Jahr in Behandlung wegen Deformität beider Handgelenksgegenden. 
Die Mutter der Patientin gibt an, daß dieselbe als Kind stets etwas schwächlicher gewesen sei als die vielen übrigen Geschwister. Jedoch ist keine nennenswerte Krankheit vorausgegangen. Patientin begann im Alter von 13 bis 14 Monaten ohne besondere Mühe zu gehen; rachitische Symptome wurden bei der Patientin wie auch bei den übrigen Kindern nicht bemerkt.

Das erste Symptom der Affektion, wegen der Patientin ärztliche Hilfe aufsucht, war eine Zunahme des Umfanges des linken Handgelenks im Alter von 11 Jahren. Bald traten in diesem zuerst deformierten Gelenke auch Schmerzen auf, die zeitweise so heftig waren, daß Jodanstriche gemacht wurden, da die Mutter an das Vorhandensein rheumatischer Schmerzen glaubte. Anstrengende Arbeit wurde nie verrichtet, Trauma hat nie stattgefunden. Die meisten Beschwerden, rasche Ermüdbarkeit, hatte das Mädchen beim Klavierspielen, das schon vor Beginn des Leidens geübt wurde. Die mangelhafte Virtuosität in dieser Kunst wird von der Patientin selbst auf die rasche Ermüdbarkeit dabei zurückgeführt.

Die nächsten paar Jahre nach dem Beginne der Deformation hatte die Tochter oft spontan sehr heftige Schmerzen, dic durch den ganzen Arm bis in die Schulter ausstrahlten. Die Bewegungen der Hand waren nie schmerzhaft. Im rechten Handgelenk bestanden nie Schmerzen; eine analoge, geringgradigere Formveränderung wurde erst durch die hiesige Untersuchung entdeckt.

Betreffend die Heredität ergab meine Untersuchung im Hause der Patientin folgendes Resultat:

Grobeltern:

GroBmutter mütterlicherseits (lebt), normale Handgelenke.

Gro6vater " $(\dagger)$ Magencarc., soll normale Handgelenke gehabt haben.

GroBmutter väterlicherseits (lebt), bedeutend prominente unt. Ulnarenden, Sublux.-Stellung angedeutet.

Großvater väterlicherseits $(\dagger)$ soll normale Handgelenke gehabt haben.

Eltern:

Vater hat normale Handgelenke, ist jedoch wegen Plattfus militärfrei. Sonst kräftig.

Mutter hat etwas prominente unt. Ulnarenden, nebenbei beidseitigen Pes valgoplanus und eine leichte dorsale Skoliose. Hatte nie Beschwerden.

Geschwister: 1 Bruder, 3 Schwestern.

24 jähr. Schwester ist skoliotisch, hat aber normale Handgelenke.

21 jähr. Schwester hat auffallend prominente unt. Ulnarenden, links angedeutete Sublux.-Stellung. Hat nie Beschwerden gehabt.

22 jähr. Schwester hat beiderseits etwas verdickte unt. Ulnarenden, ohne Beschwerden.

17 jähr. Bruder hat normale Handgelenke.

Keines der Geschwister hat andere Zeichen von Rachitis auBer der 24jähr. skoliotischen Schwester.

Status: Mittelgroßes Mädchen von schlankem Körperbau und etwas blasser Gesichtsfarbe. Schädelform nicht deutlich rachitisch, doch sind 
dìe Tubera parietalia stark entwickelt. Gebiß gut, nur zeigen die Schneidezähne rachitische Kanellierungen und stehen nach innen geneigt.

Thorax von flacher Form. Kein Rosenkranz. Leichter Rippenbuckel links. Leichte Skoliose der Brustwirbelsäule nach links mit gröBter $\mathbf{A b}$ weichung des 6. Dorsalwirbels. Kompensatorische Lumbalskoliose nach rechts.

Untere Extremitäten: Tibiae leicht nach vorn und außen konvex verbogen. Beiderseits leichter PlattfuB, rechts geringgradiger Pes valgus. Kein Hallux valgus.

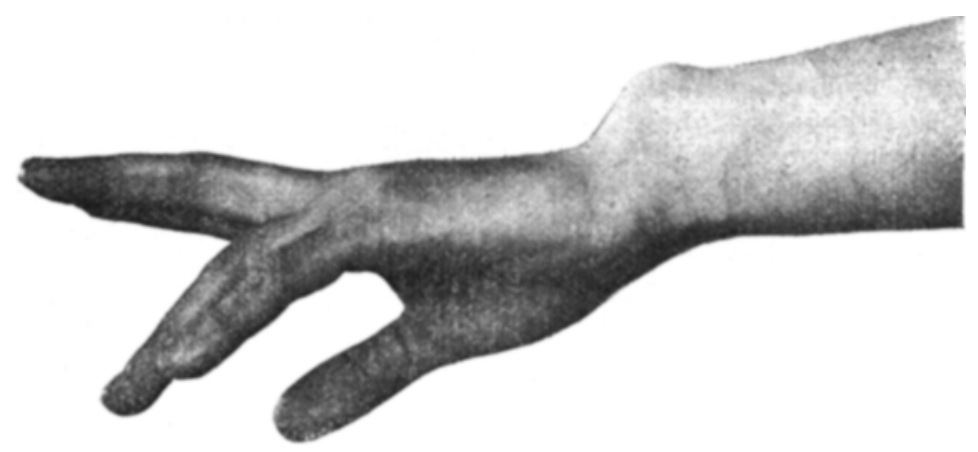

Fig. 1. Fall 1.

Linke Hand, Ulnarseite.

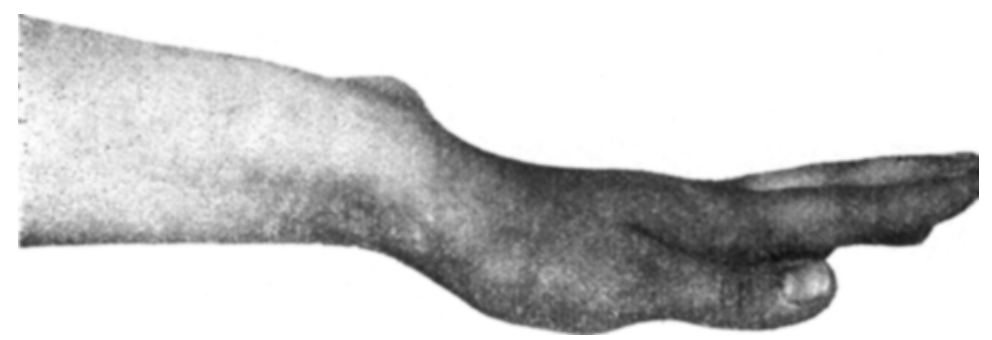

Fig. 2. Fall 1.

Linke Hand, Radialseite.

Obere Extremitäten: Auffallend ist sofort die plumpe Form beider Handgelenke, besonders des linken. Zwei photographische Aufnahmen desselben (Fig. 1 und 2) illustrieren besser als viele Worte die Ergebnisse der Inspektion: Starkes Vorragen des Capit. ulnae nach der Dorsalseite, Dickenzunahme der ganzen Handgelenksregion und Subluxationsstellung der Hand gegenüber dem Vorderarm.

Die Palpation ergibt, daß das distale Ende der Ulna im ganzen Umfange und ein Teil der unteren Radiusgelenkfläche abtastbar sind infolge der Subluxation der Hand nach der Volarseite. Eine gleichmäBige leichte Krümmung beider Vorderarmknochen mit dorsaler Konvexität so- 
wohl in der Diaphyse als besonders in der Epiphyse, beim Radius volarwärts, bei der Ulna dorsalwärts, ist deutlich palpierbar.

Die Subluxationsstellung läßt sich mechanisch, durch Zug an der Hand, nur unvollständig korrigieren.

Muskulatur und Innervation der Vorderarme normal entwickelt und funktionierend.

Diese vorstehenden Bemerkungen gelten für den linken Vorderarm; rechts finden wir die nämlichen Verhältnisse, nur geringgradiger (Fig. 3).

Messung:

Länge des Radi u s (Capit. rad. - Proc. styloid.) links $21 \mathrm{~cm}$, rechts $22 \mathrm{~cm}$. Länge der Ulna (Olekranonspitze — Proc. styloid.) links 22,5 cm, rechts $23 \mathrm{~cm}$.

Grenzen der Bewegungen im Handgelenk (passiv und aktiv gleich):

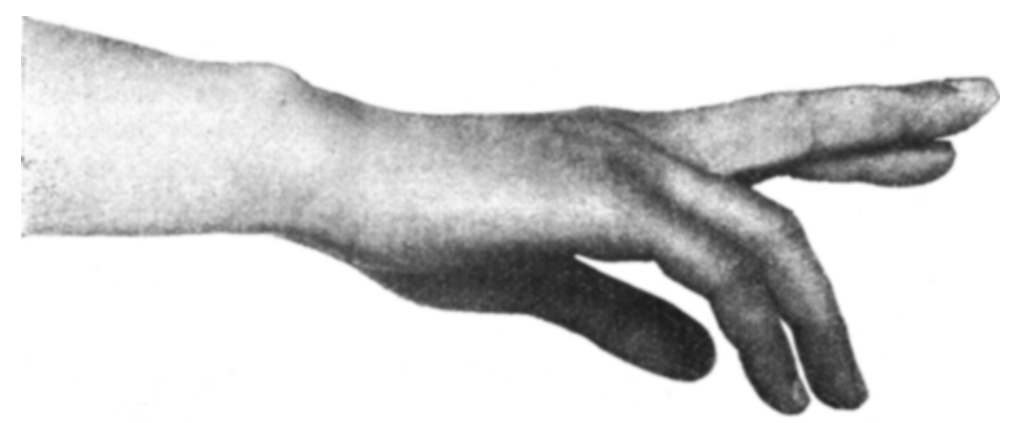

Fig. 3. Fall 1.

Rechte Hand, Ulnarseite.

Flexion links vermindert; links $125^{\circ}$, rechts $115^{\circ}$.

Extension links vermindert; links $115^{\circ}$, rechts $105^{\circ}$.

Radialadduktion links vermindert; links $135^{\circ}$, rechts $130^{\circ}$.

Ulnaradduktion links vermindert; links $175^{\circ}$, rechts $165^{\circ}$.

Supination links etwas beschränkt.

Pronation beiderseits normal.

Rohe Kraft beiderseits $18 \mathrm{~kg}$.

Bei der Flexionsbewegung weichen beide Hände deutlich nach der Ulnarseite ab.

Auf der linken, stärker deformierten Seite ist das Cubitus valgus etwas stärker als rechts (bei gestreckten Armen $4^{0}$ Unterschied).

Die Röntgenuntersuchung ergibt Folgendes:

\section{Linke, stärker deformierte $\mathrm{H}$ and:}

a) Aufnahme mit Volarseite gegen die Platte: Fig. 4 u. Tafel XIII. (Pronationsstellung).

Der Radius zeigt in seiner ganzen Länge eine Vermehrung seiner ulnarkonkaven Krümmung. Diese Krummung ist am intensivsten im 
distalen Drittel. Seine distale Gelenkfläche ist auffallend stark ulnarwärts geneigt. Eine gleichzeitige vermehrte Neigung derselben volarwärts läbt sich schon in diesem Bilde erkennen aus dem Umstand, dab bei der Betrachtung von oben, also vom Profil, eine viel gröBere Fläche der Gelenkpfanne sichtbar ist als in der Norm. Der volare Gelenkrand

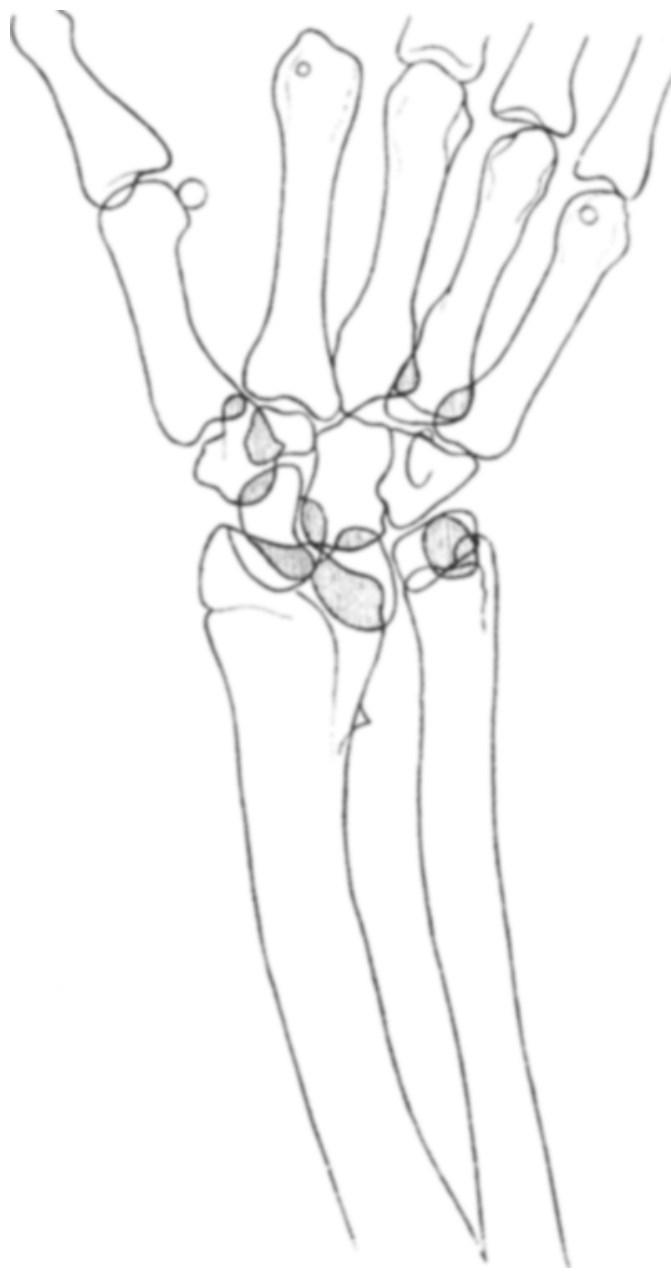

Fig. 4. Fall 1.

Linke Hand (Pronation). der Radiusgelenkflïche verläuft etwas mehr gebogen als normal. $2-3 \mathrm{~cm}$ oberhalb der Gelenkfläche, oberhalb der Epiphysenlinie, ist am Radius eine kleine, dornförmige Exostose sichtbar, die ulnarwärts sieht. Die Epiphysenlinic ist sehr deutlich erkennbar.

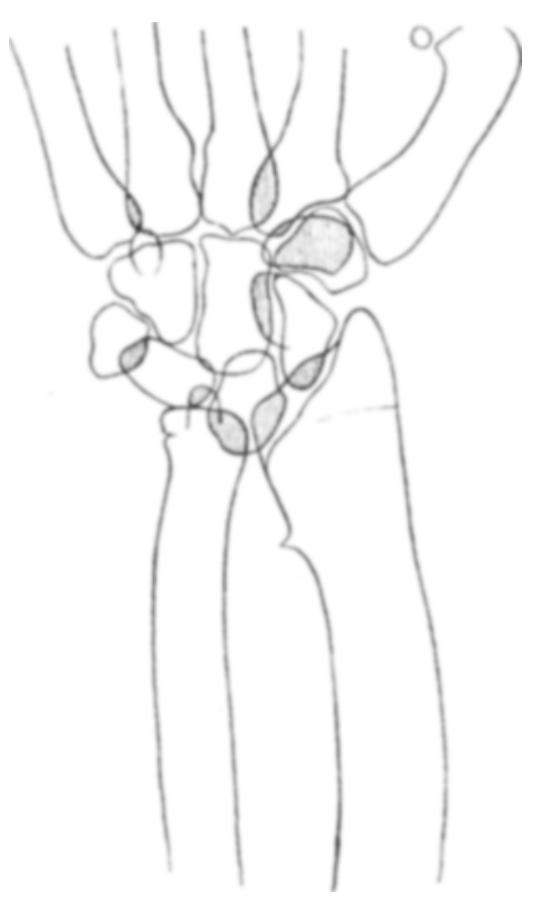

Fig. o. Fall 1.

Linke Fand (Supination).

Die Ulna ist wie der Radius, nur in weit geringerem Grade gebogen, sonst von normaler Form. Höchstens springt im untern Drittel die Crista interossea etwas scharf hervor.

Mit dem Radius hat die Ulna ihre normale Verbindung ganz auf- 
gegeben, d. h. sie ist aus dem Radioulnargelenk luxiert und reicht weiter distalwärts als normal, bis an die Ossa triquetrum und pisiforme hinab. Jadurch erscheint sie gegenüber dem Radius relativ verlängert.

Die Ossa carpi sind unter sich und mit dem Radius in normaler Verbindung. Infolge der vermehrten Neigung der Radiusgelenkfläche nach der Ulna hin und der Luxationsstellung der letzteren schieht sich die proximale Reihe der Handwurzelknochen keilfömig zwischen die distalen Enden beider Vorderarmknochen hinein. Infolge davon stehen die, diese 1. Reihe der Karpalknochen bildenden 3 Knochen statt in einem gleichmäßigen Halbkreis in einem Winkel, dessen Spitze das Os lunatum bildet. (Vergl. hiermit das von einer gleichaltrigen normalen Person stammende Handgelenk in Fig. 16).

b) Aufnahme mit Dorsalscite gegen die Platte: Fig. 5. (Supinationsstellung.)

Der Radius zeigt auch hier eine regelmäBige ulnarkonkave Krümmung; auch hier ist die dorntörmige Exostose und die Epiphysenlinie recht deutlich, ebenso die vermehrte Neigung der distalen Gelenkfläche gegen die Ulna. Bei dieser Stellung dagegen lat sich das Ulnaköpfchen seiner Radiusgelenkfläche genähert, so daß die untern Enden beider Vorderarmknochen in normaler Gelenkverbindung zu stehen scheinen. Auch die scheinbare Verlängerung der Ulna gegenüber dem Radius ist aufgehoben.

Schon aus dieser Aufnahme ist ersichtlich, das der Carpus mit der Radiusfläche gegenüber der Ulna volarwärts getreten ist, denn das keilförmige Hineinragen des Os Iunatum zwischen die untern Enden von Radius und Ulna besteht auch hier, trötzdem Radius und Ulna sich berühren.

c) Bei stereoskop ischer Betrachtung der entsprechenden Röntgenbilder in Vergleichung von zahlreichen Aufnahmen normaler Handgelenke fällt vor allem die entgegengesetzte Krümmung der untern Enden beider Vorderarmknochen auf. Während der Radius volarwärts sieht, ist die Ulna dorsal gerichtet. Das Ulnaköpfchen steht vollständig isoliert dorsalwảrts und hat jeden Kontakt mit dem Radius und mit dem Os triquetrum verloren. Die Ossa carpi sind dem Radius in seiner volaren Krümmung gefolgt und stehen also in einer, der Ebene des ganzen Vorderarms parallelen Ebene weiter volarwärts. Auch gegenüber der Radiusgelenkfläche hat sich die Stellung des Carpus insoweit geändert, als das Naviculare und Lunatum noch etwas weiter volarseits verschoben sind als durch die Volarkrümmung des untern Radiusendes bedingt ist, denn man sieht deutlich, dab letztere 2 Knochen nicht die ganze Breite der Radiusgelenkfläche einnehmen wie in der Norm, sondern nur die volaren $2 / 3$ derselben und deshalb den volaren Rand der Gelenkfläche etwas überragen. Mit andern Worten: Wir haben eine, wenn auch geringgradige, Subluxationsstellung. Am deutlichsten ist die Volarverschiebung des Os lunatum, welche es der doppelten Neigung der Radiusgelenkfläche ulnar- und volarwärts verdankt. Sein Schatten deckt sich, wie auch aus Fig. 5 ersichtlich, teilweise mit demjenigen des Capit. ulnae. Nur im stereoskopischen Bilde aber ist sichtbar, laB das Os lunatum weit volar vom Ulnaköpfchen steht. Infolge der, 
Ulnarneigung der Radiusgelenkfläche und des mangelnden Widerstandes des dorsal luxierten untern Ulnaendes sind die Ossa naviculare und lunatum auf dieser schräggerichteten Gelenkfläche aufwärts (proximalwärts) und ulnarwärts geglitten, so daß mit ihnen die ganze Hand nach der Ulnarseite verschoben erscheint (Fig. 5).

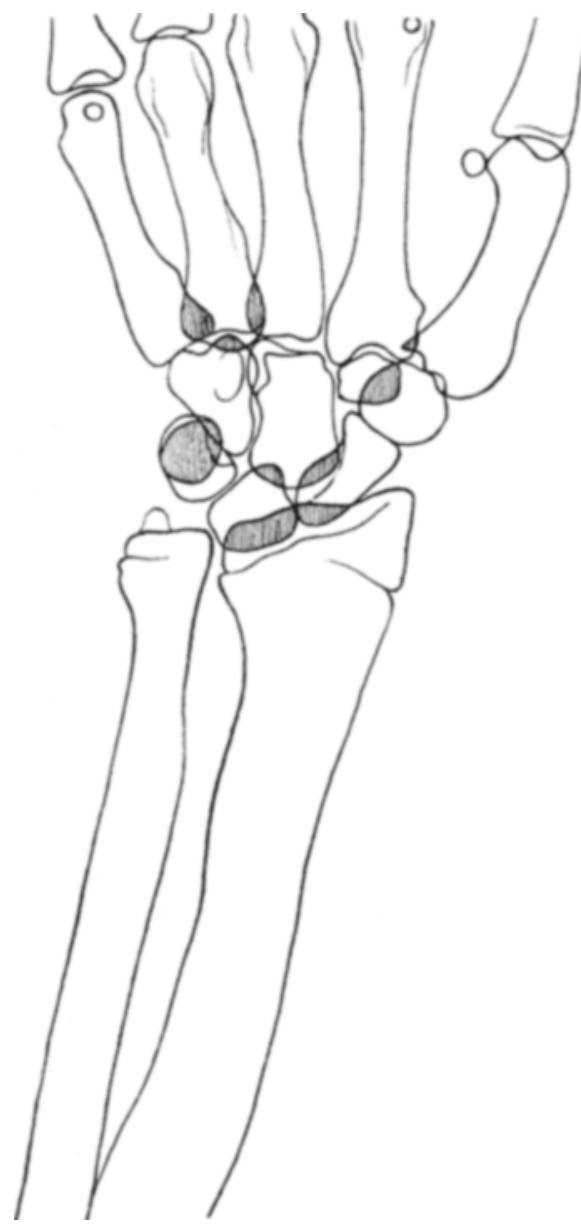

Fig. 6. Fall 1.

Rechte Hand (Pronation).

d) Aufnahme mit dem Ulnarrand gegendiePlatte: Fig. 20 und Tafel XIII.

Hier ist vor allem ein bemerkenswerter Unterschied zwischen linker und rechter Seite zu konstatieren. Berücksichtigt man zudem, das auch auf der rechten Seite bei unsrer $\mathrm{Pa}$ tientin bereits eine deutliche Deformation vorhanden ist, so muB der Unterschied von links gegenüber der Norm ein noch viel gröBerer sein. Das Bild selbst spricht so deutlich, daß ich mich hier kurz fassen Kann. Die Resultate der stereoskopischen Betrachtungen werden hier bestätigt: Entgegengesetzte Krümmung der distalen Drittel von Radius und Ulna. Die Krummung dehnt sich auf den ganzen Radius aus, während die Ulna in den obern $2 / 3$ normal ist. Die vermehrte Volarneigung des Radius hat einen Schiefstand seiner Gelenkfläche und diese eine Bayonnettstellung der Hand gegenuber dem Vorderarm zur Folge. Das linke distale Ulnardrittel erscheint etwas verdickt, das Capit. ulnae etwas loypertrophisch.

\section{Rechte, weniger deformierte Hand.}

a) Aufnahme mit Volarseite gegen die Platte: Fig. 6 u. Tafel XIII. Vergleichen wir die ganz analoge Aufnahme der linken Hand (Fig. 4) mit dieser, so finden wir, daß auch rechts der ganze Radius eine Biegung aufweist, die aber bedeutend geringer ist als links, was aus dem Unter- 
schied der Breite des Spatium interosseum hervorgeht. Die Form der Ulna ist auch hier die normale. Ebenfalls vermehrt gegenüber der Norm, obschon geringer als links, ist die Neigung der Radiusgelenkfläche nach der Ulnarseite (vergl. damit Fig. 16). Daß auch eine Volarneigung der Radiusgelenkfläche bestehen muß, läßt sich aus der Breite schließen, in der sie im Röntgenbilde erscheint. (Vergl. damit Fig. 16). Wegen der geringeren Krümmung des Radius ist hier keine relative Verlängerung der Ulna vorhanden. Dagegen hat auch hier das Capit. ulnae seine Gelenkverbindung mit dem Radius aufgegeben. Die untere Epiphysenlinie am Radius ist ebenfalls sehr seharf, dagegen ist von einer Exostose nichts zu sehen.

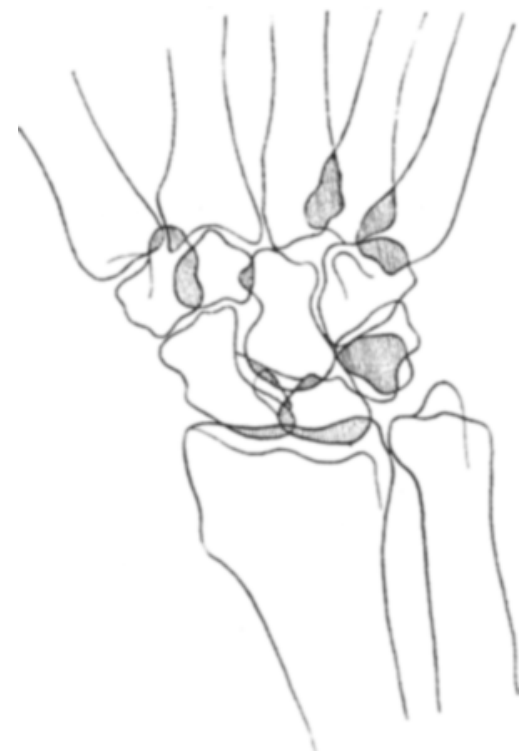

Fig. 7.

Linke Hand der Schwester von Fall 1.

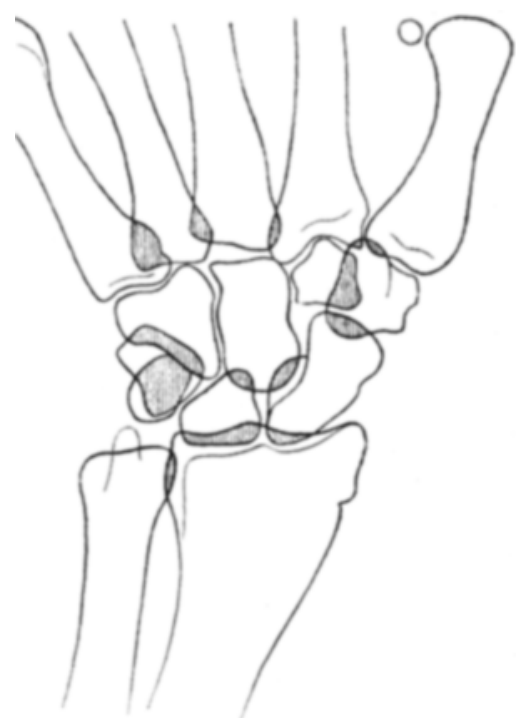

Fig. 8.

Rechte Hand der Matter von Fall 1.

Die Verschiebung des ganzen Carpus nach der Ulnarseite ist weniger deutlich als links. Der ganze Carpus ist von gröBerer Breite als der linke, der infolge der scheinbaren Verlängerung der Ulna und der größern Ulnarneigung der Radiusgelenkfläche etwas zusammengedrückt erschien.

b) Die stereoskopische Aufnahme beweist uns sehr hübsch die Volarneigung des untern Radiusendes und zeigt ebenfalls die Verschiedenheit in der Krümmungsrichtung von distalem Radius- und Ulnadrittel.

\section{Linke, deformierte Hand der 21jähr. Schwester der Patientin I.: Fig. 7.}

Bei der Inspektion fand ich stark prominente untere Ulnarenden, links leichte Subluxationsstellung. 
Wie aus der Umrißzeichnung des Röntgenogramms ersichtlich ist, haben die Handgelenksenden von Radius und Ulna eine etwas unregelmäßige Oberfläche, was vielleicht auf Wachstumsstörungen im Bereich der Epiphyse hindentet. Bei stereoskopischer Untersuchung findet man eine ganz deutliche Neigung der Gelenkfläche nach der Vola hin. Sehr bemerkenswert ist die das gewöhnliche $\mathrm{MaB}$ übersteigende doppelt bogenförmige Ausbuchtung der vordern Gelenklinie, die wohl auf eine abnorme Plastizität der Knochensubstanz schließen läßt. Navikulare und Lunatum haben sich förmliche Gelenkpfannen ausgehöhlt. Im übrigen ist aber die Lage der Karpalknochen zur Radiusgelenkfläche eine normale, so daß die bei der Besichtigung der Hand auffallende, leichtgradige Subluxationsstellung allein durch die Volarkrümmung des Radius in seinem untern Drittel bei dorsalem Zurückbleiben des Capit. ulnae hedingt ist.

\section{Hände der Mutter: Fig. 8.}

Bei der Inspektion über die Norm prominente Capitula ulnae. Die Röntgenaufnahme ist in beistehender Konturzeichnung wiedergegeben. Sie zeigt keine nennenswerte Abweichung von der Norm.

Fall 2. (Zufällig entdeckte Manus valga bei einer Verkäuferin.) R. D., 20 Jahre. Anamnese: Hat nie schwere Arbeit verrichtet und keine nambaften Krankheiten durchgemacht. Weiß nichts von überstandener Rachitis, hat das Gehen zum normalen Termin gelernt. Beginn der Handgelenksaffektion ohne vorausgegangenes Trauma im 14. Altersjahre mit spontanen Schmerzen. Bald darauf wurde links eine Deformität bemerkt. Die Schmerzen blieben bestehen und Patientin wandte sich deshalb an einen Kurpfuscher, der ihr einen Gipsverband machte, den sie ohne Erfolg einige Wochen trug. Mittlerweile sistierten die Schmerzen links und traten solche dafür rechts auf, aber weniger intensiv. Auch die sich bildende Deformation war viel geringer. Seit 3-4 Jahren ist das Leiden stationär geblieben und hindert das Mädchen in ihrer Arbeit als Verkäuferin in einem Papierladen keineswegs. Ja, sie gibt sogar an, die linke, stärker deformierte Hand besser zur Arbeit gebrauchen zu können als die rechte, wegen der vermehrten Flexionsmöglichkeit. Allerdings ermüdet die linke Hand bei andauernder Arbeit, z. B. beim Stricken, ziemlich rasch. Hat nie Klavier gespielt. Das Mädchen macht spontan die Angabe, daß ihr Leiden ererbt sei, indem ihre Großmutter (mütterlicherseits) die ganz gleiche Deformität besessen habe. Dagegen hatte die Mutter normale Handgelenke.

Status: Mädchen von mittlerer Größe, gutem Ernährungszustand, etwas blaß, Herz und Lunge gesund. Schädel von normaler Form, Zähne gut, keine rachitischen Zeichen an denselben. Thorax gut gewölbt, kein Rosenkranz. Leichter Rippenbuckel links. Leichte Skoliose der obern Dorsalwirbelsäule nach links konvex und kompensatorisehe Lumbalskoliose nach rechts. Untere Extremität: Tibiae gerade, links leichtgradiger Pes valgo-planus.

Obere Extremität: Beiderselss etwas vergrößerter Cubitus valgus, links um $2-3^{0}$ mehr als rechts. Muskulatur und Innervation der Arme 
Öber Hanus valga oder sogen. Madelungsche Deformität d. Handgelenks. 539

normal. Form der linken Knöchelgegend ähnlich wie bei Fall 1 (s. Fig. 9). Auf der Volarseite ragen die Sehnen der Mn. flexor. carpi radial. und palmar. long. vor, wie wenn sie kontrahiert wären. Die Subluxationsstellung der Hand gegen den Vorderarm ist nur angedeutet, nicht so auffällig wie bei Fall 1. Der Proc. styloid, ulnae ist ringsum abtastbar, die Radiusgelenkfläche dagegen nicht. Der Vorderarm ist gerade:

Maße:

Radiuslänge links $23 \mathrm{~cm}$, rechts $23 \mathrm{~cm}$.

Ulnalänge links $22 \mathrm{~cm}$, rechts $24 \mathrm{~cm}$.

Bewegungen im Handgelenk (aktive):

Flexion links vermehrt (bis $130^{\circ}$, rechts bis $\left.140^{\circ}\right)$.

Extension links vermindert (bis $160^{\circ}$, rechts bis $150^{\circ}$ ).

Abduktion and Adduktion, Pronation und Supination beiderseits gleich, in normalen Grenzen.

Rohe $\mathrm{Kraft}$ links $20 \mathrm{~kg}$, rechts $25 \mathrm{~kg}$.

Röntgenuntersuchung:

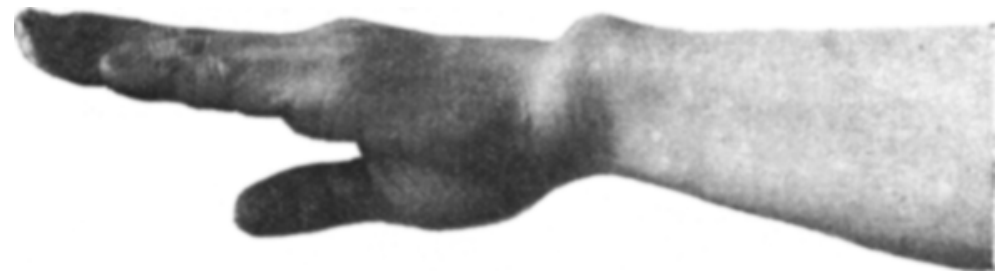

Fig. 9. Fall 2.

Linke Hand, Ulnarseite.

1. Linke, stärker deformierte Hand: Fig. 10.

Bei Betrachtung der Konturzeichnung wird man sofort an das Bild, das durch Fig. 7 wiedergegeben ist, erinnert. Es betraf dies die 21 jähr. Schwester von Fall 1. Die Analogie der beiden Radiographien ist eine so große, daB ich mich auf wenige Worte beschränken darf. Die beiden ersten Karpalknochen haben sich wie beim frühern Fall auch in diesem 2 Vertiefungen im Radius ausgehöhlt, so dab die Gelenkfläche in 2 Fassetten geteilt erscheint, was wiederum auf eine abnorme Weichheit des Knochens hinweist. Die volare Krümmung des Radius ist in diesem Fall eine bedeutendere, was aus der größern Breite der Schatten der Ossa naviculare und lunatum auf der Radiusgelenkfläche hervorgeht. Dagegen ist in Fall 2 der Radius blob volarwärts, nicht zugleich nach der Ulnarseite gekrümmt wie in Fall 1. Dies ist ersichtlich aus einer radiographischen Aufnahme des ganzen Vorderarms in analoger Stellung wie die Fig. 4 und 6. Dic Betrachtung des stereoskopischen Bildes zeigt uns, daB das Ulnaköpfchen dorsalwärts vom nach vorn gekrümmten Radius zurückgeblieben ist und daß letztere Krümmung eine recht bedeutende ist, so da $\mathrm{f}$ die Annäherung der Ossa triquetrum und pisiforme an das Ulnaköpfehen nur eine scheinbare ist, ebenso die Verlängerung der Ulna, resp. der Tief- 
stand des Ulnaköpfchens. Infolge des Ausbleibens der lateralen Krümmung des Radius besteht auch keine Ulnaverschiebung der ganzen Hand.

Eine fernere radiographische Aufnahme beider Vorderarme mit dem Ulnarrand gegen die Platte (radio-ul-

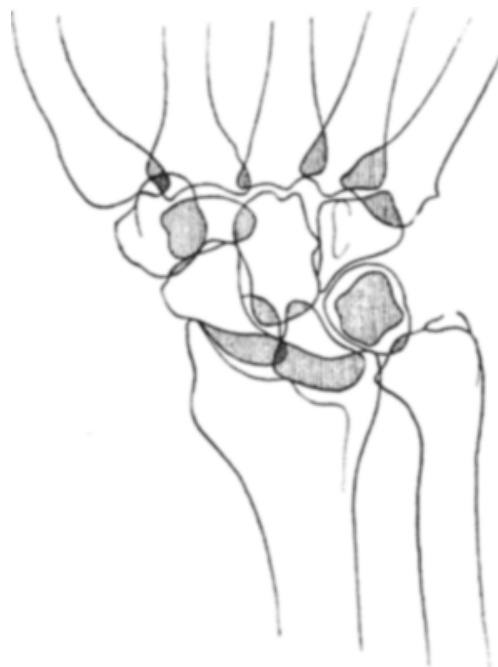

Fig. 10. Fall 2. Linke Hand (Pronation). nare Aufnahme) zeigt, daß die volare Krümmung des Radius sich gleichmäBig auf die ganze Diaphyse erstreckt, ihr Maximum sogar in der Mitte und nicht im distalen Drittel hat. Die Schiefstellung der Radiusgelenkfläche volarwärts ist denn auch keine sehr bedeutende und eine Subluxation der Hand besteht nur gegenüber dem dorsal gebliebenen unteren Ulnaende. Letzteres prominiert aher sehr weit dorsalwärts und zwar verdankt es diese Dorsalprominenz nicht nur der Volarkrümmung des Radius nach der Volarseite, sondern das unterste Ulnardrittel ist selbst nach der Dorsalseite gekrümmt, so daß sich die unteren Enden der beiden Vorderarmknochen statt einander parallel zu verlaufen, in geringem Grade allerdings, kreuzen.

\section{Rechte, weniger deformierte Hand.}

Wir finden hier die ganz analogen Verhältnisse wie links, nur alles in geringerem Grade. Der einzige qualitative Unterschied ist der, daB hier das Ulnaköpfchen weniger hypertrophisch, von schlankerer Form ist als links.

Fall 3. Anamnese: (Zufällig in der Poliklinik von Chaux-de-Fonds entdeckte doppelseitige Manus valga bei einer Wäscherin.) Die bis heute stets gesunde 44 jähr. Wäscherin G. bemerkte schon als junges Mädchen, daB ihre Handgelenke verdickt waren. Das Leiden soll im 10. Altersjahre begonnen haben mit starken Schmerzen in beiden Handgelenken. Trauma oder schwerere Arbeit war nicht vorausgegangen. Die Schmerzen begannen in beiden Händen zugleich und waren so quälend, dab ärztliche Hilfe angerufen wurde. Dieselbe bestand in Massage, Anwendung von Elektrizität und Anlegen eines festen Verbandes. Im Verlaufe von 1-2 Jahren vergingen die Schmerzen, dafür war aber die jetzige Formveränderung eingetreten. Von nun an hatte Patientin in ihrem Beruf als Wäscherin zeitweise, bei 'sogen. „f alschen Bewegungen", besonders aber beim Wäscheauswinden plötzlich sehr heftige zuckende Schmerzen in beiden Knöcheln. Im ganzen ist sie jedoch in ihrer Arbeit nicht behindert. Auch sind die Schmerzanfälle in den letzten Jahren viel seltener geworden. Soviel die Frau weiB, hatten ihre Eltern, Großeltern und Geschwister normale Hände, 
dagegen soll eine 25 jähr. abwesende Tochter stark prominente Handknöchel haben, aber nicht in dem MaBe wie Patientin selbst. Auch hat diese Tochter nie Beschwerden gebabt.

Bei Abschluß der Arbeit können wir noch zwei Töchter der Patientin untersuchen, bei denen angeblich erst in der letzten Zeit eine ähnliche Veränderung an den Handgelenkeu aufgetreten sein soll, wie bei der Mutter. Es handelt sich bei beiden in der Tat um einen sehr deutlichen Beginn von Manus valga. Wir werden weiter unten noch auf diese Fälle zurückkommen.

Status: MittelgroBe, robuste Frau. Organe gesund. Keine Symptome von Rachitis außer leichter Verkrümmung der Tibiae. Beide Hände in Valgusstellung, ulnare Abweichung von der Achse beiderseits $20^{\circ}$. Zugleich besteht deutliche Subluxationsstellung, rechts etwas stärker als links. Diese Subluxation läßt sich durch Zug an der Hand zum Teil ausrichten, kehrt aber alsdann federnd zurück. Die Capitulae ulnae ragen stark nach dem Dorsum vor und scheinen hypertrophisch. Das Capit. ulnae läBt sich fast ganz abtasten, die untere Radiusgelenkfäche aber ist der Palpation ganz unzugänglich. Das Aussehen von Vorderarm und Hand ist ganz ähnlich dem Fall 2, weshalb ich von der Wiedergabe einer Photographie abstehe.

Längenmaße:

Radius beiderseits $19,5 \mathrm{~cm}$, Ulna links $22 \mathrm{~cm}$, rechts $21,5 \mathrm{~cm}$.

Bewegungen (aktive):

Flexion beiderseits beschränkt, rechts bis $120^{\circ}$, links bis $125^{\circ}$.

Extension beiderseits beschränkt, rechts bis $135^{\circ}$, links bis $130^{\circ}$.

Ulnaradduktion leicht vermehrt.

Radialadduktion leicht vermindert.

Pro- und Supination beiderseits normal.

Rohe Kraft beiderseits gut.

Röntgenuntersuchung:

\section{Rechte, stärker deformierte Hand.}

a) Dorso-volare Aufnahme: Fig. 11. (Pronationsstellung.)

Gleicht Fig. 4 von Fall 1. Während aber bei Patientin 1 die äuBere Deformität viel bedeutender ist, finden wir im Röntgenogramm nur unbedeutenden graduellen Unterschied. In der Art der radiographisch nachweisbaren Veränderung stimmen die beiden Figuren miteinander vollkommen überein, so daß ich auf das bei Fall 1 Gesagte verweisen kann. Auch in Fall 3 befindet sich die größte ulnarwärts gerichtete Krümmung des Radius im untern Drittel, was eine sehr ansehnliche Neigung der radialen Gelenkfläche gegen die Ulna zur Folge hat.

b) Radio-ulnare Aufnabme beider Vorderarme und Hände.

Beide Radii sind in ihrer ganzen Länge gebogen mit volarer Konvexität, der rechte stärker als der linke, was der rechts stärkeren Sub- 
luxation entspricht. Eine intensivere Krümmung im distalen Drittel ist nicht vorhanden, das Maximum der Krümmung liegt in der Mitte der Diaphyse. Beide Ulnae sind von normaler, gerader Form in ihren zwei obern Dritteln. An der Grenze jedoch vom mittleren in das untere Drittel beginnt beiderseitig eine stürkere Krummung nach der Dorsalseite, rechts wieder mehr als links. Die unteren

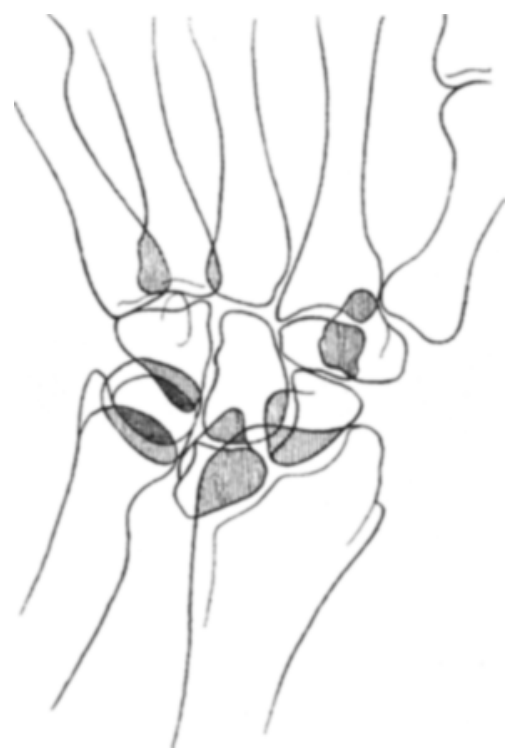

Fig. 11. Fall 3.

Rechte Hand (Pronation). Enden der zwei Vorderarmknochen kreuzen sich hierdurch wie im Fall 2. Das Ulnaköpfchen prominiert stark dorsalwärts. Die Beziehungen zwischen Radius und Carpus sind normal. Die Hände stehen zum ganzen Vorderarm in Subluxationsstellung durch die Volarkrümmung des Radius und die Dorsalkrümmung der Ulna. Eine Subluxation im Radio-Karpalgelenk ist nicht vorhanden.

c) Stereoskopische Aufnahme.

Veranschaulicht deutlich die starke Volarneigung der Gelenkfläche des Radius. Dieselbe erweist sich als viel bedeutender als bei Fall 2, wie auch die Neigung der Gelenkfläche gegen die Ulna eine größere ist. Die auf Fig. 11 sichtbare breite Kluft zwischen den untern Enden der Vorderarmknochen ist eine scheinbare in bezug auf eine Horizontalebene des Vorderarms, die durch beide Vorderarmknochen bei supiniertem Arm geht, und erklärt sich aus der doppelten Krümmung des Radius ulnar- und volarwärts, wodurch der Carpus volarwärts vom untern Ulnaende treten konnte. Auf der stark geneigten Radiusgelenkfläche ist das Os lunatum wie in Fall 1 ellenbogenwärts geglitten, so daB es sich scheinbar keilförmig in das Spatium interosseum hineindrängt. Stereoskopisch ist aber sichtbar, daß die ersten drei Karpalknochen mit der volarwärts geneigten Radiusgelenkfläche weit vor das dorsal gebliebene untere Ulnaende vorragen. Durch die Verkürzung des Radius gegenüber der Ulna reicht letztere sehr weit hinab, so dab sich die Schatten des Ulnaköpfchens und der Ossa triquetrum und pisiforme fast vollständig decken. Daß der Process. styloid. ulnae viel tiefer steht als derjenige des Radius kommt zum Teil von der extremen Ulnarabduktionsstellung der Hand, welche aber gerade für diesen Fall sehr charakteristisch ist.

\section{Linke, für die Inspektion weniger deformierte Hand.}

Die analog wie für die rechte Hand gemachten Aufnahmen zeigen, daß alle Veränderungen der rechten Seite ganz genau symme- 
Über Manus valga oder sogen. Madelungsche Deformität d. Handgelenks. $\bar{\jmath} 43$

trisch den linksseitigen sind, nicht nur qualitativ, sondern auch quantilativ.

Bei den beiden Töchtern, von denen die eine 14, die andere 16 Jahre alt ist. zeigt schon die Inspektion einen Beginn von Manus valga. Die Röntgenuntersuchung zeigt bei der dorsopalmaren Aufnahme bei beiden Mädchen eine abnorm starke Neigung der Gelenkfläche des Radius nach der Ulna hin. Dabei ist der Radius selbst nicht deutlich ulnarwärts abgebogen. Wohl aber ist besonders bei dem 14 jährigen Mädchen das Ende der Diaphyse stark ulnarwärts ausgeladen (siehe Fig. 12). Bei beiden Mädchen zeigt die Gelenkfläche eine gesonderte. Aushöhlang für das Naviculare und für das Lunatum. Bei der seitlichen Aufnahme findet sich der Radius Ieicht volar, die Ulna stärker dorsal abgebogen.

Funktionelle Störungen fehlen.

Die Untersuchung des übrigen Körpers zeigt bei dsm 14 jährigen Mädchen beiderseits leichten PlattfuB, leichte linksseitige lumbale Skoliose mit dorsaler Rechtsskoliose. Vorderseite des Thorax ausgesprochen rachitisch. Bei dem 16 jährigen Mädchen findet sich beiderseits ausgesprochener Pes valgo-planus. Wirbelsäule normal. Thorax vorn etwas abgeflacht.

Im AnschluB an diese 3 Fälle

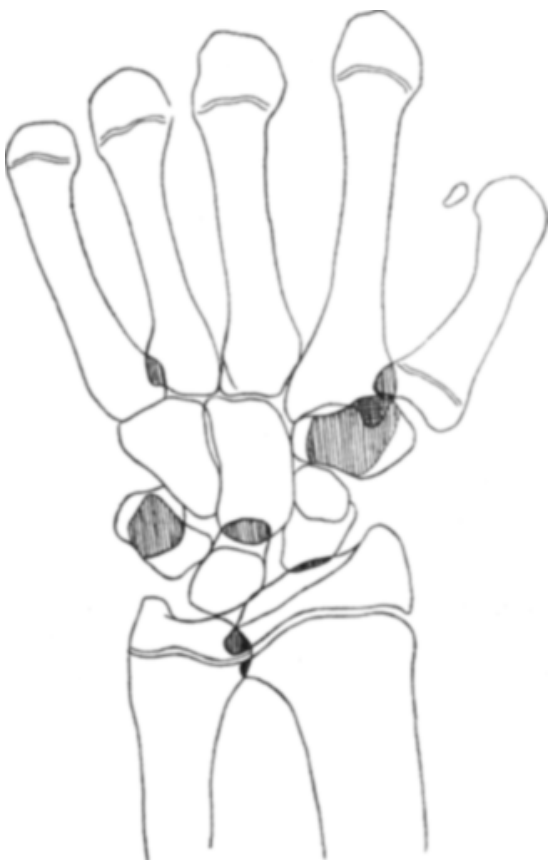

Fig. 12.

Jiingere Tochter von Fall 3. von wirklicher Manvalgaus möchte ich an dieser Stelle in Kürze einer von mir letzhin gemachten Beobachtung Erwähnung tun, die vielleicht zur Pathogenese unsrer Affektion einigen AufschluB geben kann, indem sie vielleicht den Übergang des normalen zum pathologischen Handgelenk bildet.

Es handelt sich um den Fall, wo alle männlichen Mitglieder einer Familie mit einer Deformation ihrer Handgelenke behaftet sind, die in einem abnorm starken Vorragen des Ulnaköpfchens nach dem Dorsum besteht olıne daB dazu eine Verbiegung im Niveau des Vorderarmes oder eine Subluxationsstellung der Hand besteht. In dieser Weise veränderte Hände besitzen der ca. 60 jähr. Vater und alle seine 4 Söhne im Alter von 22-32 Jahren, während die Mutter und ihre 2 Töchter von ca. 20 bis 22 Jahren davon frei sind. Wie es bei den GroBeltern war, ist leider nicht zu erfahren. Keiner der 5 Männer hat je von seiner Eigentümlichkeit Beschwerden empfunden oder irgend eine Funktionsstörung bemerkt. 
Keiner hat eine schwere Krankheit durchgemacht oder schwere Arbeit verrichtet. Keiner hat ferner andere Symptome von überstandener Rachitis.

Ich habe die Hände und Vorderarme des, die stärkste Veränderung aufweisenden $24 \mathrm{jähr}$. Sohnes radiographisch aufgenommen und dabei als

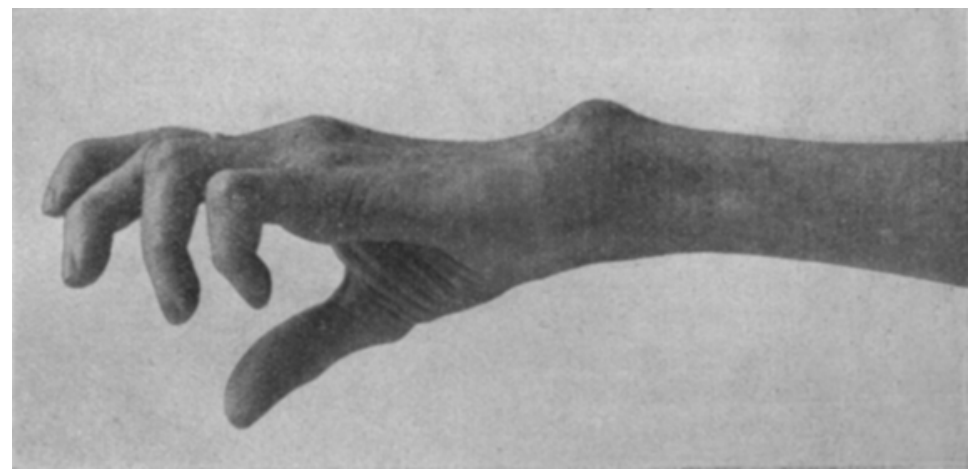

Fig. 13.

Scheinbare Manus valga bei deformierender Arthritis.

einzige Abnormität eine schwache Biegung des untern Ulnaendes dorsalwärts mit ziemlich beträchtlicher Hypertrophie des Ulnaköpfchens gefunden, wie ubrigens auch das untere Radiusende auffallend breit, wie keulen-

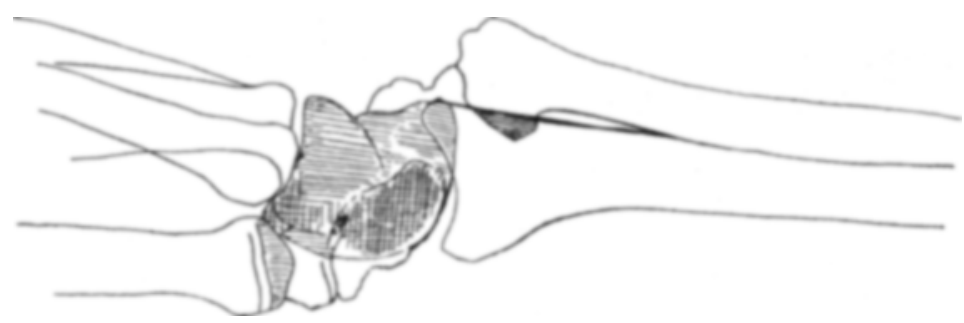

Fig. 14.

Seheinbare Manus valga bei deformierender Arthritis. Knochengrenzen im Carpus der Knochenzerstörung wegen nicht mehr völlig erkennbar.

förmig verdickt ist. Eine Verkrümmung des Radius oder ein Schiefstand der Radiusgelenkfiäche besteht nicht.

Es erinnert diese Beobachtung an eine Mitteilung von Féré, der bei 25 männlichen Epileptischen eine Hypertrophie des Ulnaköpfchens gefunden hat, welche er'als körperliches Degenerationszeichen auffaBte und den Madelungschen Fällen anreiht. Durch diese Beobachtung Férés auf- 
merksam gemacht, habe ich bei Gelegenheit des Besuches einer Irrenanstalt die meisten dort untergebrachten Epileptiker beiden Geschlechts daraufhin untersucht, obne die genannte Anomalie zu finden.

Hier wäre endlich noch ein

Fall anzuführen, der zwar äuBerlich ebenfalls das Bild der Madelungschen Deformitat zeigt, bei dem die Ursache des Übels aber in einer deformierenden Arthritis liegt.

Die 37 jährige Patientin P. H., wegen Malum perforans pedis im Spitale in La Chaux-de-Fonds in Behandlung, leidet seit Jahren an teils deformierender, tsils ankylosierender chronischer Polyarthritis. Beide Handgelenke zeigen bei der Inspektion das Bild der Madelungschen Deformität. Die Röntgenuntersuchung zeigt aber, daB es sich um einen, der deformierenden Arthritis angehörigen ProzeB handelt. der mit der typischen Manus valga nur die starke Abbiegung der Ulna nach dem Dorsum und die Verschiebung des Carpus dem Radius gegenüber nach der Vola hin gemein hat. (Siehe Figuren 13, 14 und 15).

$Z_{\text {wei weitere, leichte Fälle von }}$ Manus valga, welche mir kurz vor der Drucklegung dieser Arbeit von

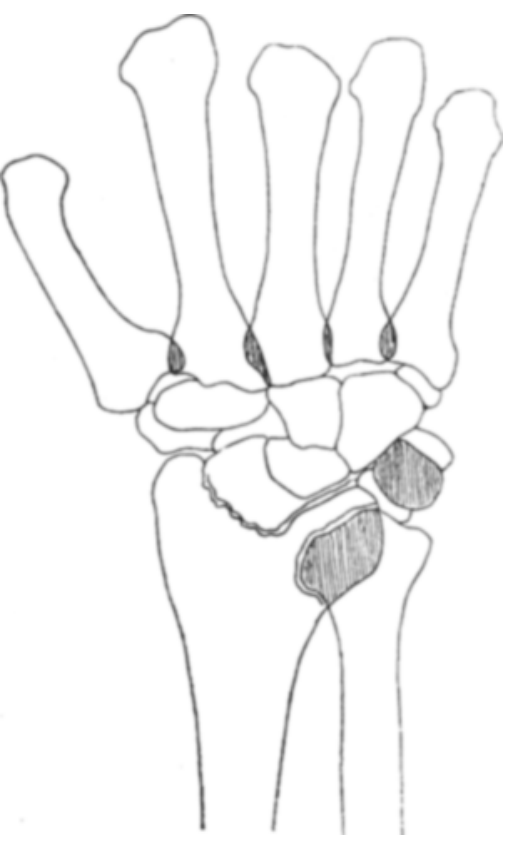

Fig. 15.

Scheinbare Manus valga bei deformierender Arthritis. Prof. de Quervain zugewiesen wurden, konnten nicht mehr eingehender berücksichtigt werden. Beide stellen leichtere Grade der Deformität dar, und bei beiden finden sich am übrigen Skelett ausgesprochen rachitische Veränderungen (Skoliose, rachitischer Thorax, PlattfuB) vor. 


\section{Tabellarische Zusammen}

\section{[Auf Grund der Tabelle von Abadie}

\begin{tabular}{|c|c|c|c|c|c|c|}
\hline 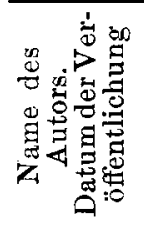 & 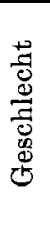 & 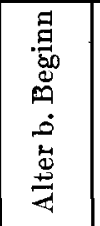 & 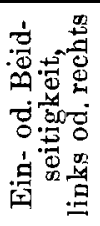 & 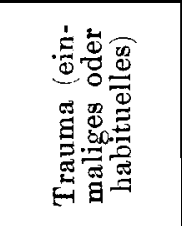 & Inspektion & 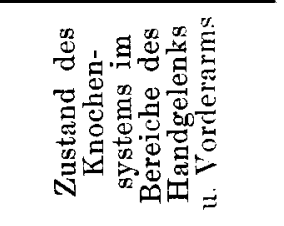 \\
\hline $\begin{array}{l}\text { Dupuy- } \\
\text { tren-Bé- } \\
\text { gin } \\
1832-1841\end{array}$ & $\mathrm{~m}$. & - & - & $\begin{array}{l}\text { Arbeiter der } \\
\text { Tuchfabri- } \\
\text { kation } \\
\text { (Drucker u. } \\
\text { Walker). }\end{array}$ & $\begin{array}{l}\text { Luxation desCarp. } \\
\text { nach vorne vom } \\
\text { Vorderarm. }\end{array}$ & $\begin{array}{l}\text { Carpus direkt vor d. } \\
\text { Vorderarmknochen. } \\
\text { Durch Zug reduzier- } \\
\text { bar, kehrt aber sofort } \\
\text { zurück. }\end{array}$ \\
\hline $\begin{array}{l}\text { Mal- } \\
\text { gaigne } \\
1855\end{array}$ & $\mathrm{~m}$. & 13 & $\begin{array}{l}\text { Ein- } \\
\text { seitig }\end{array}$ & $\begin{array}{l}\text { Mit 8-9 J. } \\
\text { Trauma; } \\
\text { Fraktur d. } \\
\text { Radius in } \\
\text { seiner Mitte. } \\
\text { Heilung. } \\
\text { 3-4J.später } \\
\text { Beginn der } \\
\text { Affektion bei } \\
\text { anstreagea- } \\
\text { der Arbeit } \\
\text { (Lasten- } \\
\text { tragen). }\end{array}$ & $\begin{array}{l}\text { Handin einer, dem } \\
\text { Vorderarm paral- } \\
\text { lelen, aber vorge- } \\
\text { schobenen Ebene. } \\
\text { Diam. ant.-post } \\
=5 \mathrm{~cm} \text { für Ulna, } \\
=4 \mathrm{~cm} \text { für d. Ra- } \\
\text { dius. }\end{array}$ & $\begin{array}{l}\text { Carpus nach vorn } \\
\text { vom Radius u. Ulna, } \\
\text { mehr als } 2 \mathrm{~cm} \text { vor der } \\
\text { Ulna u. } 1 \mathrm{~cm} \text { vor dem } \\
\text { Radius hinaufge- } \\
\text { treten. Krümmung } \\
\text { des Radius in seinem } \\
\text { unteren Ende. Ge- } \\
\text { lenkrand des Radius } \\
\text { nach vorn geneigt } u . \\
\text { eingedrückt. }\end{array}$ \\
\hline $\begin{array}{l}\text { Mal- } \\
\text { gaigne- } \\
\text { Smith } \\
1855\end{array}$ & w. & $\begin{array}{c}\text { Junge } \\
\text { Frau }\end{array}$ & $\begin{array}{l}\text { Ein- } \\
\text { seitig } \\
\text { r. }\end{array}$ & - & - & $\begin{array}{l}\text { Autopsie: Radius } \\
\text { länger als Ulna, ohne } \\
\text { normale Gelenk- } \\
\text { fläche, abgerundet } \\
\text { endigend. Oberhalb } \\
\text { davon am Radius } \\
\text { vorn eine Höhle, wo- } \\
\text { rin das Os naviculare } \\
\text { und lunatum. }\end{array}$ \\
\hline $\begin{array}{c}\text { Weber } \\
1859\end{array}$ & w. & 16 & $\begin{array}{l}\text { Ein- } \\
\text { seitig } \\
\text { r. }\end{array}$ & $\underset{\text { Trauma. }}{\text { Kein }}$ & - & $\begin{array}{l}\text { Hand auf der Volar- } \\
\text { seite der Vorderarm- } \\
\text { knochen. Carp. un- } \\
\text { terd. Rad., von ihm u. } \\
\text { d. Capit. ulnae über- } \\
\text { ragt. }\end{array}$ \\
\hline$\underset{1864}{\text { Busch }}$ & w. & $\begin{array}{c}12 \mathrm{bis} \\
15\end{array}$ & $\begin{array}{l}\text { Beid- } \\
\text { seitig }\end{array}$ & $\begin{array}{c}\text { Kein } \\
\text { Trauma. }\end{array}$ & $\begin{array}{l}\text { Subluxation } \\
\text { beider Hände } \\
\text { nach vorne. }\end{array}$ & - \\
\hline
\end{tabular}




\section{stellung der Fälle.}

(1903) ergänzt und weitergeführt.]

\begin{tabular}{|c|c|c|c|c|}
\hline Schmerzen? & 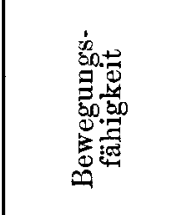 & 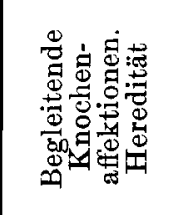 & 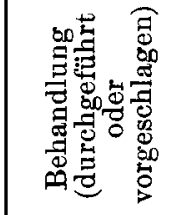 & $\begin{array}{l}\text { Benennung und } \\
\text { pathogenetische Theorje }\end{array}$ \\
\hline $\begin{array}{l}\text { Nur bei Be- } \\
\text { ginn des } \\
\text { Leidens. }\end{array}$ & $\begin{array}{l}\text { Kaum beein- } \\
\text { trächtigt. }\end{array}$ & - & - & $\begin{array}{l}\text { Erschlaffung der Ligamente } \\
\text { infolge brüsker, heftiger, oft } \\
\text { wiederholter Traktionen. Durch } \\
\text { das Überwiegen der Beugemus- } \\
\text { kulatur entsteht eine progressive } \\
\text { Luxation. }\end{array}$ \\
\hline $\begin{array}{c}\text { Keine, nach } \\
18 \text { Monaten. } \\
\text { Im 12.-13. } \\
\text { Jahre } \\
\text { Schmerzen. }\end{array}$ & $\begin{array}{l}\text { Im Alter von } \\
36 J a h r e n \text { Be- } \\
\text { wegungen so } \\
\text { ausgedehnt } \\
\text { wie auf der } \\
\text { gesunden } \\
\text { Seite, außer } \\
\text { Dorsalflexion } \\
\text { u. Pronation. }\end{array}$ & $\begin{array}{l}\text { Vorn am Ra- } \\
\text { dius, ober- } \\
\text { halb d. Car- } \\
\text { pusknöcher- } \\
\text { ne Exostose. }\end{array}$ & Irreduktibel. & $\begin{array}{l}\text { Zu den „Pathologischen Luxa- } \\
\text { tionen“ gezählt. Erschlaffung } \\
\text { der Ligamente des Gelenks. Der } \\
\text { Carpus gleitet vor den 2. Vorder- } \\
\text { armknochen. }\end{array}$ \\
\hline 一 & - & - & - & $\begin{array}{l}\text { Pseudoluxation oder wirkliche } \\
\text { Luxation? }\end{array}$ \\
\hline $\begin{array}{l}\text { Schmerz- } \\
\text { hafte Ent- } \\
\text { wicklung. }\end{array}$ & $\begin{array}{l}\text { Extension } \\
\text { sehr be- } \\
\text { schränkt. } \\
\text { Alle Be- } \\
\text { wegungen } \\
\text { schmerzhaft. }\end{array}$ & - & $\begin{array}{l}\text { Reposition } \\
\text { in Narkose. } \\
\text { Rezidiv trotz } \\
\text { Gipsverband. } \\
\text { Apparat mit } \\
2 \text { Federn. }\end{array}$ & $\begin{array}{l}\text { "DieserFall war offenbar durch } \\
\text { Muskelkontraktion bewirkt, da } \\
\text { dasMädchen sichdurchaus keiner } \\
\text { traumatischen Einwirkung er- } \\
\text { innerte. Eine nähere Ursache } \\
\text { der ersteren war aber nicht zu } \\
\text { ermitteln." }\end{array}$ \\
\hline $\begin{array}{c}\text { Schmerzen } \\
\text { während der } \\
\text { Entwicklung. }\end{array}$ & - & - & \begin{tabular}{|} 
Reduktion \\
erfolglos. Zu- \\
nahme der \\
Subluxation \\
nach Teno- \\
tomie.
\end{tabular} & Muskelkontraktur. \\
\hline
\end{tabular}




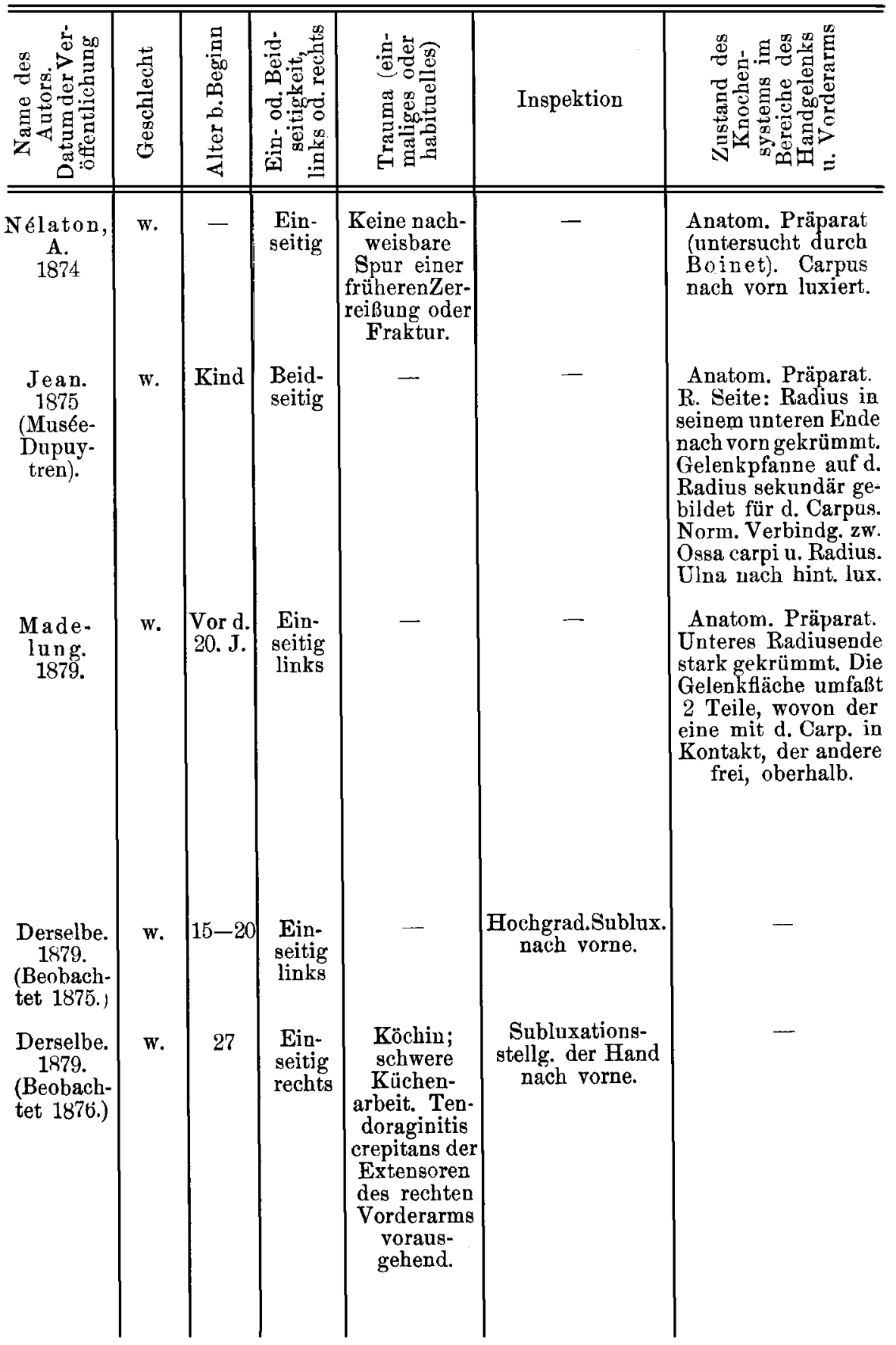


Über Manus valga oder sogen. Madelungsche Deformität d. Handgelenks. 549

\begin{tabular}{|c|c|c|c|c|}
\hline Schmerzen? & 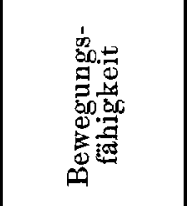 & 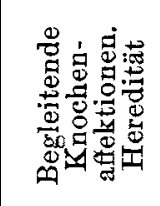 & 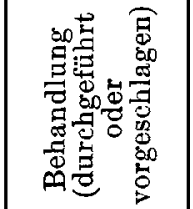 & $\begin{array}{c}\text { Benennung und } \\
\text { pathogenetische Theorie }\end{array}$ \\
\hline - & - & - & - & $\begin{array}{l}\text { Jean hält die Affektion für } \\
\text { kongenital. (Beschreibung und } \\
\text { Besprechung des Präparats auch } \\
\text { durch Delbet.) }\end{array}$ \\
\hline $\begin{array}{l}\text { Lebhafte } \\
\text { Schmerzen } \\
\text { bei Beginn. }\end{array}$ & $\begin{array}{l}\text { Zw. Rad. u. } \\
\text { Carp. keine } \\
\text { größere Ver- } \\
\text { schiebbarkeit } \\
\text { als beim nor- } \\
\text { malen Hand- } \\
\text { gelenk. Da- } \\
\text { gegen Be- } \\
\text { wegungenim } \\
\text { Intercarpal- } \\
\text { gelenk das } \\
\text { Normale } \\
\text { übertreftend. } \\
\text { Dorsal- } \\
\text { flexion sehr } \\
\text { behindert. } \\
\text { Fast voll- }\end{array}$ & - & Monatela & $\begin{array}{l}\text { "Spontane Subluxation der } \\
\text { Hand nach vorne." Gehört zu d. } \\
\text { Wachstumsstörungen der Ge- } \\
\text { lenke(Volkmann). Analogie m. } \\
\text { Pes valg., Genu valg., Skoliose. } \\
\text { Die Vorbedingung ist eine pri- } \\
\text { märe Schwäche des Knochen- } \\
\text { systems, wie sie das Wachstum } \\
\text { od. irgend eine Ernährungsstö- } \\
\text { rung mit sich bringen kann. Die } \\
\text { individuell verschiedene Form } \\
\text { des Handgelenks u. sogarder ein- } \\
\text { zeinen Knochen desseJben eat- } \\
\text { steht unter dem Einfluß der ver- } \\
\text { schiedenen Beschäftigung. Diese } \\
\text { Umformung der Gelenktächen } \\
\text { durch anstrengende Berufsarbeit } \\
\text { istimmer mitSchmerz verbunden } \\
\text { n. mitdem Schmerz wiederum ist } \\
\text { eine Umformung der Bewegungs- }\end{array}$ \\
\hline \multirow[t]{2}{*}{$\begin{array}{l}\text { Schmerz bei } \\
\text { Bewegungen } \\
\text { im Handge- } \\
\text { lenk auch } \\
\text { nach ge- } \\
\text { heilter Ten- } \\
\text { doraginitis. }\end{array}$} & $\begin{array}{l}\text { Fast voll- } \\
\text { ständige } \\
\text { Arbeits- } \\
\text { unfähigkeit. }\end{array}$ & \multirow{2}{*}{\multicolumn{2}{|c|}{$\begin{array}{l}- \\
\text { Monatelange } \\
\text { Gipsverband war in 1 Falle } \\
\text { erfolglos u. läßt sich meist } \\
\text { nicht durchführen. Von } \\
\text { jedem energischen Kurver- } \\
\text { such ist abzusehen u. dem } \\
\text { Pat. der Rat zu geben, die } \\
\text { Hand mögl.zu schonen, be- } \\
\text { sonders keine energische } \\
\text { Dorsalflexionen zu machen. } \\
\text { leistet ein ledernes Armband } \\
\text { elenk, das durch Riemenzug } \\
\text { keret angezogen werd. kann. }\end{array}$}} & $\begin{array}{l}\text { exkurse des Handgelenks ver- } \\
\text { bunden. Der mechan Vorgang } \\
\text { bierbei ist folgender: Für dieBe- } \\
\text { wegungsexkursionen im Handge- } \\
\text { lenke bestehen folgende } 3 \text { Arten } \\
\text { Bewegungshemmungsvorrich- } \\
\text { tungen: die knöcherne, die Bän- } \\
\text { der- u. Muskelhemmung. Für die } \\
\text { Handgelenksbewegungen ist die }\end{array}$ \\
\hline & $\begin{array}{l}\text { Gute Dienste } \\
\text { üb. dasHandg } \\
\text { fester od. lock }\end{array}$ & & & $\begin{array}{l}\text { ter gezeigt hat. Die Beugungs- } \\
\text { muskeln übertreffen an Masse d. } \\
\text { Streckmuskeln um ein Beden- }\end{array}$ \\
\hline
\end{tabular}




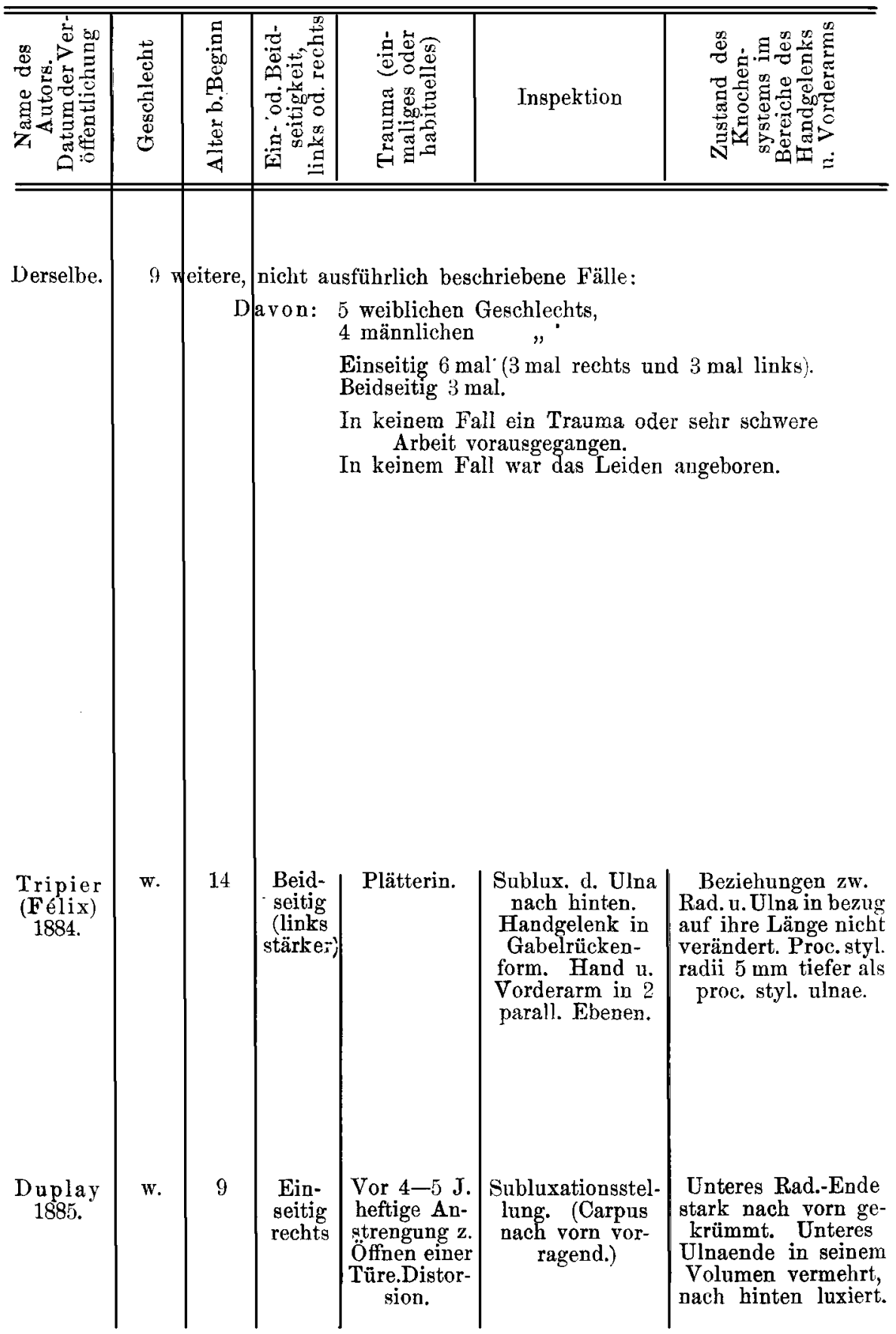




\begin{tabular}{|c|c|c|c|c|}
\hline Schmerzen? & 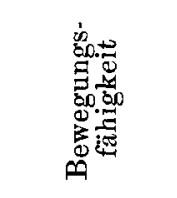 & 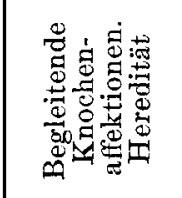 & 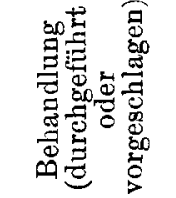 & $\begin{array}{l}\text { Benennung und } \\
\text { pathogenetische Theorie }\end{array}$ \\
\hline & & & & \multirow{2}{*}{$\begin{array}{l}\text { tendes. Die Haupthemmungs- } \\
\text { vorrichtung für die volare Hyper- } \\
\text { flexion wird durch e. Spannung } \\
\text { der Sehne der Flexoren gegeben. } \\
\text { Diese Sehnen aber verlaufen } \\
\text { fast ausschließlich über d. vord. } \\
\text { Epiphyse d. Radius, bevor sie } \\
\text { zum Rücken d. Handwurzel- } \\
\text { knochen u. weiter gelangen. So } \\
\text { muß jede extreme Volarflexion } \\
\text { e. Druck auf d. vord. Epiphyse } \\
\text { d. Radius nach d. Vola zu aus- } \\
\text { üben. Aus diesem immer wieder- } \\
\text { kehrenden Druck und Zug ent- } \\
\text { steht e. Wachstumsstörung, wel- } \\
\text { che d. Achse d. Radius nach } \\
\text { d. Vola zu krümmt. Doch d. } \\
\text { Muskelhemmung wird im Falle } \\
\text { der Ubermüdung überwanden. } \\
\text { nung tritt in Wirksamkeit, u. es } \\
\text { n, knochen- u. bandschwachen } \\
\text { Struktur des Knochen- und des } \\
\text { arker Druck belastet d. untern } \\
\text { iche u. des Handwurzelknochens } \\
\text { wund. Entlastet von Druck da- } \\
\text { l. Radiusgelenkfläche. Er wächst } \\
\text { d.Femurb. Genu valg. Die Form- } \\
\text { Abschluß mit d. Stillstand des } \\
\text { rlischt dann d.Schmerzhaftigkeit. }\end{array}$} \\
\hline & & \multicolumn{2}{|c|}{$\begin{array}{l}\text { Die Knochen- u. Bandhemmung tritt in Wirksamkeit, u. es } \\
\text { entstehen beim wachsenden, knochen- u. bandschwachen } \\
\text { Individuum Störungen in d. Struktur des Knochen- und des } \\
\text { Bandapparats. Abnorm starker Druck belastet d. untern } \\
\text { Kanten der Radiusgelenkfläche u. des Handwurzelknochens } \\
\text { a. bringt dieselben z. Schwund. Entlastet von Druck da- } \\
\text { gegen wird d. obere Rayd d. Radiusgelenkfläche. Er wächst } \\
\text { ebenso wie d. Condylus int. d. Femur b. Genu valg. Die Form- } \\
\text { veränderung erreicht ihren Abschluß mit d. Stillstand des } \\
\text { Knochenwachtums, ebenso erlischt dann d.Schmerzhaftigkeit. }\end{array}$} & \\
\hline $\begin{array}{l}\text { Im Beginn } \\
\text { lebhafte } \\
\text { Schmerzen, } \\
\text { später ab- } \\
\text { nehmend. }\end{array}$ & - & - & $\begin{array}{c}\text { Orthopäd. } \\
\text { Apparat z. } \\
\text { Fixierung } \\
\text { d. Hand in } \\
\text { Extension. } \\
\text { Elektrisa- } \\
\text { tion d. Ex- } \\
\text { tensoren. } \\
\text { Vorüber- } \\
\text { gehender } \\
\text { Erfolg, } \\
\text { später Rezi- } \\
\text { div. }\end{array}$ & $\begin{array}{l}\text { Überanstrengung d. Handge- } \\
\text { lenks im Wachstumsalter als } \\
\text { Gelegenheitsursache. Dieselbe } \\
\text { erzeugt e. Zustand von patholog. } \\
\text { Hyperexzibilität d. Rücken- } \\
\text { markes; dessen Folgen sind: } \\
\text { 1. Errährungsstörung im Gelenk. } \\
\text { 2. Muskelkontraktur, Deforma- } \\
\text { tion mit folgender Subluxation. }\end{array}$ \\
\hline- & $\begin{array}{l}\text { Keine Be- } \\
\text { hinderung } \\
\text { im Alter von } \\
13 \text { Jahren. }\end{array}$ & $\begin{array}{l}\text { Hyperostose } \\
\text { der Ulna. } \\
\text { Skoliose. }\end{array}$ & $\begin{array}{l}\text { Orthopäd. } \\
\text { Apparat, } \\
\text { später } \\
\text { lineare } \\
\text { Osteotomie } \\
\text { d. Ruad. mit } \\
\text { Erfolg. }\end{array}$ & $\begin{array}{l}\text { Spätrachitis (verglichen mit } \\
\text { Genu valg.). Das primäre Mo- } \\
\text { ment ist d. Krümmung d. Radius. }\end{array}$ \\
\hline
\end{tabular}




\begin{tabular}{|c|c|c|c|c|c|c|}
\hline 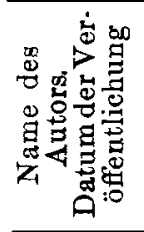 & 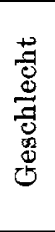 & 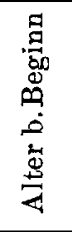 & 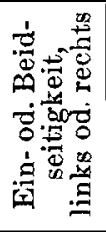 & 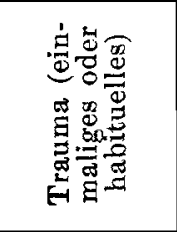 & Inspektion & 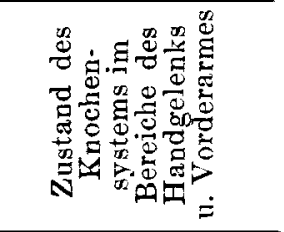 \\
\hline Duplay & w. & 15 & $\begin{array}{l}\text { Beid- } \\
\text { seitig }\end{array}$ & - & $\begin{array}{l}\text { Subluxations- } \\
\text { stellung (Carpus } \\
\text { nach vorn vor- } \\
\text { ragend). }\end{array}$ & $\begin{array}{l}\text { Regelmäß. Krüm- } \\
\text { mung d. unt. Endes } \\
\text { von Rad. u. Ulna } \\
\text { palmarwärts. Capit. } \\
\text { ulnae hypertroph. }\end{array}$ \\
\hline $\begin{array}{c}\text { v. Berg- } \\
\text { mann } \\
1888 .\end{array}$ & w. & $\begin{array}{l}\text { Vor } \\
17 \text { J. }\end{array}$ & $\begin{array}{l}\text { Beid- } \\
\text { seitig }\end{array}$ & $\begin{array}{l}\text { Kein Trau- } \\
\text { ma. }\end{array}$ & $\begin{array}{c}\text { Symmetr. Sublux. } \\
\text { beider Hände } \\
\text { nach vorn. }\end{array}$ & 一 \\
\hline $\begin{array}{c}\text { Guépin } \\
1892 .\end{array}$ & w. & $\begin{array}{l}\text { Kin- } \\
\text { des- } \\
\text { alter }\end{array}$ & $\begin{array}{l}\text { Beid- } \\
\text { seitig, } \\
\text { stärker } \\
\text { links }\end{array}$ & $\begin{array}{l}\text { Leichtes } \\
\text { Trauma im } \\
\text { Kindesalter } \\
\text { auf d. linken } \\
\text { Seite. }\end{array}$ & $\begin{array}{l}\text { Handgelenks- } \\
\text { gegend verdickt. } \\
\text { Ulna nach hinten } \\
\text { vorragend. }\end{array}$ & $\begin{array}{l}\text { Capit. ulnae sub- } \\
\text { luxiert einers. gegen- } \\
\text { überd.Radius, ander- } \\
\text { seits gegenüber d. } \\
\text { Carpus, ohne Zu- } \\
\text { nabme d. Vol. Redu- } \\
\text { zierbar rechts durch } \\
\text { Druck auf d. Ulna } \\
\text { (Vergleich mit } \\
\text { Klaviertaste). Über- } \\
\text { dies leichte Sublux. } \\
\text { des Carpus vor den } \\
\text { Rad., leicht reduzier- } \\
\text { bar. }\end{array}$ \\
\hline $\begin{array}{c}\text { Redard } \\
1892 .\end{array}$ & w. & 14 & $\begin{array}{l}\text { Beid- } \\
\text { seitig }\end{array}$ & $\begin{array}{l}\text { Fall auf d. } \\
\text { l. Hand, in } \\
\text { d. Folge De- } \\
\text { formation, } \\
\text { später } \\
\text { rechts. } \\
\text { Wäscherin; } \\
\text { windet d. } \\
\text { Wäsche aus. }\end{array}$ & $\begin{array}{c}\text { Handgelenke be- } \\
\text { trächtl. verdickt. } \\
\text { Sublux.-Stellung } \\
\text { d. Hände } z \text {. } \\
\text { Vorderarm. } \\
\text { Gabelrückenform. }\end{array}$ & $\begin{array}{l}\text { Beide Radii nach } \\
\text { vorn gekrümmt, d. } \\
\text { beiden Ulnae ebenso. } \\
\text { Proc. styloid. rad. } \\
\text { tiefer als diejenigen } \\
\text { d. Ulna. }\end{array}$ \\
\hline
\end{tabular}


Über Manus valga oder sogen. Madelungsche Deformität d. Handgelenks. 553

\begin{tabular}{|c|c|c|c|c|}
\hline Schmerzen? & 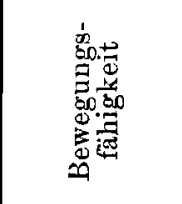 & 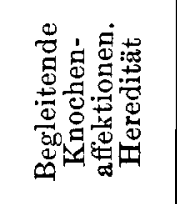 & 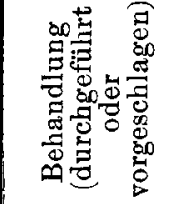 & $\begin{array}{l}\text { Benennung und } \\
\text { pathogenetische Theorie }\end{array}$ \\
\hline $\begin{array}{c}\text { Unbestimm- } \\
\text { te Schmer- } \\
\text { zen am An- } \\
\text { fang. }\end{array}$ & $\begin{array}{l}\text { Funktions- } \\
\text { störg. mittl. } \\
\text { Grades mit } \\
18 \text { Jahren. }\end{array}$ & $\begin{array}{l}\text { Hyperostose } \\
\text { d. untern } \\
\text { Ulnaendes. }\end{array}$ & $\begin{array}{l}\text { Osteotomie } \\
\text { angeraten. }\end{array}$ & - \\
\hline $\begin{array}{c}\text { Allmähliche } \\
\text { Entwick- } \\
\text { lung mithef- } \\
\text { tigen } \\
\text { Schmerzen. }\end{array}$ & $\begin{array}{l}\text { Flexion nor- } \\
\text { mal. Exten- } \\
\text { sion d. Hand } \\
\text { beschräukt. }\end{array}$ & $\begin{array}{l}\text { Symmetr. } \\
\text { Verkürzg. d. } \\
\text { Metacarpal- } \\
\text { knochen } \\
\text { beider } \\
\text { Ringfinger. }\end{array}$ & - & $\begin{array}{l}\text { Ursache rätselhaft. Sicher ist } \\
\text { nur d. Vorkommen im Wachs. } \\
\text { tumsalter. Hierin große Analo- } \\
\text { gie mit d. sog. entzündl. Platt- } \\
\text { fuß d. Jünglingszeit, die daran } \\
\text { denken läßt, d. Krankh. als eine } \\
\text { durch Wachstumsstörungen be- } \\
\text { dingte anzusehen. Meist blut- } \\
\text { arme a. muskelschwache Indi- } \\
\text { viduen. }\end{array}$ \\
\hline$\cdots$ & - & $\begin{array}{c}\text { Heredität: } \\
\text { Vater u. } \\
\text { Mutter } \\
\text { haben ver- } \\
\text { dickte } \\
\text { Handge- } \\
\text { lenke. 9 Ge- } \\
\text { schwister d. } \\
\text { Pat. haben } \\
\text { alle seit } \\
\text { ihrer Kind- } \\
\text { beit vor- } \\
\text { spring. Cap. } \\
\text { ulnae, eben- } \\
\text { so d. Kinder } \\
\text { einer } \\
\text { Schwester } \\
\text { u. Onkel u. } \\
\text { Tanten der } \\
\text { Patientin. }\end{array}$ & - & $\begin{array}{l}\text { Erschlaffung der Bänder (kon- } \\
\text { genitale Schlaffheit?). }\end{array}$ \\
\hline $\begin{array}{c}\text { Schmerzen } \\
\text { sehr lebhaft, } \\
\text { besonders b. } \\
\text { Ausdrehen } \\
\text { d. Wäsche. }\end{array}$ & $\begin{array}{l}\text { Behinderung } \\
\text { in d. Bewe- } \\
\text { gungen. Be- } \\
\text { sonders be- } \\
\text { hindert die } \\
\text { Supination, } \\
\text { Extension, } \\
\text { Dorsal- } \\
\text { flexion d. } \\
\text { Hand. }\end{array}$ & $\begin{array}{l}\text { Keine Zei- } \\
\text { chen von } \\
\text { Rachitis } \\
\text { usw. Skelett } \\
\text { völlig nor- } \\
\text { mal. Keine } \\
\text { Heredität. }\end{array}$ & $\begin{array}{l}\text { Ruhigstellg. } \\
\text { d. Handge- } \\
\text { lenks. Elek- } \\
\text { trisation d. } \\
\text { Vorderarm- } \\
\text { muskeln mit } \\
\text { konst. Strom. } \\
\text { Innerlich } \\
\text { Phosphor. } \\
\text { Die Osteo- } \\
\text { tomie n. Du- } \\
\text { play ist oft } \\
\text { rationell. }\end{array}$ & $\begin{array}{l}\text { Die Deformität ist d. Folge } \\
\text { einer Störung im Wachstum d. } \\
\text { Epiphysenknorpels am untern } \\
\text { Ende beiderVorderarmknochen. } \\
\text { Unter d. Einfluß von oft wieder- } \\
\text { holten mäßigen Reizen (Berufs- } \\
\text { arbeit) haben gewisse Partien } \\
\text { dieses Knorpels e. Hyperfunk- } \\
\text { tion, was z. Bildg. von knöcher- } \\
\text { nen Hypertrophien führt, welche } \\
\text { d. Sublux. d. Handgelenks her- } \\
\text { vorrufen. }\end{array}$ \\
\hline
\end{tabular}




\begin{tabular}{|c|c|c|c|c|c|c|}
\hline 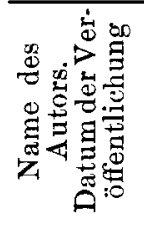 & 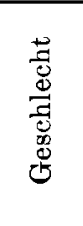 & 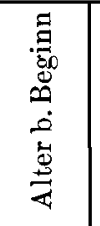 & 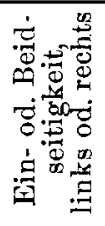 & 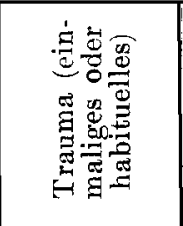 & Inspektion & 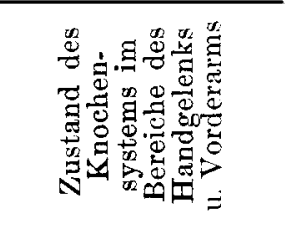 \\
\hline $\begin{array}{l}\text { Malfu- } \\
\text { son } \\
1894\end{array}$ & w. & 13 & $\begin{array}{l}\text { Beid. } \\
\text { seitig, } \\
\text { mehr } \\
\text { rechts }\end{array}$ & $\begin{array}{c}\text { Plötzl. Supi- } \\
\text { nationsbe- } \\
\text { wegung, } \\
\text { dann fort- } \\
\text { schreitende } \\
\text { Deforma- } \\
\text { tion. } \\
\text { Nähterin. }\end{array}$ & $\begin{array}{c}\text { Hand ulnawärts } \\
\text { verschoben. Carp. } \\
\text { in volarer Sublux. } \\
\text { z. Vorderarm. } \\
\text { Ebenen d.Vorder- } \\
\text { arms u. d. Hand } \\
\text { parallel, } 1 \mathrm{~cm} \mathrm{Ab-} \\
\text { stand. }\end{array}$ & $\begin{array}{l}\text { Rad.inseinem untern } \\
\text { Viertel leicht nach } \\
\text { vorn gekrümmt. }\end{array}$ \\
\hline Derselbe. & $\begin{array}{l}\text { w. } \\
\text { Mut. } \\
\text { ter d. } \\
\text { Vorig. }\end{array}$ & - & $\begin{array}{l}\text { Beid- } \\
\text { seitig }\end{array}$ & $\ldots$ & $\begin{array}{l}\text { Dasselbe. } \\
\text { Nur geringgradi- } \\
\text { ger. }\end{array}$ & - \\
\hline $\begin{array}{c}\text { Hoffa } \\
1894 .\end{array}$ & - & - & - & $\begin{array}{l}\text { Keine gen } \\
(1894) \text { in }\end{array}$ & $\begin{array}{l}\text { Auen Angaben. Fa } \\
\text { Hoffas Behandlur }\end{array}$ & $\begin{array}{l}\text { lll steht gegenwärtig } \\
\text { ng. }\end{array}$ \\
\hline $\begin{array}{l}\text { Féré } \\
1896 .\end{array}$ & - & - & - & $\begin{array}{r}\text { Hat } 25 \mathrm{Epi} \\
\text { gelenken } \\
\text { vorragen }\end{array}$ & $\begin{array}{r}\text { eptiker beobachtet } \\
\text { Unteres Ulnare } \\
\text {, nach hinten subl }\end{array}$ & $\begin{array}{l}\text { mit verdickten Hand- } \\
\text { ende hypertrophisch, } \\
\text { luxiert. }\end{array}$ \\
\hline $\begin{array}{c}\text { Jagot } \\
1897 .\end{array}$ & w. & $\mid 13-14$ & $\begin{array}{l}\text { Beid- } \\
\text { seitig }\end{array}$ & $\begin{array}{l}\text { Mühsame } \\
\text { Arbeit: } \\
\text { Melker. }\end{array}$ & \begin{tabular}{|} 
Handgelenks- \\
gegend beträchtl. \\
verdickt. Hände \\
in einer dem \\
Vorderam paral- \\
lelen Ebene, be- \\
sonders auf d. \\
Außenseite aus- \\
gesprochen.
\end{tabular} & $\begin{array}{l}\text { Radiogramm: Ulna } \\
\text { in ihrem unteren } \\
\text { Drittel regelmäßig } \\
\text { hypertrophisch und } \\
\text { nach hinten luxiert. } \\
\text { Radius hypertro- } \\
\text { phisch und nach vorn } \\
\text { gekrümmt; sein proc. } \\
\text { styloid. ist tiefer als } \\
\text { derjenige der Ulna. }\end{array}$ \\
\hline
\end{tabular}


Über Manus valga oder sogen. Madelungsche Deformität d. Handgelenks. $55 \check{5}$

\begin{tabular}{|c|c|c|c|c|}
\hline Schmerzen? & 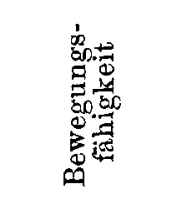 & 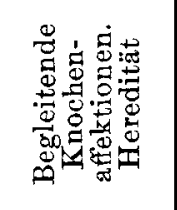 & 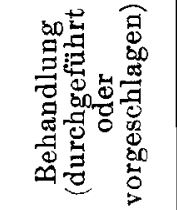 & $\begin{array}{l}\text { Benennung und } \\
\text { pathogenetische Theorie }\end{array}$ \\
\hline $\begin{array}{l}\text { Intermittie. } \\
\text { render } \\
\text { Schmerz in } \\
\text { beiden } \\
\text { Hand- } \\
\text { gelenken. }\end{array}$ & $\begin{array}{l}\text { Rechts Ex- } \\
\text { tension be- } \\
\text { schränkt u. } \\
\text { Supination } \\
\text { etwas } \\
\text { schmerzhaft. } \\
\text { Links } \\
\text { normal. }\end{array}$ & $\begin{array}{l}\text { Leichte } \\
\text { Skoliose. } \\
\text { Heredität: } \\
\text { Mutter hat } \\
\text { d. gleiche } \\
\text { Deformität } \\
\text { (s. unten). }\end{array}$ & $\begin{array}{c}\text { Massage, } \\
\text { Jodanstrich, } \\
\text { Schwefel- } \\
\text { bäder. } \\
\text { Ruhigstellg. } \\
\text { d. Gelenks } \\
\text { empfohlen. } \\
\text { B. größerer } \\
\text { Funktions- } \\
\text { störg. Osteo- } \\
\text { tomie nach } \\
\text { Duplay em- } \\
\text { pfehlens } \\
\text { wert. }\end{array}$ & $\begin{array}{l}\text { Die Deformation ist eine ganz } \\
\text { typische und ist d. Folge einer } \\
\text { Störung im Wachstum und in } \\
\text { d. Funktion beider Vorderarm- } \\
\text { knochen auf rachitischer Grund- } \\
\text { lage (Rachitis ist d. prädispo- } \\
\text { nierende Moment). }\end{array}$ \\
\hline $\begin{array}{c}\text { Nie } \\
\text { Schmerzen. }\end{array}$ & $\begin{array}{l}\text { Nie Funk- } \\
\text { tionsstö- } \\
\text { rung. }\end{array}$ & $\begin{array}{l}\text { Keine Here- } \\
\text { dität iu auf- } \\
\text { steig. Linie. }\end{array}$ & - & - \\
\hline - & - & $\begin{array}{l}\text { Apparat z. F } \\
\text { neben Faradi } \\
\text { ge, Gymnasti } \\
\text { von forcierter }\end{array}$ & $\begin{array}{l}\text { Orthopäd. } \\
\text { ixation. Da- } \\
\text { ation,Massa- } \\
\text { k, Vermeidg. } \\
\text { Volarflexion. }\end{array}$ & - \\
\hline- & - & - & $\ldots$ & $\begin{array}{l}\text { Die Symmetrie der Deform. } \\
\text { u. d. Entwicklg. im Wachstums- } \\
\text { alter sprechen für e. Entwick- } \\
\text { lungsstörung. Dafür sprichtauch } \\
\text { d. mehrfach beobachtete Here- } \\
\text { ditä. Die Entwickiungsanoma- } \\
\text { lie ist unabhängig von äußeren } \\
\text { Ursachen. }\end{array}$ \\
\hline $\begin{array}{c}\text { Nie } \\
\text { Schmerzen. }\end{array}$ & $\begin{array}{l}\text { Mit } 21 \text { Jah- } \\
\text { ren alle Be- } \\
\text { wegungen } \\
\text { mögl., aber } \\
\text { Extension } \\
\text { beschränkt, } \\
\text { ebenso Seit- } \\
\text { wärtsbewe- } \\
\text { gungen. }\end{array}$ & $\begin{array}{c}\text { Heredität: } \\
\text { Vater,Onkel } \\
\text { u. Großvater } \\
\text { d.Pat. haben } \\
\text { stark ver- } \\
\text { dickte } \\
\text { Handge- } \\
\text { lenke, ohne } \\
\text { Sublux. u. } \\
\text { ohne Funk- } \\
\text { tionsstörung. }\end{array}$ & - & $\begin{array}{l}\text { Kongenitale Anomalie, ver- } \\
\text { bunden mit e. allgemeinen Er- } \\
\text { nährungsstörung, hereditär od. } \\
\text { von anderweitiger Ursache. }\end{array}$ \\
\hline
\end{tabular}




\begin{tabular}{|c|c|c|c|c|c|c|}
\hline 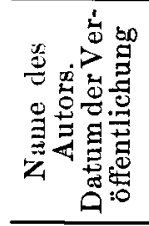 & 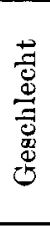 & 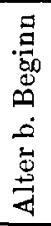 & 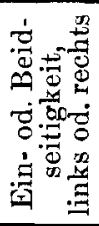 & 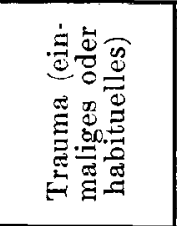 & Inspektion & 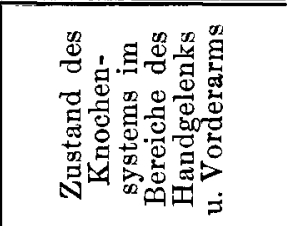 \\
\hline $\begin{array}{l}\text { Nélaton, } \\
\text { Ch., } \\
1897 .\end{array}$ & - & - & $\begin{array}{l}\text { Ein- } \\
\text { seitig } \\
(?)\end{array}$ & - & - & $\begin{array}{l}\text { Ulna nach hinten } \\
\text { luxiert. Radius stark } \\
\text { nach vorn gekrümmt } \\
\text { in seinem untern } \\
\text { Ende. (Präparat im } \\
\text { Musée Dupuytren.) }\end{array}$ \\
\hline $\begin{array}{c}\text { Guéry } \\
1898 .\end{array}$ & $\mathrm{m}$. & 13 & $\begin{array}{l}\text { Ein- } \\
\text { seitig } \\
\text { links }\end{array}$ & $\begin{array}{c}\text { Plötzl. } \\
\text { Schmerz mit } \\
\text { leichter An- } \\
\text { schwellung } \\
\text { d. l. Hand- } \\
\text { gelenks b. } \\
\text { Heben eines } \\
\text { schweren } \\
\text { Teppichs } \\
\text { (Tapezierer- } \\
\text { lehrling). } \\
\text { Allmähl.Zu- } \\
\text { nahme d. } \\
\text { Schmerzen } \\
\text { u. Schwäche } \\
\text { im Gelenk } \\
\text { u. besonders } \\
\text { der Defor- } \\
\text { mität. }\end{array}$ & $\begin{array}{c}\text { Typische Made- } \\
\text { lungsche Defor- } \\
\text { mität. Hand } \\
\text { leicht ulnawärts } \\
\text { verschoben. }\end{array}$ & $\begin{array}{l}\text { Unteres Ulnaende } \\
\text { etw. hypertroph., } \\
\text { dorsalwärts abste- } \\
\text { hend u. vom untern } \\
\text { Rad.-Ende getrennt } \\
\text { durch Zerreißung } \\
\text { der Ligamente der } \\
\text { radio-ulnaren Arti- } \\
\text { kulation. (Radio- } \\
\text { gramm.) } \\
\text { Durch starken } \\
\text { Druck ist d. Capit. } \\
\text { ulnae reponibel, } \\
\text { federt aber sofort } \\
\text { zurück wie eine } \\
\text { Klaviertaste. Unteres } \\
\text { Radiusende nicht } \\
\text { hypertroph. Os } \\
\text { navic. u. lunat. in } \\
\text { norm. Beziehung mit } \\
\text { d. unt. Ende d. Rad. } \\
\text { geblieben. }\end{array}$ \\
\hline $\begin{array}{c}\text { Delbet, } \\
1899 .\end{array}$ & w. & 12 & $\begin{array}{l}\text { Beid- } \\
\text { seitig }\end{array}$ & $\begin{array}{c}\text { Trauma } \\
\text { verneint. }\end{array}$ & $\begin{array}{l}\text { Ulna nach hinten } \\
\text { vorragend. Hand } \\
\text { nach innen ver- } \\
\text { schoben. }\end{array}$ & $\begin{array}{l}\text { Ulua luxiert. Radius } \\
\text { stark gekrümmt an } \\
\text { seinem untern Ende. }\end{array}$ \\
\hline Derselbe. & - & - & - & 5 weitere $\mathrm{I}$ & rauen; bei 3 beids & eitige Deformität. \\
\hline $\begin{array}{c}\text { Custodio } \\
\text { Cabeça. } \\
1899 .\end{array}$ & w. & 14 & $\begin{array}{l}\text { Beid- } \\
\text { seitig, } \\
\text { zuerst } \\
\text { rechts }\end{array}$ & $\begin{array}{l}\text { Kein } \\
\text { Trauma. } \\
\text { ISpielt } \\
\text { Klavier. }\end{array}$ & $\begin{array}{c}\text { Handgelenk ver- } \\
\text { dickt; Vlna vorrag. } \\
\text { Handu.Vorderarm } \\
\text { in 2parall.Ebenen. } \\
\text { Radialseitenormal. } \\
\text { Drrsal. Vorsprung } \\
\text { d.Ulnarseite. Hand } \\
\text { nach außen ver- } \\
\text { schoben. }\end{array}$ & $\begin{array}{l}\text { Radiogramm: } \\
\text { Ulna nach binten } \\
\text { luxiert, hat ihre } \\
\text { normale Richtg. bei- } \\
\text { behalten. Radius in } \\
\text { seinem untern Ende } \\
\text { nach vorn gekrümmt. }\end{array}$ \\
\hline
\end{tabular}




\begin{tabular}{|c|c|c|c|c|}
\hline Schmerzen? & 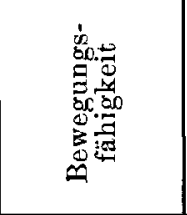 & 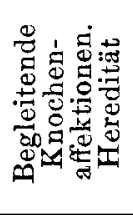 & 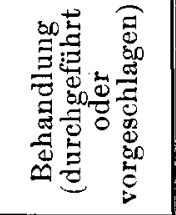 & $\begin{array}{l}\text { Benennung und } \\
\text { pathogenetische Theorie }\end{array}$ \\
\hline - & - & - & - & Spätrachitis. \\
\hline $\begin{array}{l}\text { Schmerzen } \\
\text { vorhanden. }\end{array}$ & $\begin{array}{c}\text { Flexion u. } \\
\text { Abduktion } \\
\text { vermehrt, } \\
\text { Addukt. u. } \\
\text { Extension } \\
\text { leicht ver- } \\
\text { mindert.Alle } \\
\text { Bewegungen } \\
\text { leicht } \\
\text { schmerzhaft. }\end{array}$ & - & $\begin{array}{c}\text { Gipsver- } \\
\text { band mit } \\
\text { dorsaler } \\
\text { Schiene, bei } \\
\text { halber Pro- } \\
\text { nation u. } \\
\text { leichter Ex- } \\
\text { tension. } \\
\text { Nach } \\
2 \text { Wochen } \\
\text { keine } \\
\text { Schmerzen } \\
\text { u. Deform. } \\
\text { fast ver- } \\
\text { schwunden. } \\
\text { Dann Leder- } \\
\text { bracelet mit } \\
\text { Pelotte zur } \\
\text { Arbeit. }\end{array}$ & $\begin{array}{l}\text { Krankheitd. Wachstumsalters. } \\
\text { Analogie mit Genu valg., Sko- } \\
\text { liose u. pes valg. Mitwirkend } \\
\text { sind drei Faktoren: } \\
\text { 1. Konktitutionelle Schwäche } \\
\text { der Bänder. } \\
\text { 2. Ermüdung b. d. Arbeit. } \\
\text { 3. Einfluß d. Wachstums. } \\
\text { Benennungsvorschlag (mit } \\
\text { Kirmiss on) , ,Subluxationpro- } \\
\text { gressive du poignet chez les } \\
\text { adolescents“. }\end{array}$ \\
\hline $\begin{array}{c}\text { Schmerzen } \\
\text { b. Begins, } \\
4 \text { Jahre } \\
\text { später noch } \\
\text { bestehend. }\end{array}$ & $\begin{array}{l}\text { Ungeschick- } \\
\text { lichkeit } z \\
\text { Schreiben b. } \\
\text { Beginn. }\end{array}$ & - & $\begin{array}{l}\text { Osteotomie } \\
\text { d. Radius. } \\
\text { Dann Gips- } \\
\text { verband, } \\
\text { später } \\
\text { Apparat. } \\
\text { Tendenz z. } \\
\text { Rezidi- } \\
\text { vieren. }\end{array}$ & $\begin{array}{l}\text { "Carpus currus." Deformation } \\
\text { d. Radius mit Luxation d. Ulaa, } \\
\text { infolge von Spätrachitis. Ver- } \\
\text { bindg. zwischen Radius u. Car- } \\
\text { pus normal. Sekundär Luxation } \\
\text { der Ulna nach hinten infolge } \\
\text { Krümmung des Radius nach } \\
\text { vorn. }\end{array}$ \\
\hline - & - & - & - & - \\
\hline $\begin{array}{l}\text { Schmerzen } \\
\text { b. Beginn, } \\
\text { besonders b. } \\
\text { Klavier- } \\
\text { spielen. }\end{array}$ & $\begin{array}{l}\text { Bewegun- } \\
\text { gen vollstän- } \\
\text { djg } 4-5 \text { Mo- } \\
\text { nate später. }\end{array}$ & - & $\begin{array}{l}\text { Lineäre } \\
\text { Osteotomie } \\
\text { empfohlen. }\end{array}$ & $\begin{array}{l}\text { "Spontane Subluxation" od. } \\
\text { "Carpus curvus" (wie Delbet). }\end{array}$ \\
\hline
\end{tabular}




\begin{tabular}{|c|c|c|c|c|c|c|}
\hline 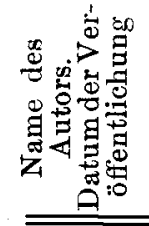 & 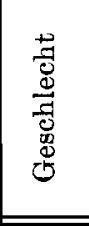 & 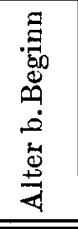 & 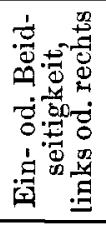 & 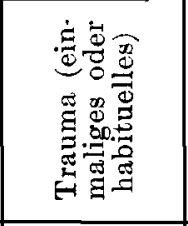 & Inspektion & 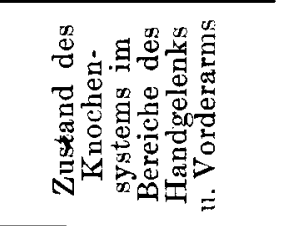 \\
\hline $\begin{array}{l}\text { Dekey- } \\
\text { ser. } 1901 \text {. }\end{array}$ & w. & 14 & $\begin{array}{l}\text { Ein- } \\
\text { seitig, } \\
\text { rechts }\end{array}$ & \begin{tabular}{|c|} 
Kein \\
Trauma, \\
keine ermü- \\
dende \\
Arbeit.
\end{tabular} & $\begin{array}{l}\text { Typ. Madelung- } \\
\text { sche Deformität. }\end{array}$ & $\begin{array}{l}\text { Radiogramm: } \\
\text { Ulna sehr beträchtl. } \\
\text { verkürzt. Unteres } \\
\text { Radiusende stark } \\
\text { nach vorn gekrümmt. } \\
\text { Gelenkverbindg. d. } \\
\text { Hand mit d. Rad. } \\
\text { normal. Hand voll- } \\
\text { ständig unabhängig } \\
\text { von d. Ulna, die s. } \\
\text { weiter nach hinten } \\
\text { befindet. }\end{array}$ \\
\hline Derselbe. & $\begin{array}{l}\text { w. } \\
\text { Mut- } \\
\text { ter d. } \\
\text { Vorig. }\end{array}$ & $\begin{array}{l}\text { Kin- } \\
\text { des- } \\
\text { alter }\end{array}$ & $\begin{array}{l}\text { Ein- } \\
\text { seitig, } \\
\text { links }\end{array}$ & \begin{tabular}{|} 
Kein \\
Trauma, \\
progre- \\
diente lang- \\
same Ent- \\
wicklung.
\end{tabular} & Dasselbe. & - \\
\hline $\begin{array}{l}\text { Kirmis. } \\
\text { son. } 1902 .\end{array}$ & w. & 10 & $\begin{array}{l}\text { Beid- } \\
\text { seitig, } \\
\text { zuerst } \\
\text { rechts }\end{array}$ & $\begin{array}{l}\text { Trauma } \\
\text { verneint. }\end{array}$ & $\begin{array}{l}\text { Vorderarme ver- } \\
\text { kürzt, Hände in } \\
\text { Hyperextension, } \\
\text { gegen d. Ulnar- } \\
\text { rand abgewichen, } \\
\text { in Rotationsstel- } \\
\text { lung zum Vorder- } \\
\text { arm. }\end{array}$ & $\begin{array}{l}\text { Radiogramm: } \\
\text { Radius u. Ulna ver- } \\
\text { kürzt. Ulna von } \\
\text { normaler Form; } \\
\text { Radius deformiert, } \\
\text { in seinem untern } \\
\text { Drittel nach hin te n } \\
\text { u. einwärts ge- } \\
\text { krümmt, in normaler } \\
\text { Verbindg. mit d. } \\
\text { Carpus. Ulna nach } \\
\text { vorn luxiert. }\end{array}$ \\
\hline $\begin{array}{c}\text { Gevaert. } \\
1902 .\end{array}$ & m. & 14 & $\begin{array}{l}\text { Beid- } \\
\text { seitig, } \\
\text { zuerst } \\
\text { links }\end{array}$ & $\begin{array}{c}\text { Kein } \\
\text { Trauma. } \\
\text { Rhythm. } \\
\text { Traktionen } \\
\text { mit beiden } \\
\text { Händen, } \\
\text { ohne Kraft- } \\
\text { aufwand. } \\
\text { (Weberlehrl.) }\end{array}$ & $\begin{array}{l}\text { Unteres Ulnaende } \\
\text { stark nach hinten } \\
\text { vorragend. }\end{array}$ & $\begin{array}{l}\text { Ulna nach hinten } \\
\text { luxiert. Carpus in } \\
\text { normaler Verbindg. } \\
\text { mit d. Rad. Radius } \\
\text { in seinem untern } \\
\text { Ende nach vorn ge- } \\
\text { krümmt. }\end{array}$ \\
\hline $\begin{array}{l}\text { Ardouin. } \\
\quad 1902 .\end{array}$ & w. & - & $\begin{array}{l}\text { Beid- } \\
\text { seitig }\end{array}$ & $\underset{\text { Trauma. }}{\text { Kein }}$ & $\begin{array}{c}\text { Vorderarm sehr } \\
\text { verkürzt, besond. } \\
\text { links }(5-6 \mathrm{~cm}) . \\
\text { Ulna nach hinten } \\
\text { vorragend.Radial- } \\
\text { seite leicht ge- } \\
\text { krümmt. }\end{array}$ & $\begin{array}{l}\text { Radiogramm: } \\
\text { Ulna nach hinten } \\
\text { luxiert. Radius in } \\
\text { normaler Verbindg. } \\
\text { mit d. Carpus. Alle } \\
\text { Knochen haben ihre } \\
\text { normale Form. }\end{array}$ \\
\hline
\end{tabular}


Über Manus valga oder sogen. Madelungsche Deformität d. Handgelenks. 559

\begin{tabular}{|c|c|c|c|c|}
\hline Schmerzen? & 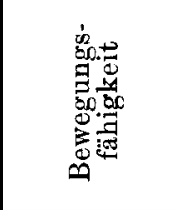 & 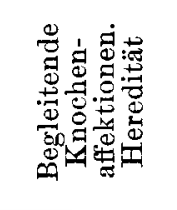 & 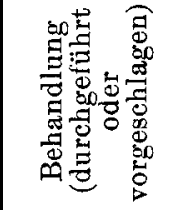 & $\begin{array}{c}\text { Benennung und } \\
\text { pathogenetische Theorie }\end{array}$ \\
\hline $\begin{array}{c}\text { Wenig } \\
\text { Schmerz, } \\
\text { nur leichte } \\
\text { Ermüdbar- } \\
\text { keit. }\end{array}$ & $\begin{array}{c}\text { Bewegun- } \\
\text { gen normal, } \\
\text { nur geringe } \\
\text { Muskel- } \\
\text { kraft. }\end{array}$ & $\begin{array}{l}\text { Heredität: } \\
\text { Mutter hat } \\
\text { dieselbe } \\
\text { Subluxation } \\
\text { (s. unten). }\end{array}$ & $\begin{array}{l}\text { Ruhigstel- } \\
\text { lung, ev. } \\
\text { Armband, } \\
\text { rationelle } \\
\text { Gymnastik } \\
\text { empfohlen. } \\
\text { Chirurg. Be- } \\
\text { handlung } \\
\text { aussichtslos. }\end{array}$ & $\begin{array}{l}\text { Unterstützende Faktoren sind } \\
\text { die drei von früheren Autoren } \\
\text { genannten: Konstitutt. Schwäche } \\
\text { der Ligamente, Überanstren- } \\
\text { gung u. Einfluß d. Wachstums- } \\
\text { alters. Die eigentl. Ursache ist } \\
\text { e. Störung im Wachstum der } \\
\text { Knochen. } \\
\text { Die Deformität ist in d. beiden } \\
\text { Fällen von Dekey ser einzig } \\
\text { hervorgerufen durch d. Krüm- } \\
\text { mung des unt. Radiusendes nach } \\
\text { vorn u. d. Verkürzung d. Ulna. }\end{array}$ \\
\hline $\begin{array}{l}\text { Keine } \\
\text { Schmerzen } \\
\text { beachtet. }\end{array}$ & $\begin{array}{l}\text { Flexion } \\
\text { links ver- } \\
\text { mehrt. Kraft } \\
\text { normal. }\end{array}$ & - & - & - \\
\hline $\begin{array}{l}\text { Leichte } \\
\text { Ermüdbar- } \\
\text { keit, rechts } \\
\text { zeitweise et- } \\
\text { was Schmer- } \\
\text { zen b. Hand- } \\
\text { arbeit } \\
\text { (Nähen), } \\
\text { später auch } \\
\text { links. }\end{array}$ & $\begin{array}{c}\text { Extension } \\
\text { vermehrt, } \\
\text { Flexion ver- } \\
\text { mindert, } \\
\text { Abduktion } \\
\text { unmögl., } \\
\text { Adduktion } \\
\text { vermehrt. } \\
\text { Supination } \\
\text { behindert. }\end{array}$ & $\begin{array}{l}\text { Scoliosis } \\
\text { dorsalis. }\end{array}$ & $\begin{array}{c}\text { Lineäre } \\
\text { Osteotomie } \\
\text { mit Exzision } \\
\text { von } 7-8 \mathrm{~mm} \\
\text { Radius. } \\
\text { Resultat be- } \\
\text { friedigend. } \\
\text { Nachher } \\
\text { Gips- } \\
\text { verband. }\end{array}$ & $\begin{array}{l}\text { Kirmisson trennt diesen } \\
\text { Fall von dem, den er mit Gu éry } \\
\text { beobachtet hat und stellt sie } \\
\text { einander gegenüber. Den Gué- } \\
\text { ryschen Fall rechnet er zu d. } \\
\text { Fällen von Madelungscher De- } \\
\text { formität, und seinen eigenen } \\
\text { reiht er den Fällen D uplays an. }\end{array}$ \\
\hline $\begin{array}{c}\text { Keine } \\
\text { Schmerzen, } \\
\text { nur leichte } \\
\text { Ermüdbar- } \\
\text { keit, Kräfte- } \\
\text { abnahme u. } \\
\text { Unge- } \\
\text { schicklich- } \\
\text { keit. }\end{array}$ & $\begin{array}{l}\text { Alle Bewe- } \\
\text { gungen nor- } \\
\text { mal möglich, } \\
\text { nur Flexion } \\
\text { links etw. } \\
\text { vermindert. }\end{array}$ & $\begin{array}{l}\text { Scoliosis } \\
\text { dors. mit } \\
\text { Kompensa- } \\
\text { tor. Scoliosis } \\
\text { lumb. genu } \\
\text { valgum } \\
\text { rechts, ge- } \\
\text { ringgradig } \\
\text { auch links. }\end{array}$ & $\begin{array}{l}\text { Massage, } \\
\text { Elektri- } \\
\text { sation d. } \\
\text { Muskeln d. } \\
\text { Vorderarms. } \\
\text { Passive Be- } \\
\text { wegungen. } \\
\text { Erfolglos. }\end{array}$ & $\begin{array}{l}\text { Spätrachitis. Vergleich mit } \\
\text { Skoliose u. Genu valg. Ge- } \\
\text { vaert trennt noch schärfer als } \\
\text { Kirmisson d. Fälle von Ma- } \\
\text { delung u. Duplay. }\end{array}$ \\
\hline - & $\begin{array}{l}\text { Alle Bewe- } \\
\text { gungen } \\
\text { mögl. Kraft } \\
\text { vermindert. }\end{array}$ & $\begin{array}{l}\text { Leichte } \\
\text { Skoliose. }\end{array}$ & - & $\begin{array}{l}\text { „Unvollständige kongenitale } \\
\text { Luxation." }\end{array}$ \\
\hline
\end{tabular}




\begin{tabular}{|c|c|c|c|c|c|c|}
\hline 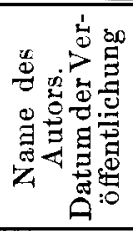 & 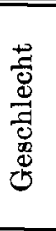 & 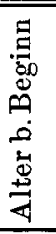 & 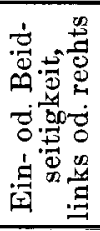 & 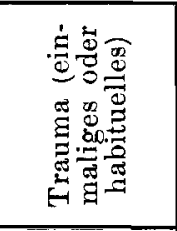 & Inspektion & 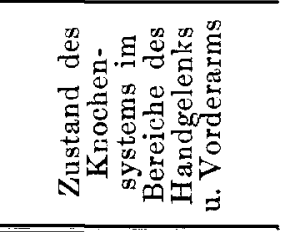 \\
\hline $\begin{array}{c}\text { Abadie. } \\
1903 .\end{array}$ & $\mathrm{m}$. & 13 & $\begin{array}{l}\text { Ein- } \\
\text { seitig } \\
\text { links }\end{array}$ & $\begin{array}{l}\text { Fall auf d. } \\
\text { l. Arm als } \\
\text { Kind; } \\
\text { Frakt.?; } \\
\text { später müh- } \\
\text { same Arbeit. } \\
\text { (Koch.) }\end{array}$ & $\begin{array}{c}\text { Vorderarm sehr } \\
\text { verkürtt }(10 \mathrm{~cm}) \\
\text { Auf d. Ulnarseite } \\
\text { Hand nach vorn } \\
\text { luxiert. Auf d. } \\
\text { Radialseite } \\
\text { leichte Biegung } \\
\text { gegen d. Carpus. } \\
\text { Hand nach außen } \\
\text { geneigt. }\end{array}$ & $\begin{array}{l}\text { Radiogramm: } \\
\text { Ulna nach hinten } \\
\text { luxiert. Rad. in sei- } \\
\text { nem untern Ende } \\
\text { gekrümmt, kürzer als } \\
\text { d. Ulna; mit e. Ex- } \\
\text { ostoste. Radius mit } \\
\text { Carp. in normaler } \\
\text { Verbindg. Rad. u. } \\
\text { Ulna beträchtl. ver- } \\
\text { kürzt gegenüber d. } \\
\text { normalen Seite. Ex- } \\
\text { ostose d. innern } \\
\text { Radialrands in } \\
\text { seinem untern Ende. }\end{array}$ \\
\hline $\begin{array}{c}\text { Cnop f. } \\
1903 .\end{array}$ & w. & 15 & $\begin{array}{l}\text { Ein- } \\
\text { seitig }\end{array}$ & $\begin{array}{l}\text { Nie } \\
\text { Trauma, } \\
\text { nie schwere } \\
\text { Arbeit. All- } \\
\text { mähl. Ent- } \\
\text { stehen. }\end{array}$ & $\begin{array}{l}\text { Abnormes Vor- } \\
\text { springen d. Hand- } \\
\text { gelenkendes d. } \\
\text { rechten Ulna. } \\
\text { Ulna ragt haken- } \\
\text { förmig auf der } \\
\text { Streckseite d. } \\
\text { Hand vor. Hand- } \\
\text { rücken ca. } 1,5 \mathrm{~cm} \\
\text { nach d. Vola ver- } \\
\text { lagert, durch Zug } \\
\text { od. Druck nicht } \\
\text { reduzierbar. }\end{array}$ & $\begin{array}{l}\text { Radiogramm: } \\
\text { Die Ulna hat am } \\
\text { obern Ende e. Krüm- } \\
\text { mung in } 2 \text { Ebenen } \\
\text { gegen d. Rad. zu kon- } \\
\text { vex u. dorsalkonvex. } \\
\text { Am untern Ende } \\
\text { zeigt sie e. Achsen- } \\
\text { drehung von 900. Der } \\
\text { Radiu zeigt in } \\
\text { seinem obern Drittel } \\
\text { kürzere dorsalkon- } \\
\text { kave Krümmung. } \\
\text { Über d. untern zwei } \\
\text { Drittel erstreckt s. } \\
\text { e. mäßige volar- } \\
\text { konkave Ausbiegung. } \\
\text { Amuntern Kndenahe } \\
\text { d. Gelenkfläche e. } \\
\text { "volare Knickung“, } \\
\text { so daß d. Gelenk-' } \\
\text { fläche d Rad. stark } \\
\text { nach d.Vola u.schräg } \\
\text { gegen d. Ulna sieht. } \\
\text { Auf d. Ulnarseite } \\
\text { besteht Luxation d. } \\
\text { Os triquetrum volar- } \\
\text { wärts u. aufwärts. } \\
\text { Radius u. Carp. in } \\
\text { normalen Beziehun- } \\
\text { gen. }\end{array}$ \\
\hline
\end{tabular}


Über Manus valga oder sogen. Madelungsche Deformität d. Handgelenks. 561

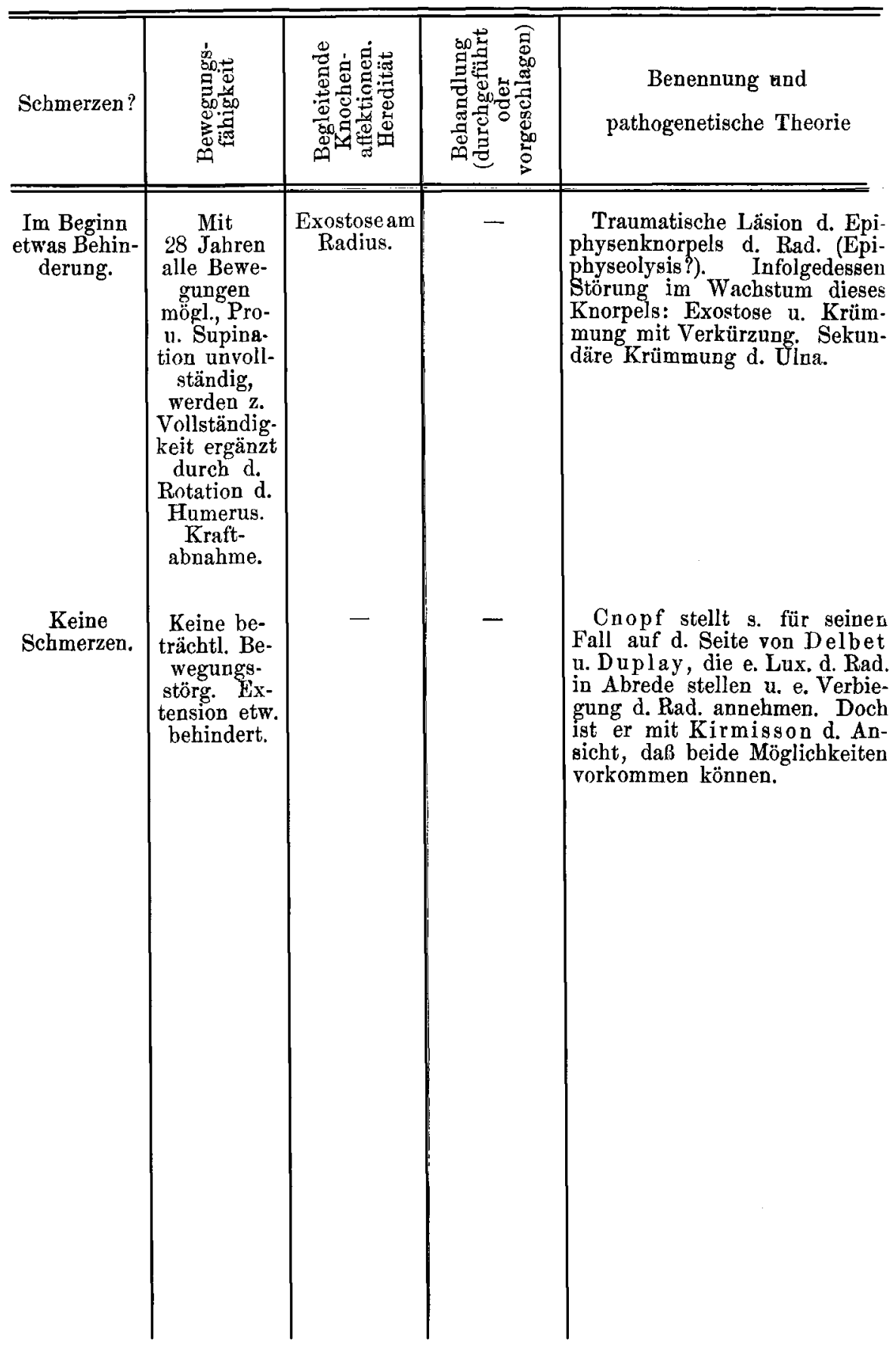

Deutsche Zeitschrift f. Chirurgie. 91. Bd. 


\begin{tabular}{|c|c|c|c|c|c|c|}
\hline 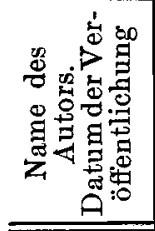 & 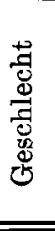 & 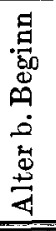 & 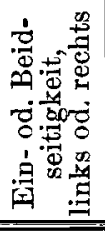 & 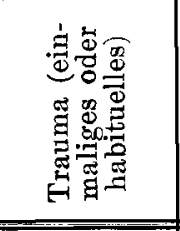 & Inspektion & 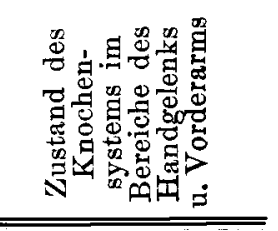 \\
\hline $\begin{array}{c}\text { Barthès. } \\
1904 . \\
\text { (Beispiel } \\
\text { für B.) }\end{array}$ & w. & 36 & $\begin{array}{l}\text { Ein- } \\
\text { seitig, } \\
\text { rechts }\end{array}$ & $\begin{array}{l}\text { Vor 6 Mona- } \\
\text { ten Sturz d. } \\
\text { Treppe hin- } \\
\text { unter aufs } \\
\text { Hand- } \\
\text { gelenk. An- } \\
\text { schwellung, } \\
\text { Schmerz, } \\
\text { zunehmende } \\
\text { Deformation. }\end{array}$ & $\begin{array}{l}\text { Form d. Defor- } \\
\text { mität ist d. cha- } \\
\text { rakteristische der } \\
\text { Madelungschen } \\
\text { Deformität. }\end{array}$ & 一 \\
\hline Derselbe. & w. & 24 & $\begin{array}{l}\text { Beid. } \\
\text { seitig }\end{array}$ & $\begin{array}{l}\text { Vor } 2 \text { Mon. } \\
\text { hyster. An- } \\
\text { fälle, d. von } \\
\text { Kontrak- } \\
\text { turen ge- } \\
\text { folgt waren. }\end{array}$ & $\begin{array}{c}\mathrm{R} . \text { Hand stark } \\
\text { abduziert u.leicht } \\
\text { flektiert. L.Hand } \\
\text { stark flektiert. } \\
\text { Deutl. Subluxa- } \\
\text { tion d. Radio- } \\
\text { carpalgelenks. } \\
\text { (Umgekehrte } \\
\text { Gabelrücken- } \\
\text { stellung.) }\end{array}$ & - \\
\hline Derselbe. & m. & 32 & $\underset{\text { seitig }}{\text { Ein- }}$ & $\begin{array}{l}\text { Unteroffi- } \\
\text { zier. Kon- } \\
\text { tusion b. } \\
\text { Exerzieren. } \\
\text { Schwellung. }\end{array}$ & $\begin{array}{l}\text { Schwellung d. } \\
\text { Gelenks. Erguß. }\end{array}$ & $\begin{array}{l}\text { Carpus vor d. Ulna } \\
\text { luxiert. }\end{array}$ \\
\hline $\begin{array}{l}\text { Poulsen. } \\
1904 .\end{array}$ & w. & 12 & $\begin{array}{l}\text { Ein- } \\
\text { seitig, } \\
\text { links }\end{array}$ & $\begin{array}{c}\text { Kein } \\
\text { Trauma, } \\
\text { keine an- } \\
\text { strengende } \\
\text { Arbeit. } \\
\text { Spontaner } \\
\text { Beginn, all- } \\
\text { mähl. } \\
\text { Zunahme. }\end{array}$ & $\begin{array}{l}\text { L. Hand gegen } \\
\text { d. Volarseite ver- } \\
\text { schoben; Stellung } \\
\text { wie b. Lux. d. } \\
\text { Hand nach vorn. } \\
\text { Capit. ulnae pro- } \\
\text { minent u. ver- } \\
\text { dickt. Hand- } \\
\text { rücken u. Rücken } \\
\text { d. Vorderarms in } \\
\text { zwei parall. ver- } \\
\text { schiedenen Ebe- } \\
\text { nen. Verkürzg. d. } \\
\text { linken Vorder- } \\
\text { arms um } 3 \mathrm{~cm} \text {. }\end{array}$ & $\begin{array}{l}\text { Distales Drittel des } \\
\text { Radius volarwärts } \\
\text { gebogen mit Konka- } \\
\text { vität nach vorn. } \\
\text { Carpus in normaler } \\
\text { Verbindg.mit Radius. } \\
\text { Corp. ulnae gerade; } \\
\text { carpale Gelenkfläche } \\
\text { d. Capit. ulnae läßt } \\
\text { s. abtasten. } \\
\text { Radiogranm: } \\
\text { Radius sehr stark, } \\
\text { Ulna leicht volar- } \\
\text { wärts gekrümmt. } \\
\text { Krümmung d. Ulna } \\
\text { gleichmäßig,des Rad. }\end{array}$ \\
\hline
\end{tabular}

u. über d. distalen Epiphyse, so daß d. Gelenkfläche stark gegen d. Volarseite gekehrt ist. Ossa carpi radialwärts verschoben, sonst in normalen Bezieh. ungen. Die Knochen d. proximalen Reihe stehen dorsalflektiert, aber nicht subluxiert. Radius $u$. Uina etwas verdickt, plump. 


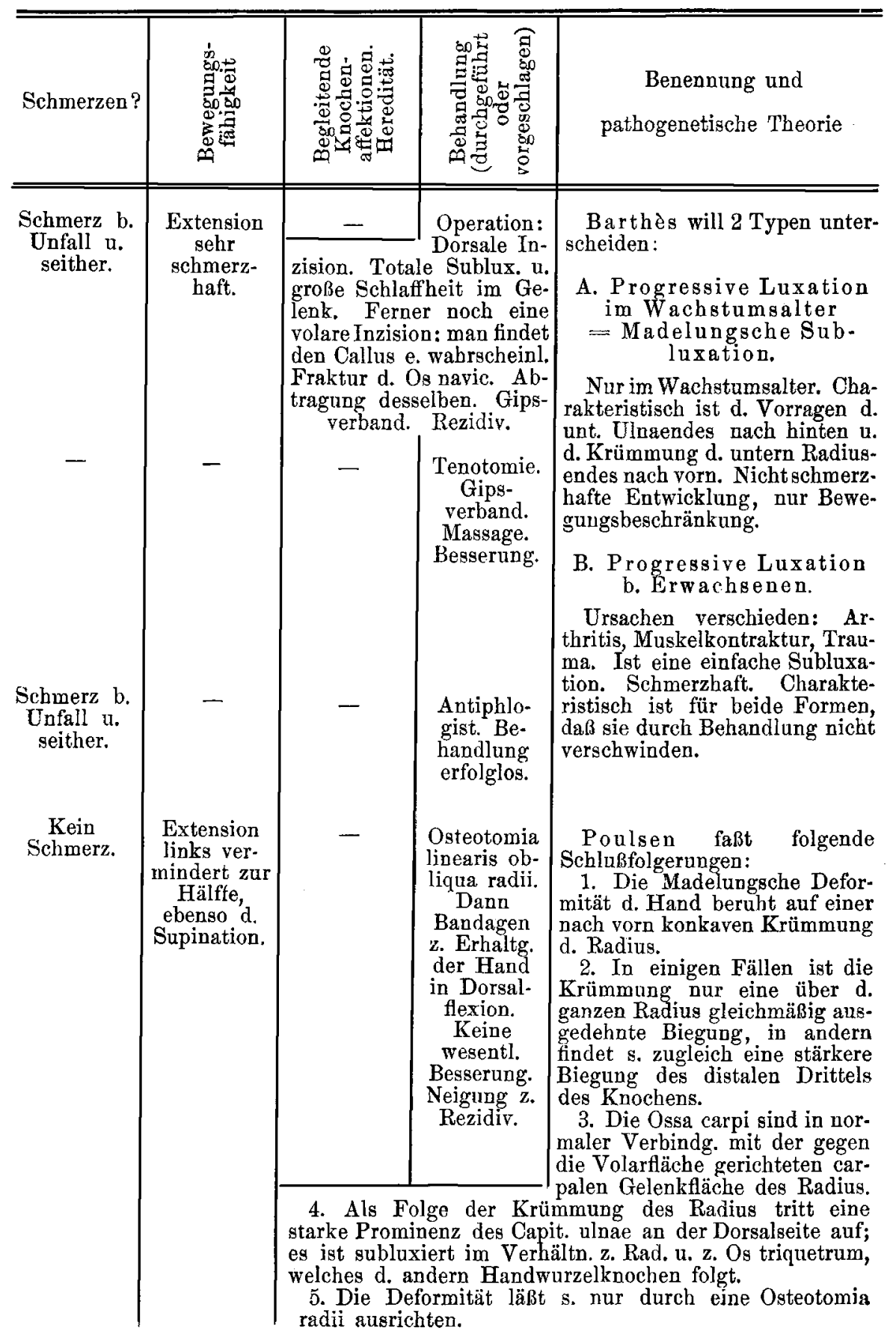




\begin{tabular}{|c|c|c|c|c|c|c|}
\hline 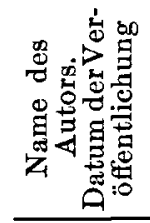 & 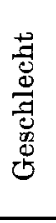 & 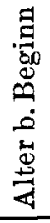 & 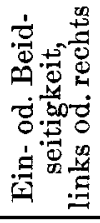 & 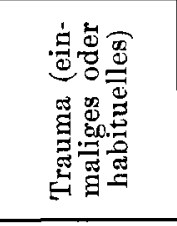 & Inspektion & 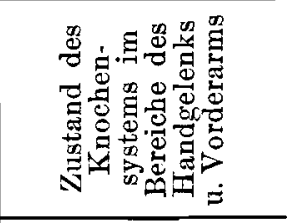 \\
\hline Derselbe. & w. & 12 & $\begin{array}{l}\text { Beid- } \\
\text { seitig, } \\
\text { mehr } \\
\text { links }\end{array}$ & $\begin{array}{c}\text { Kein } \\
\text { Trauma, } \\
\text { keine Über- } \\
\text { anstren- } \\
\text { gung. } \\
\text { (Haus- } \\
\text { arbeit.) }\end{array}$ & $\begin{array}{l}\text { Linke Hand } \\
\text { volarwärts ver- } \\
\text { schoben. Capit. } \\
\text { ulnae stark pro- } \\
\text { minent. Volar- } \\
\text { seite d. Vorder- } \\
\text { arms leicht } \\
\text { exkaviert. Sehnen } \\
\text { d. Palmaris long. } \\
\text { u. Flexor carpi } \\
\text { ulnaris prominie- } \\
\text { ren.Rechts leichte } \\
\text { Exkavation d. } \\
\text { Vorderseite d. } \\
\text { Radius u. leichte } \\
\text { Prominenz d. } \\
\text { Capit. uluae. } \\
\text { Keine Verkürzg. } \\
\text { der Arme. Nur } \\
\text { teilweise Reduk- } \\
\text { tion durch Druck } \\
\text { u. Zug mögl. } \\
\text { Gelenkfläche d. Ca } \\
\text { Keine Verdickg. } \\
\text { Ossa carpi im Ver } \\
\text { keine Subluxatio } \\
\text { Exkavation n. von } \\
\text { gegend. Capit. u } \\
\text { prominent. }\end{array}$ & $\begin{array}{l}\text { Ganzer Radius } \\
\text { volarwärts ge- } \\
\text { krümmt, jedoch be- } \\
\text { sonders d. distale } \\
\text { Ende. } \\
\text { Radiogramm: } \\
\text { Links: Ulna ganz } \\
\text { leicht gekrümmt mit } \\
\text { Konkavität nach } \\
\text { vorn. Radius zeigt } \\
\text { in seiner ganzen } \\
\text { Länge e. zweifache } \\
\text { Krümmung: e. nach } \\
\text { vorn konkave, sowie } \\
\text { eine nach außen kon- } \\
\text { vexe. Erstere am dis- } \\
\text { talen Ende am deut- } \\
\text { lichsten. Carpale Ge- } \\
\text { lenkfläche sieht nach } \\
\text { vorn u. ist in ihrem } \\
\text { volaren Abschnitt } \\
\text { stark exkaviert. } \\
\text { Ebenso ist d. carpale } \\
\text { pit. ulnae ausgehöhlt. } \\
\text { der beiden Knochen. } \\
\text { aältnis z. Rad. normal, } \\
\text { Re cht ts: Leichte } \\
\text { n. r. Handgelenks- } \\
\text { nae etw. dorsalwärts } \\
\end{array}$ \\
\hline$\underset{1905 .}{S c h u l z e .}$ & w. & 9 & $\begin{array}{l}\text { Ein- } \\
\text { seitig, } \\
\text { rechts }\end{array}$ & $\begin{array}{l}\text { Angeblich } \\
\text { "Verdrehen" } \\
\text { der Hand } \\
\text { beim } \\
\text { Spielen. }\end{array}$ & $\begin{array}{c}\text { Stärkeres Hervor- } \\
\text { treten d. Knöchels } \\
\text { der rechten Hand. } \\
\text { Rechter Arm in } \\
\text { starker Cubitus- } \\
\text { valgus-Stellg. R. } \\
\text { Handgelenk in s. } \\
\text { antero-posterior. } \\
\text { Durchmesser ver- } \\
\text { größert gegenüb. } \\
\text { links. Capit.ulnae } \\
\text { luxiert; seine Ge- } \\
\text { lenkfläche ganz } \\
\text { abtastbar. Ulna } \\
2 \text { cm länger als l. } \\
\text { Radiusdiaphyse } \\
\text { in ihren untern } \\
\text { ln gekrümmt mit } \\
\text { ach vorn. Bajonett- } \\
\text { ig d. Hand. }\end{array}$ & $\begin{array}{l}\text { Radiogramm: } \\
\text { Verlängerungd.UUlna } \\
\text { u. vollständ. Luxat. } \\
\text { derselben nach d. } \\
\text { dorsalen Seite hin. } \\
\text { Krümmung d. untern } \\
\text { Radiushälfte u. star- } \\
\text { kes Hervortreten d. } \\
\text { dorsalen Hälfte der } \\
\text { untern Radiusepi- } \\
\text { physe. }\end{array}$ \\
\hline
\end{tabular}


Über Manus valga oder sogen. Madelungsche Deformität d. Handgelenks. 565

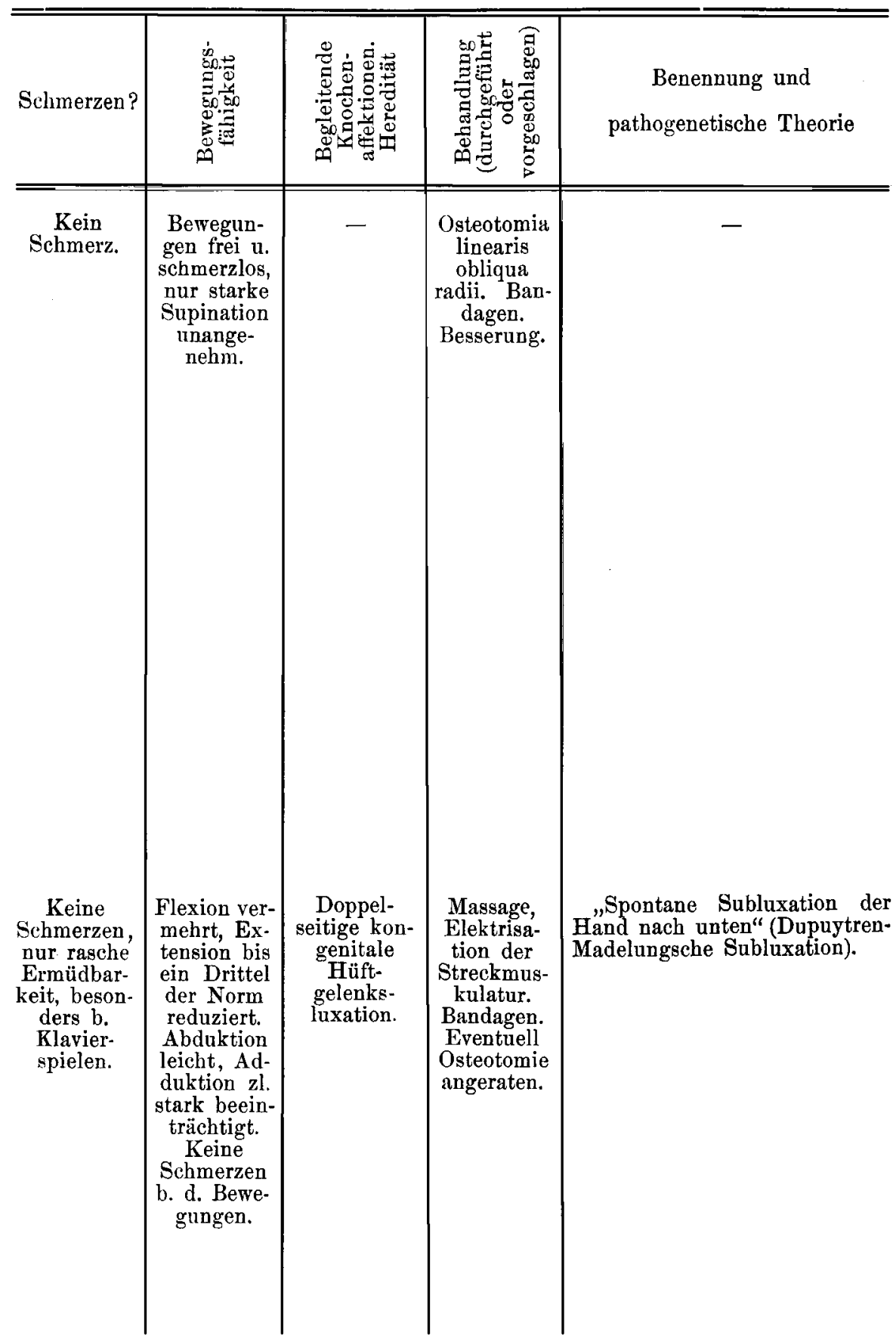




\begin{tabular}{|c|c|c|c|c|c|c|}
\hline 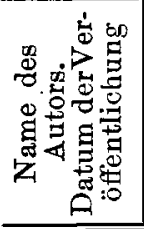 & 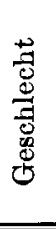 & 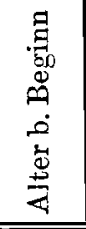 & 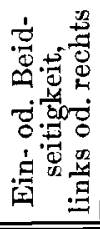 & 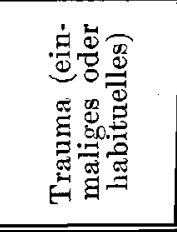 & Inspektion & 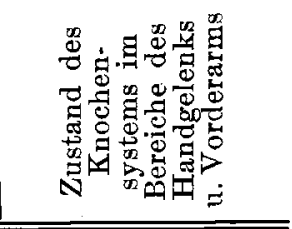 \\
\hline $\begin{array}{l}\text { Volk. } \\
\text { mann. } \\
1905 .\end{array}$ & w. & $\begin{array}{c}\text { Vor } \\
16 \mathrm{~J} .\end{array}$ & $\begin{array}{l}\text { Beid- } \\
\text { seitig }\end{array}$ & $\begin{array}{c}\text { Allmählich. } \\
\text { Entstehen } \\
\text { ohne } \\
\text { Schmerz. }\end{array}$ & $\begin{array}{l}\text { Vorderarme auf- } \\
\text { fallend kurz. Ver- } \\
\text { biegung d. ganzen } \\
\text { Vorderarms mit } \\
\text { Konvexität nach } \\
\text { der Streckseite. } \\
\text { Diese Krümmung } \\
\text { im untern Drittel } \\
\text { am stärksten. } \\
\text { Hand im ganzen } \\
\text { nach d.Beugeseite } \\
\text { verschoben, zum } \\
\text { Vorderarm in Ba- } \\
\text { jonettstellg. Ulna- } \\
\text { ende stark promi- } \\
\text { nent. Hände in } \\
\text { dauernder Prona- } \\
\text { tionsstellung z. } \\
\text { Vorderarm. Repo- } \\
\text { sition durch Zug } \\
\text { unmöglich. }\end{array}$ & $\begin{array}{l}\text { Unteres Ulnaende } \\
\text { frei unter der Haut } \\
\text { fühlbar, mitd. Carpus } \\
\text { nichtin Kontakt. Ra- } \\
\text { dius in d. obern zwei } \\
\text { Dritteln gerade, im } \\
\text { untern Drittel stark } \\
\text { volarwärts gebogen. } \\
\text { An d.Ulna ist d. Carp. } \\
2 \mathrm{~cm} \text { hinaufgescho- } \\
\text { ben. Carpus mit Rad. } \\
\text { in innigem Zusam- } \\
\text { menhg., nicht luxiert. } \\
\text { Radiogramm: } \\
\text { Bestätigt das oben b. } \\
\text { d. Palpation Gefun- } \\
\text { dene. Radius nicht } \\
\text { nur nach d. Streck- } \\
\text { seite, sondern auch } \\
\text { nach d. Daumenseite } \\
\text { konvex verbogen. }\end{array}$ \\
\hline Derselbe. & w. & $\begin{array}{l}\text { Vor } \\
14 \mathrm{~J} .\end{array}$ & $\begin{array}{c}\text { Beid- } \\
\text { seitig, } \\
\text { mehr } \\
\text { rechts }\end{array}$ & $\begin{array}{l}\text { Nie Schmer- } \\
\text { zen, nie } \\
\text { schwere Ar- } \\
\text { beit. Keine } \\
\text { Behinde- } \\
\text { rung. } \\
\\
\text { federn ab.sog } \\
\text { seitl. Versc. } \\
\text { Hand nur } \\
\text { Beugeseite } \\
\text { rückt. }\end{array}$ & $\begin{array}{l}\text { Hände volarwärts } \\
\text { verlagert. Ulna- } \\
\text { enden dorsal weit } \\
\text { vorspringend, ha- } \\
\text { bend.Kontakt mit } \\
\text { d. Carp. u. d. Rad. } \\
\text { verloren, durch } \\
\text { Druck reponibel, } \\
\text { leich zurück. Keine } \\
\text { aiebg. der Hand. } \\
\text { anz wenig auf d. } \\
\text { l. Arms hinaufge. } \\
\text { abitus valgus. }\end{array}$ & $\begin{array}{l}\text { Radiogramm: } \\
\text { Biegung d. Radius. } \\
\text { Schatten des Radius } \\
\text { deckt s. teilweise mit } \\
\text { demjenigen v. Kahn-, } \\
\text { Mond- u. Pyramiden- } \\
\text { bein, während b. nor- } \\
\text { malen Handgelenk } \\
\text { nur e. ganz schmale } \\
\text { Partie d. Schattens } \\
\text { vom Mondbeim vom } \\
\text { Radiusschatten be- } \\
\text { deckt wird. }\end{array}$ \\
\hline $\begin{array}{c}\text { Schade. } \\
1906 .\end{array}$ & w. & $\begin{array}{l}\text { Vor } \\
8 \mathrm{~J} .\end{array}$ & $\begin{array}{l}\text { Beid- } \\
\text { seitig, } \\
\text { mehr } \\
\text { rechts }\end{array}$ & $\underset{\text { Trauma. }}{\text { Kein }}$ & $\begin{array}{l}\text { Distale Enden d. } \\
\text { Ulnaeprominieren } \\
\text { dorsalwärts sehr } \\
\text { stark: Luxations- } \\
\text { stellg. Hände in } \\
\text { leichter Ulnar- u. } \\
\text { scheinbarer Vo- } \\
\text { larflexion. } \\
\text { Radiogramm: Ab } \\
\text { Radioulnargelenks } \\
\text { krümmg. des Radi } \\
\text { luxiert. Radius do } \\
\text { Carpus mitd.Radi }\end{array}$ & $\begin{array}{l}\text { Ganze carpale Ge- } \\
\text { lenkfläche der Ulnae } \\
\text { samt Proc. styloid., } \\
\text { ebenso d. radiale Ge- } \\
\text { lenkfläche d. Ulna- } \\
\text { enden sindabzutasten. } \\
\text { Unterstes Drittel d. } \\
\text { Rad. dorsal- u. radial } \\
\text { konvex verbogen. } \\
\text { norm breiter Spalt d. } \\
\text {. Radialkonvexe Ver- } \\
\text { us. Ulna dorsal völlig } \\
\text { rsalkonvexgekrümmt. } \\
\text { us in normal.Verbindg. }\end{array}$ \\
\hline
\end{tabular}


Über Manus valga oder sogen. Madelungsche Deformität d. Handgelenks. 567

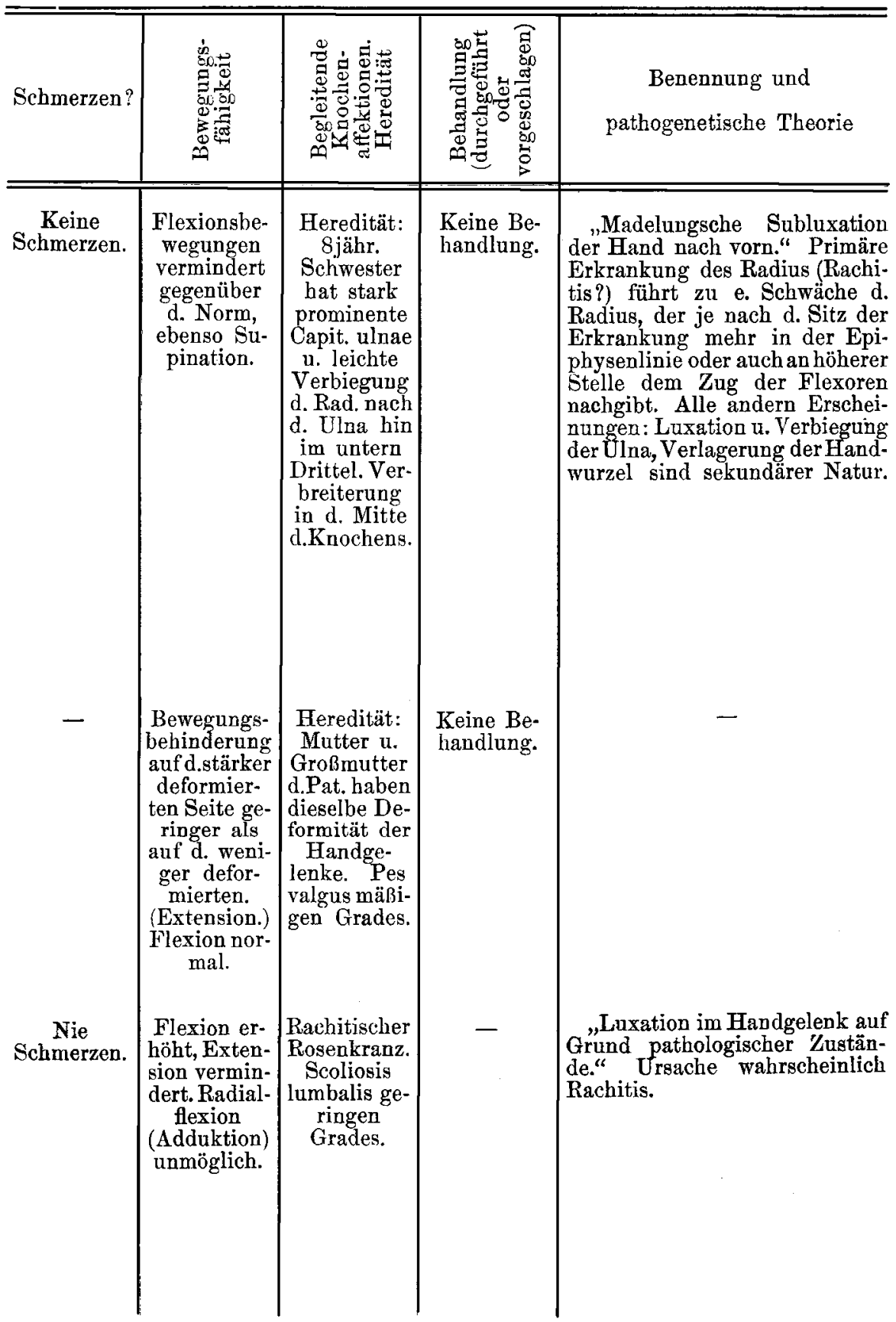




\begin{tabular}{|c|c|c|c|c|c|c|}
\hline 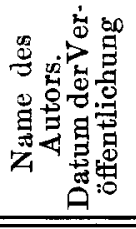 & 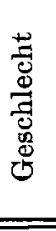 & 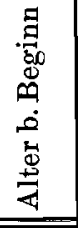 & 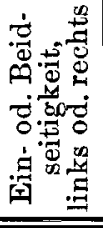 & 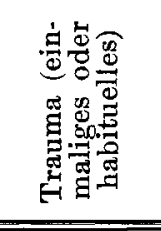 & Inspektion & 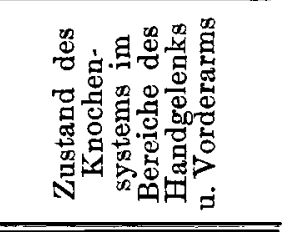 \\
\hline $\begin{array}{c}\text { Putti. } \\
1906 .\end{array}$ & w. & 15 & $\begin{array}{l}\text { Ein- } \\
\text { seitig, } \\
\text { links. }\end{array}$ & $\begin{array}{c}\text { Kein } \\
\text { Trauma. } \\
\text { Häusl., } \\
\text { nicht an- } \\
\text { strengende } \\
\text { Beschäfti- } \\
\text { gung im } \\
\text { Beginn. } \\
\text { Später } \\
\text { Wäscherin. }\end{array}$ & $\begin{array}{l}\text { Zunahme d. Um- } \\
\text { fangs d. Handge- } \\
\text { gelenks u. Vorra- } \\
\text { gung d. untern } \\
\text { Ulnaendes dorsal- } \\
\text { wärts. Form d. } \\
\text { Handgelenks wie } \\
\text { b. e. Luxatiou. } \\
\text { Hand volarwärts } \\
\text { getreten. Hand in } \\
\text { Mittelstellg. zw. } \\
\text { Ab-u. Adduktion } \\
\text { u. Vorderarm zw. } \\
\text { Pro- u. Supina- } \\
\text { tion. }\end{array}$ & $\begin{array}{l}\text { Radius mit Carpus in } \\
\text { normaler Verbindg., } \\
\text { Ulna luxiert. Radius } \\
\text { in sein. untern Drittel } \\
\text { leicht gekrümmt mit } \\
\text { Konvexität nach } \\
\text { außen u. dorsalwärts. } \\
\text { Ulna gerade. Repo- } \\
\text { sition möglich, aber } \\
\text { nicht bleibend. } \\
\text { Radiogramm: } \\
\text { Ulna gleichmäßig u. } \\
\text { leicht dorsalkonvex } \\
\text { gekrümmt. Ebenso d. } \\
\text { Radius gekrümmt } \\
\text { mit Konvexität nach } \\
\text { außen. Radius pal. } \\
\text { marwärts getreten. } \\
\text { Ulua an ihrer Stelle } \\
\text { nur scheinbarluxiert. } \\
\text { Radius u. Carp. in } \\
\text { normaler Beziehung. }\end{array}$ \\
\hline $\begin{array}{c}\text { Sauer. } \\
1906 .\end{array}$ & w. & $18 \mathrm{~J}$. & $\begin{array}{c}\text { Ein- } \\
\text { seitig, } \\
\text { links }\end{array}$ & $\begin{array}{l}\text { Dienst- } \\
\text { mädchen. }\end{array}$ & $\begin{array}{l}\text { Capit. ulnae stark } \\
\text { prominent, seine } \\
\text { Gelenkfläche zum } \\
\text { größten Teil frei. } \\
\text { Ulnar. Handrand } \\
\text { gegen d. Vola ab- } \\
\text { gesunken. Um- } \\
\text { fang d. Handgel. } \\
\text { vermehrt gegen- } \\
\text { über d. normalen } \\
\text { (rechten) Seite. }\end{array}$ & $\begin{array}{l}\text { Radiogramm: } \\
\text { Auffallend breite un- } \\
\text { regelmäßige Epiphy- } \\
\text { senfuge d. unt. Ra- } \\
\text { diusendes (zackige, } \\
\text { unregelmäß. Linie). } \\
\text { Radiusgelenkfläche } \\
\text { gegen d. Ulna steil } \\
\text { abfallend. Radius in } \\
\text { normaler Verbindg. } \\
\text { mitd.Carpalknochen; } \\
\text { Capit. ulnae hat zum } \\
\text { größten Teil sein. Ge- } \\
\text { lenkverbindg. mit d. } \\
\text { Carp. verloren. Vor- } \\
\text { derarmknochen nor- } \\
\text { mal geformt. }\end{array}$ \\
\hline
\end{tabular}




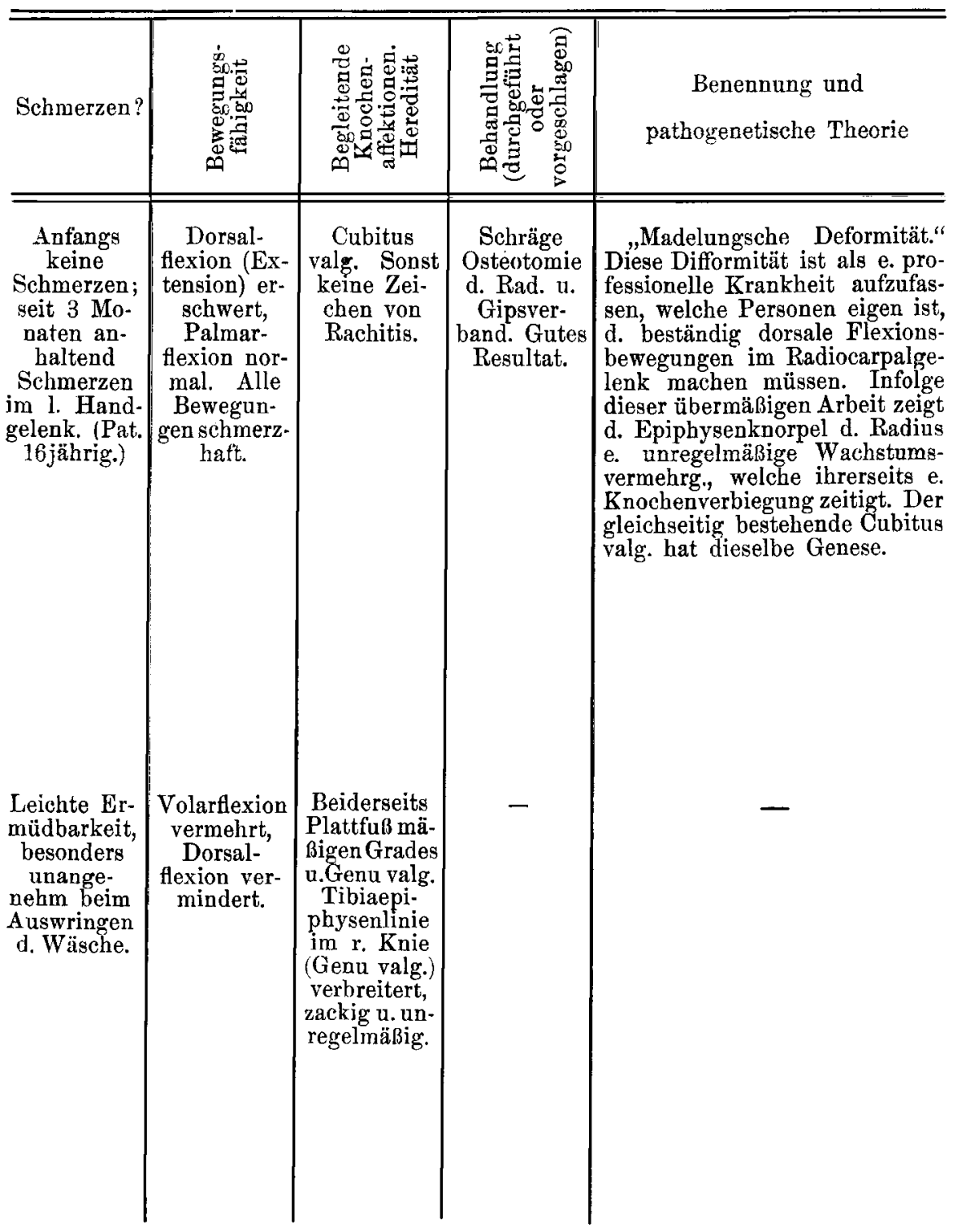




\begin{tabular}{|c|c|c|c|c|c|c|}
\hline 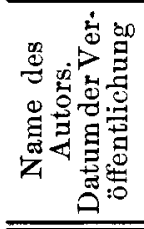 & 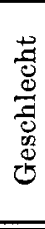 & 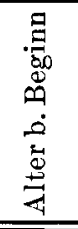 & 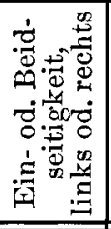 & 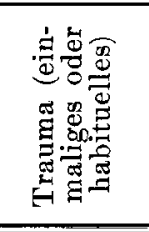 & Inspektion & 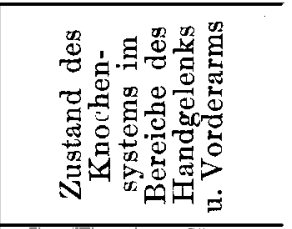 \\
\hline $\begin{array}{c}\text { Derselbe. } \\
1906 .\end{array}$ & w. & $\begin{array}{l}\text { Kin- } \\
\text { des- } \\
\text { alter }\end{array}$ & $\begin{array}{l}\text { Beid- } \\
\text { seitig }\end{array}$ & $\begin{array}{c}\text { Kein } \\
\text { Trauma. } \\
\text { Häusliche } \\
\text { Arbeit. }\end{array}$ & $\begin{array}{l}\text { Capit. ulnae stark } \\
\text { dorsalprominent; } \\
\text { distale Gelenk- } \\
\text { fläche d. Ulna ab- } \\
\text { tastbar. Umfang } \\
\text { d. Handgelenks } \\
\text { vergrößert, da- } \\
\text { durch, daß d. ul- } \\
\text { nare Handrand } \\
\text { volarwärts gesun- } \\
\text { ken ist. Flexor- } \\
\text { sehnen volarwärts } \\
\text { vorspringend.Dis- } \\
\text { tales Radiusende } \\
\text { leicht volarwärts } \\
\text { geneigt. Radius- } \\
\text { gelenkfläche in } \\
\text { norm. Verbindg. } \\
\text { mit d. Carpal- } \\
\text { knochen (Palpa- } \\
\text { tion). Rückfäche } \\
\text { dcs Vorderarms } \\
\text { geht aufd.Radial- } \\
\text { seite in e. sanften } \\
\text { Neigung in den } \\
\text { Handrücken über, } \\
\text { aber auf d. Ulnar- } \\
\text { seitesteilerAbfall. } \\
\text { Hand steht in } \\
\text { leichter Ulnarab- } \\
\text { duktion. Reposi- } \\
\text { tion unmöglich. }\end{array}$ & 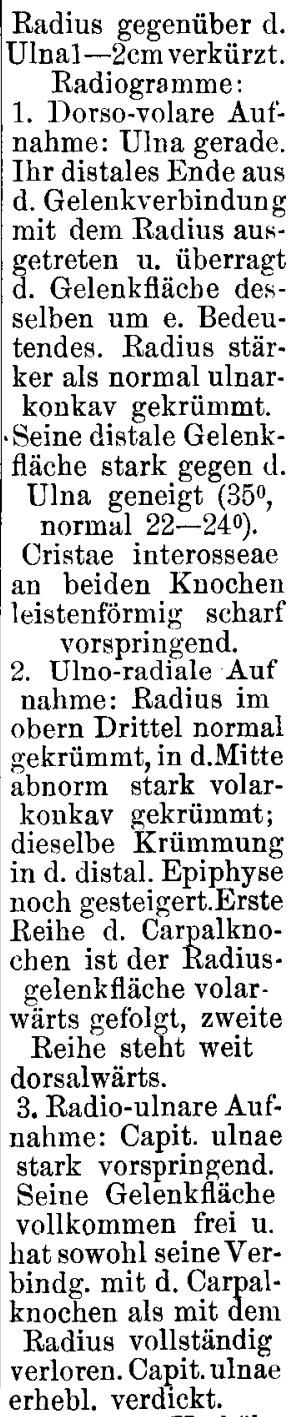 \\
\hline
\end{tabular}

4. Volo-dorsale Aufnahme: Verhältnisse am Rad. wie b. d. ersten Aufnahme. 
Über Manus valga oder sogen. Madelungsche Deformität d. Handgelenks. 571

\begin{tabular}{|c|c|c|c|c|}
\hline Schmerzen? & 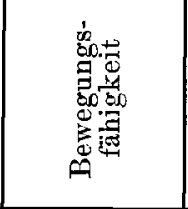 & 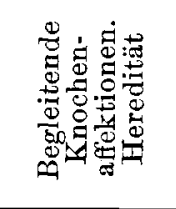 & 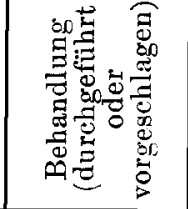 & $\begin{array}{l}\text { Benennung und } \\
\text { pathogenetische Theorie }\end{array}$ \\
\hline $\begin{array}{c}\text { Nie } \\
\text { Schmerzen. }\end{array}$ & $\begin{array}{l}\text { Keine Ar- } \\
\text { beitsbehin- } \\
\text { derung. Ak- } \\
\text { tive u. pass. } \\
\text { Bewegun- } \\
\text { gen nicht } \\
\text { schmerz- } \\
\text { haft. Pro- u. } \\
\text { Supination } \\
\text { nicht behin- } \\
\text { dert, Dorsal- } \\
\text { flexion be- } \\
\text { schränkt (bis } \\
135^{\circ} \text { ), Volar- } \\
\text { flexion ver- } \\
\text { mehrt (bis } \\
\text { s00). Radiale } \\
\text { Abduktion } \\
\text { fast aufge- } \\
\text { hoben, ul- } \\
\text { nare Abduk- } \\
\text { tion wesentl. } \\
\text { vermehrt. }\end{array}$ & $\begin{array}{c}\text { Mehrere } \\
\text { Geschwister } \\
\text { sollen ähnl. } \\
\text { deformierte } \\
\text { Handgelen- } \\
\text { ke haben. } \\
\text { Trichter- } \\
\text { brust; sonst } \\
\text { keine Zei- } \\
\text { chen von } \\
\text { Rachitis. }\end{array}$ & $\begin{array}{l}\text { Operation } \\
\text { wegen d. un- } \\
\text { sichern Er- } \\
\text { folgs nicht } \\
\text { ratsam. Ver- } \\
\text { meidung v. } \\
\text { forcierter } \\
\text { Volarflexion. } \\
\text { Methodische } \\
\text { Übungen z. } \\
\text { Kräftigung } \\
\text { d. Arms, ev. } \\
\text { zirkuläre } \\
\text { Lederban- } \\
\text { dage em- } \\
\text { pfohlen. }\end{array}$ & $\begin{array}{l}\text { "Manus valga." Die Made- } \\
\text { lungsche Deformität des Hand- } \\
\text { gelenks besteht in den ausge- } \\
\text { sprochenen Fällen in einer voll- } \\
\text { kommenen Luxation d. Carpus } \\
\text { im Ulnocarpalgelenk und des } \\
\text { Radius im Radioulnargelenk. } \\
\text { DieseLuxation ist bedingt durch } \\
\text { e. volare Krümmung d. Radius } \\
\text { teils an seinem distalen Ende, } \\
\text { teils in seiner Mitte. Das Radio- } \\
\text { carpalgelenk ist in der über- } \\
\text { wiegenden Mehrzahl der Fälle } \\
\text { intakt, nur ausnahmsweise be- } \\
\text { steht in demselben eine volare } \\
\text { Subluxationssteliung der Hand. } \\
\text { Der letzte Grund der Erkran- } \\
\text { kung ist mit Wahrscheinlichkeit } \\
\text { in e. rachitischen Knochenaffek- } \\
\text { tion zu suchen, die sowohl imo } \\
\text { Kindesalter als auch zurZeit der } \\
\text { Pubertät zur Entwicklung der } \\
\text { Deformität führen kann. }\end{array}$ \\
\hline
\end{tabular}




\begin{tabular}{|c|c|c|c|c|c|c|}
\hline 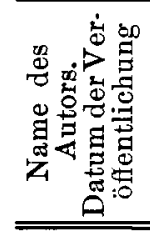 & 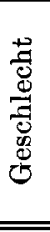 & 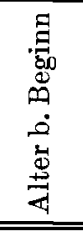 & 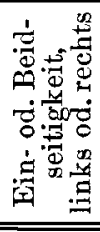 & 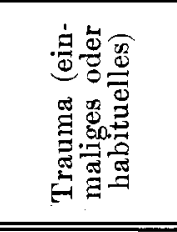 & Inspektion & 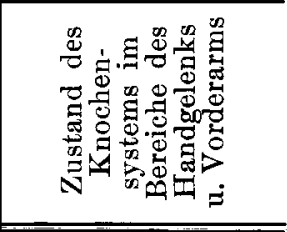 \\
\hline $\begin{array}{c}\text { Derselbe. } \\
1906 .\end{array}$ & w. & $\begin{array}{l}\text { Vor } \\
20 \mathrm{~J} .\end{array}$ & $\begin{array}{l}\text { Ein- } \\
\text { seitig, } \\
\text { links }\end{array}$ & $\begin{array}{l}\text { Dienst- } \\
\text { mädchen. }\end{array}$ & $\begin{array}{c}\text { Capit. ulnae stark } \\
\text { prominent, so daß } \\
\text { man e. groß. Teil } \\
\text { sein. Gelenkfläche } \\
\text { abtasten kann. } \\
\text { Ulnare Seite der } \\
\text { Hand etw. volar- } \\
\text { wärts gerückt, ra- } \\
\text { diale jedoch steht } \\
\text { genau in d. Längs- } \\
\text { achse d. Vorder- } \\
\text { arms. }\end{array}$ & $\begin{array}{l}\text { Radiogramm: } \\
\text { Radius verkürzt in- } \\
\text { folge Volarkrüm- } \\
\text { mung d. unt. Endes. } \\
\text { Radius mit d. Carpus } \\
\text { in normal. Verbinda. } \\
\text { Capit. ulnae vollstän- } \\
\text { dig aus d. Verbindg. } \\
\text { mit d. Carp. ausge- } \\
\text { treten, stark dorsal } \\
\text { prominent. Diese } \\
\text { Dorsalprominenz } \\
\text { noch vermehrt durch } \\
\text { e. leichte Krümmung } \\
\text { d. untern Ulnaendes } \\
\text { dorsalwärts. }\end{array}$ \\
\hline $\begin{array}{c}\text { Siegrist. } \\
1907 . \\
\text { (Fall I.) }\end{array}$ & $w$. & $11 \mathrm{~J}$. & $\begin{array}{l}\text { Beid- } \\
\text { seitig } \\
\text { (mehr } \\
\text { links) }\end{array}$ & $\begin{array}{l}\text { Nie Trauma, } \\
\text { keine } \\
\text { schwere Ar- } \\
\text { beit (spielt } \\
\text { Klavier). }\end{array}$ & $\begin{array}{l}\text { Deutl. Subluxa- } \\
\text { tionsstellg. Ver- } \\
\text { krümmung der } \\
\text { Vorderarme. St. } \\
\text { dorsales Vorragen } \\
\text { d. Capit. ulnae. }\end{array}$ & $\begin{array}{l}\text { 1. Krümmung d. gan- } \\
\text { zen Rad., besonders } \\
\text { aber d.distalen Endes } \\
\text { volarwärts u. dadurch } \\
\text { Schrägstellung der } \\
\text { distalen unt. Radius } \\
\text { gelenkfläche volar- } \\
\text { wärts (Diehung um e. } \\
\text { guere Achse). } \\
\text { 2. Krümmung d. un- } \\
\text { tern Radiusendes n. } \\
\text { d. Ulnarseite u. da- } \\
\text { durch Schrägstellg. } \\
\text { d.Radiusgelenkfüche } \\
\text { ulnarwärts (Drehung } \\
\text { um eine senkrechte } \\
\text { Achse). Dorsales } \\
\text { (passives) Zurück- } \\
\text { bleiben d. unt. Ulna- } \\
\text { endes. Leichte Sub- } \\
\text { luxation d. Carpus. } \\
\text { Verschiebg. d. Hand } \\
\text { ulnarseits. (Radio- } \\
\text { graphien.) }\end{array}$ \\
\hline $\begin{array}{l}\text { Derselbe. } \\
\text { (Fall II.) }\end{array}$ & w. & $14 \mathrm{~J}$ & $\begin{array}{l}\text { Beid- } \\
\text { seitig } \\
\text { (mehr } \\
\text { links) }\end{array}$ & $\begin{array}{c}\text { Kein } \\
\text { Trauma u. } \\
\text { keine } \\
\text { schwere Ar- } \\
\text { beit. (Ver- } \\
\text { käuferin.) }\end{array}$ & $\begin{array}{c}\text { Leichte Subluxa- } \\
\text { tionsstellung. } \\
\text { Starkes dorsales } \\
\text { Prominieren der } \\
\text { Capit. ulnae. } \\
\text { d. Radiusgelenkf } \\
\text { e. quer }\end{array}$ & $\begin{array}{l}\text { Gleichmäßige, volar- } \\
\text { wärts gerichtete } \\
\text { Krümmung d. ganzen } \\
\text { Rad. Unteres Ulna- } \\
\text { ende dorsalwärts ge- } \\
\text { krümmt, Capit. ulnae } \\
\text { dorsal lux. Neigung } \\
\text { ache volarwärts (um } \\
\text { e Achse). }\end{array}$ \\
\hline
\end{tabular}


Über Manus valga oder sogen. Madelungsche Deformität d. Handgelenks. 573

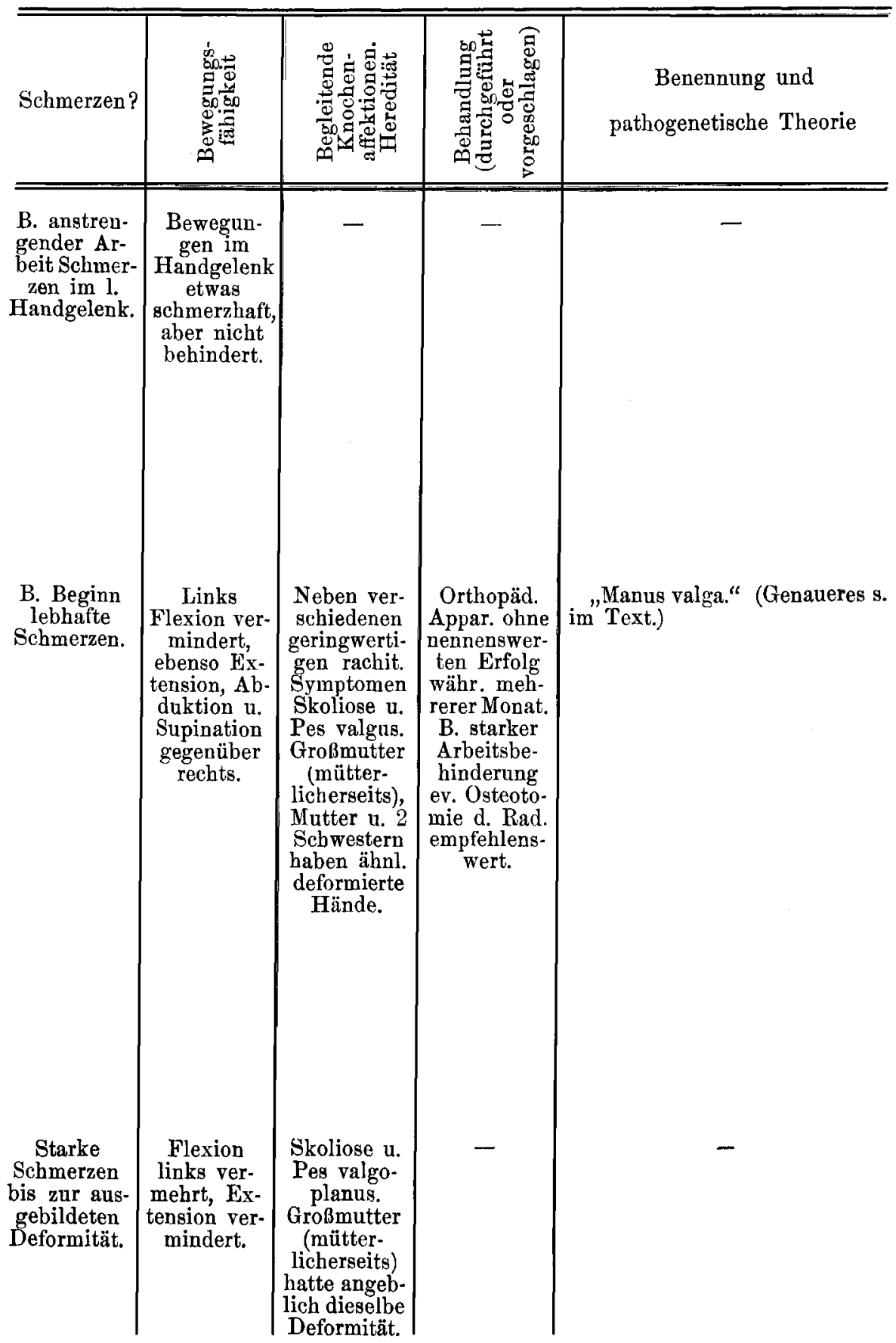




\begin{tabular}{|c|c|c|c|c|c|c|}
\hline 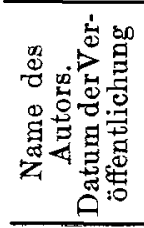 & 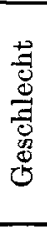 & 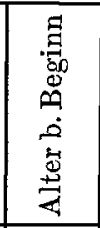 & 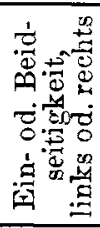 & 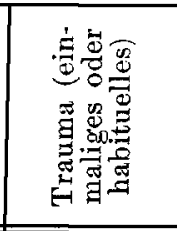 & Inspektion & 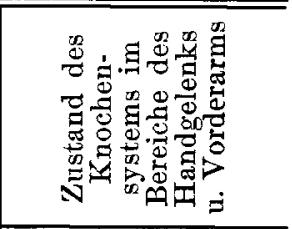 \\
\hline $\begin{array}{l}\text { Siegrist. } \\
\text { (Fall III.) }\end{array}$ & w. & $\begin{array}{c}10-12 \\
\mathrm{~J} .\end{array}$ & $\begin{array}{l}\text { Beid- } \\
\text { seitig }\end{array}$ & $\begin{array}{c}\text { Kein } \\
\text { Trauma, da- } \\
\text { gegen an- } \\
\text { strengende } \\
\text { Arbeit } \\
\text { (Wäscherin.) }\end{array}$ & $\begin{array}{l}\text { Starke Dorsalpro- } \\
\text { minenz d. Capit. } \\
\text { ulnae, Subluxa- } \\
\text { tionsstellung der } \\
\text { Hände gering- } \\
\text { gradig. }\end{array}$ & $\begin{array}{l}\text { Gleichmäßige Krüm- } \\
\text { mung des Radius in } \\
\text { seiner ganzen Länge } \\
\text { volarwärts, des dis- } \\
\text { talen Endes zugleich } \\
\text { ulnarwärts. Krümmg. } \\
\text { d. distalen Ulnaendes } \\
\text { dorsalwärts. Schief- } \\
\text { stellung d. Radius- } \\
\text { gelenkfläche volar-u. } \\
\text { ulnarwärts.(Drehung } \\
\text { um eine quere u. eine } \\
\text { senkrechte Achse wie } \\
\text { bei Fall I.) }\end{array}$ \\
\hline
\end{tabular}

\section{Klinische Besprechung.}

\section{1. Ätiologie.}

Sehen wir von den Theorien früherer Autoren $a b$, die nur historisches Interesse haben und die in der tabellarischen Übersicht kurz gewürdigt sind, so müssen wir doch als die erste Theorie diejenige des Autors erwähnen, welcher der Affektion den Namen gegeben hat. Madelung lokalisierte den deformierenden Prozeß in das Handgelenk selbst und zählte ihn unter die von Volkmann als "Wachstumsstörungen der Gelenke" beschriebenen Affektionen, zu denen auch der Pes valgus, das Genu valgum und die Skoliose gehörten. Nach Volkmanns Definition faßt diese Gruppe diejenigen Deformationen zusammen, „die nur bei Kindern und jugendlichen Individuen entstehen und abhängig sind von allmählichen Umformungen der zuvor wohlgebildeten artikulierenden Flächen durch mechanische Einflüsse, welche das normale Knochenwachstum alterieren". Madelung selbst suchte die letzte Ursache für das Zustandekommen der spontanen Handluxation in einem "primären Schwächezustand der Knochen", fügt aber sofort bei, daß derselbe bloß hypothetisch sei, indem er sich nicht genauer über denselben aussprechen kann. In den Arbeiten von Duplay und Delbet begegnen wir zuerst der bestimmt ausgesprochenen Ansicht, daß derselbe rachitischer Natur sei und als solcher seinen Sitz nicht im 


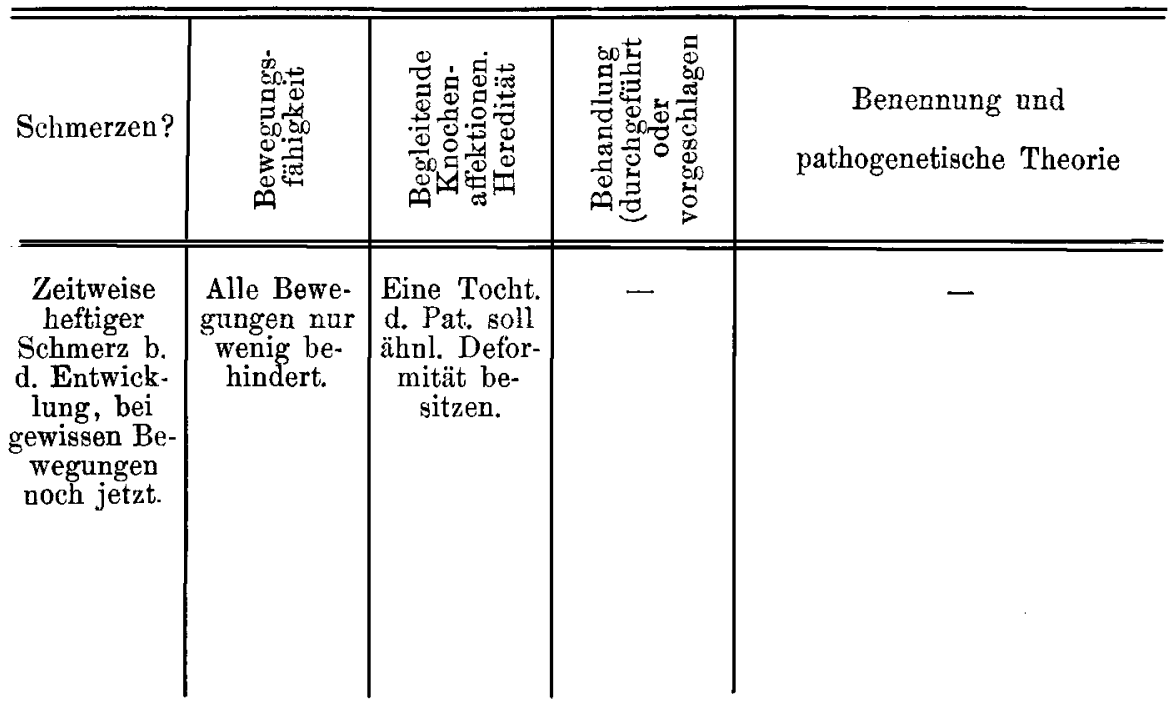

Gelenk selbst habe, sondern in den an das Gelenk herantretenden Vorderarmknochen. Die Verkrümmung des Radius ist nach Duplay das ursächliche Moment der Subluxationsstellung der Hand. Erstere hat ihren Sitz im unteren Radiusende. (Courbure rachitique de l'extrémité inférieure du radius.) Gemäß dem Zustandekommen der Deformität erst nach dem 10. Lebensjahr nimmt er Spätrachitis an. Noch weiter geht Delbet, der die Madelungsche Annahme einer Subluxation ganz verwirft und den alleinigen Grund für die Deformität in der Krümmung des Radius sucht. Kirmisson dagegen nimmt eine vermittelnde Stellung ein, indem er sowohl die Ansicht Madelungs von einer bloßen Krümmung der Epiphyse (ohne Ergriffensein der Diaphyse), veränderten Stellung der Gelenkfläche und Schlaftheit der Ligamente, als auch diejenige von Duplay und Delbet von einer Krümmung in der Diaphyse als möglich annimmt.

Da wir bei allen Autoren von Duplay an der Annahme von Rachitis oder Spätrachitis begegnen, so drängt sich uns die Frage auf, welche Anhaltspunkte für Annahme dieser Ätiologie bestehen. Von vorne herein muß auch ich bemerken, daß ich bei dem Mangel einer anatomischen Untersuchung keinen histologischen Beweis für das Vorhandensein von Rachitis erbringen kann. Die Annahme einer solchen dürfte trotzdem berechtigt sein, und zwar auf Grund von folgenden Tatsachen: In den meisten neueren Beobachtungen, d. h. in den Fällen, in denen überhaupt auf diesen Punkt 
geachtet wurde, finden sich gleichzeitig mit der Manus valga noch andere rachitische Deformitäten erwähnt, besonders häufig die Sk0liose und der Pes valgus, also die beiden rachitischen Erkrankungen, die beim weiblichen Geschlecht besonders häufig vorkommen, im Gegensatz zum Genu valgum, das beim männlichen Geschlecht vorwiegt. Auch in unsern beiden ersten Fällen und ebenso in den vier erst bei Abschluß der Arbeit beobachteten Fällen fanden wir rachitische Veränderungen des Skeletts, insbesondere Skoliose und Pes valgus und planus, während allerdings die Untersuchung des dritten Falles hierauf kein positives Resultat ergab. Dies beweist freilich um so weniger gegen die Möglichkeit einer ursprünglich rachitischen Veränderung, als es sich um eine 44 jährige Person handelte, bei der die augenfälligen Zeichen einer einstigen Rachitis geschwunden sein konnten.

Mit der Annahme einer Spätrachitis haben wir jedoch noch nicht alles erklärt; es bildet dieselbe bloß die pathologische Grundlage, auf der sich beim Vorhandensein fernerer Bedingungen die Manus valga entwickeln kann. Die wichtigste dieser Bedingungen liegt in der individuellen Prädisposition, die in besonders geformten Handgelenken besteht. Die Betrachtung einer Reihe von unter gleichen Bedingungen radiographisch aufgenommenen scheinbar ganz normalen Handgelenken, sowohl von gleichaltrigen, als von Personen verschiedenen Alters belehrte mich, daß schon beim sogenannten normalen Handgelenk nicht geringe Verschiedenheiten bestehen, und daß gewisse Eigentümlichkeiten vorkommen, die beim Vorhandensein eines abnorm weichen plastischen Knochens leicht in eine ausgesprochene Deformität übergehen können. Zur Illustration dieser Beobachtung gebe ich hier die Konturzeichnungen dreier normaler Handgelenke (Fig. 16, 17 und 18). So fand ich eine recht bemerkenswerte Verschiedenheit einmal in der Form der Handgelenksenden der Vorderarmknochen, ferner in der Lage der Epiphysenlinie bei gleichaltrigen Individuen ma damn auch in der Form und gegenseitigen Lage der Handwurzelknochen. Die klarste Auskunft über die Form der einzelnen Knochen und über die Lage derselben zueinander gibt uns die von uns stets benutzte stereoskopische Untersuchung, auf die wir hier nicht eingehen können. Es möge genügen, auf das Vorkommen solcher Verschiedenheiten im Bau des normalen Handgelenks aufmerksam gemacht zu haben. Es ist nun sehr wohl möglich, ja wahrscheinlich, daß solche Eigentümlichkeiten einen familialen Charakter zeigen. Dies würde uns die mehrfach beobachtete Heredität der Manus valga erklären. 
Eine solche weisen neben mehreren Fällen, die ich in der Literatur fand, meine sämtlichen drei Fälle auf. Besonders beweisend sind hierfür Fall 1 und 3 wo die objektive Untersuchung der ganzen Familie stattfinden konnte und wo besonders die radiographische Untersuchung den sichersten Beweis für eine Veränderung der Hand im Sinne der Madelungschen Deformität lieferte. Welcher Art

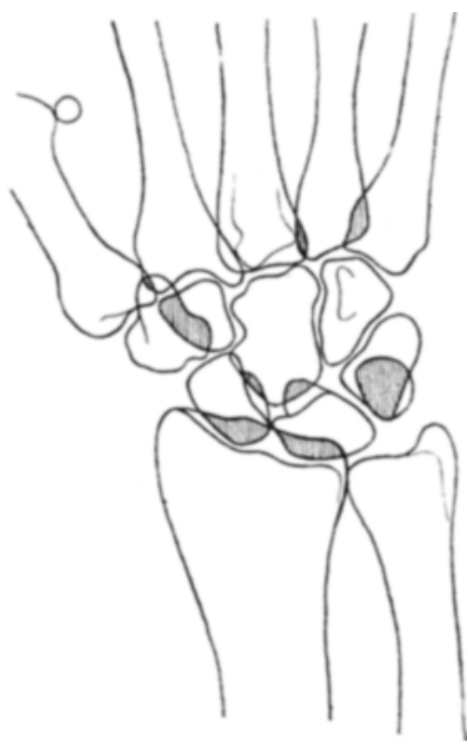

Fig. 16.

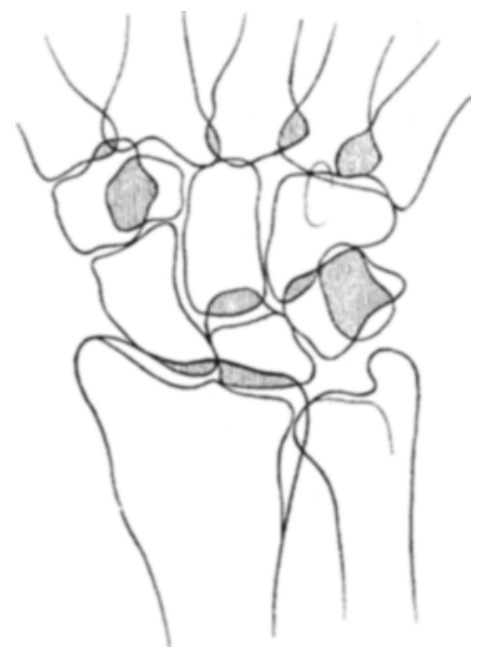

Fig. 17. Normales Handgelenk.

die hereditäre Veranlagung ist, das werden wir im nächsten Abschnitt sehen.

Zur Ausbildung der Deformität bei den vorhandenen zwei Bedingungen, - rachitischer Knochen und besonders formiertes Handgelenk - gehört endlich noch ein drittes Moment: die Frage des Berufes. Diese spielt aber nur eine sekundäre Rolle, indem bloß durch gewisse Berufsbeschäftigungen oder Anstrengungen eine schon vorhandene Deformität verstärkt werden kann. Eine Überanstrengung des Handgelenks durch bestimmte Berufsarbeit (z. B. Auswinden von Wäsche - einige der Patientinnen waren Wäscherinnen - bei uns Fall 3), führt natürlich viel leichter zur Deformation, ist aber durchaus nicht immer vorhanden, wie z. B. in unserem 1. Fall nicht. Übrigens ist der Begriff der Ü̉beranstrengung nur ein relativer, 
denn für ein allgemein schwächliches Mädchen, wie die Patientin des Falles 1, ist ein eifrig betriebenes Klavierspiel vielleicht nicht weniger mühsam als für eine robuste Person, wie Fall 3, die Berufsarbeit als Wäscherin. In der Literatur finden wir

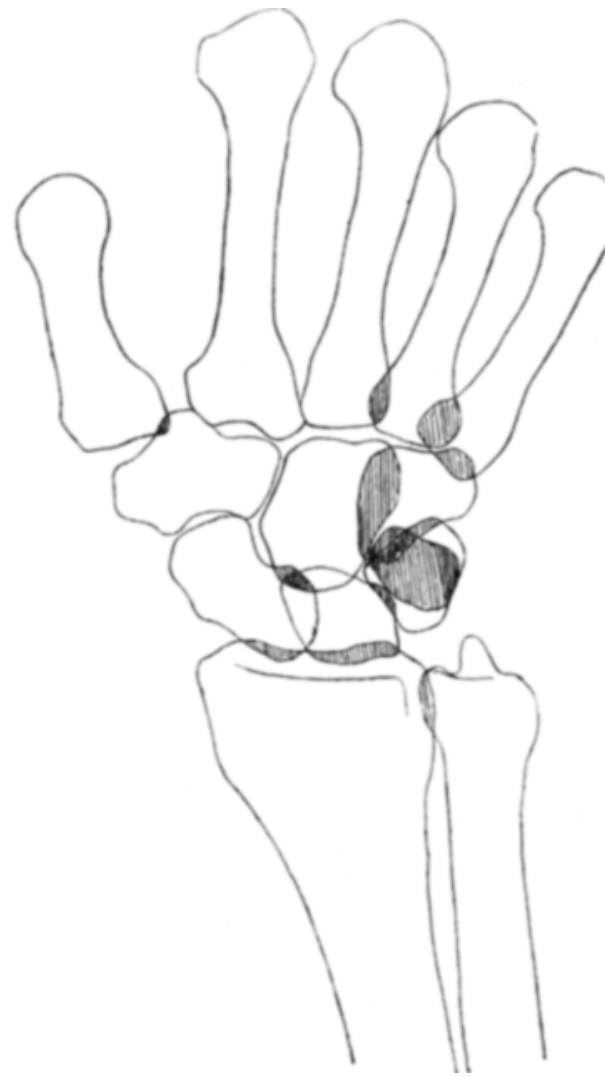

Fig. 18.

Normales Handgelenk. denn unter den an Manus valga leidenden Patienten sowohl Vertreter der wohlhabenden als der arbeitenden Gesellschaftsklasse. Daß letztere zahlreicher sind, erklärt sich schon aus dem häufigeren Vorkommen der Rachitis in jenen Kreisen.

Die Deformität findet. sich ungefähr gleich häufig einseitig wie doppelseitig; unter den einseitigen Fällen ebenso häufig rechts wie links, was jedenfalls von den Zufälligkeiten des einzelnen Falles abhängig ist. In bezug auf die Häufigkeit des Vorkommens der Krankheit besteht ein auffallender Unterschied zwischen den beiden Geschlechtern, indem das weibliche ungleich viel häufiger befallen wird als das männliche. Den Grund für dieses Überwiegen des weiblichen Geschlechts anzugeben ist mir vorläufig unmöglich; wahrscheinlich spielt hierbei die größere Schlankheit des Skeletts beim weiblichen Geschlecht mit. Beachtenswert ist, wie auch Sauer bemerkt, daß von einer andern Knochenerkrankung, der Osteomalacie, ebenfalls fast ausschließlich Frauen befallen werden. Das überwiegende Vorkommen der Madelungschen Deformität bei den Frauen scheint jedenfalls gegen eine rein mechanische Entstehungsweise des Leidens zn sprechen, da die An- 
forderungen, die an die Leistungsfähigkeit des Handgelenks bei jungen Männern gestellt werden, zweifellos höhere sind als bei Mädchen.

Das Lebensalter, in dem die Manus valga zur Entwicklung kommt, ist das Wachstumsalter und zwar meist das spätere, vom 1.2. bis zum 18. Jahre, also die Zeit, während der viele Patientinnen bei noch vorhandenem Knochenwachstum anstrengendere Arbeiten zu verrichten beginnen. Nur in einem sicheren Fall (1. Fall von Sauer) bestand die Erkrankung schon im frühen Kindesalter und schloß sich unmittelbar an eine Rachitis an.

Die Entwicklung des Leidens, das meist mit Schmerzen beginnt, erstreckt sich bis zur völlig ausgebildeten Deformation meist über mehrere Jahre, nach welcher Zeit die größern Schmerzen sistieren und der deformierende Prozeß stationär bleibt. In den meisten Fällen beginnt das Leiden ohne jede Veranlassung, in einigen schien es sich an ein Trauma z. B. eine brüske Bewegung, anzuschließen. Eine diesbezügliche anamnestische Angabe durch den Patienten selbst darf aber natürlich nur mit Vorsicht verwertet werden.

\section{Pathogenese.}

Wie wir aus unsern Beobachtungen ersehen haben, ist das Maßgebende an der Manus valga nicht in einer Veränderung im Handgelenk selber zu suchen, sondern in einer solchen der Vorderarmknochen. Die Formveränderung des Gelenkes ist also nicht die Folge einer Bändererschlaffung, wie sie Dupuytren u. a. als primäre Ursache hinstellten, sondern die Folge einer krankhaften Veränderung an den Vorderarmknochen. Betrachten wir dieselbe für jeden der beiden Knochen einzeln:

a) Das Verhalten der Ulna, um diese gleich vorwegzunehmen, ist ein passives. Infolge der Volarkrümmung des Radius bleibt sie dorsal luxiert zurück, wird aus dem Gelenkverband vollständig ausgeschaltet, verliert ihre das Handgelenk unterstützende Funktion und wächst dahin, wo sie den geringsten Widerstand findet. Da die Hauptmasse der Sehnen der Vorderarmstreckmuskeln radialseits von der Ulna verläuft, ohne deren unteres Ende selbst zu überbrücken, so liegt die Stelle des geringsten Widerstandes auf der Dorsalseite. Es erfolgt denn auch das Wachstum des untern Ulnaendes dorthin, wenigstens in den Fällen, wo das Knochenwachstum noch ein intensives ist, und es resultiert hieraus die regelmäßig vorhandene Krümmung des untern Ulnaendes nach dem Dorsum hin. Durch den 
verminderten Sehnenwiderstand erklärt sich auch, ein abnor'mes Knochenwachstum vorausgesetzt, die in vielen Fällen erfolgende Hypertrophie des Proz. styloid. ulnae. Es gilt natürlich die schon oben gemachte Bemerkung, daß ein I'eil der Hypertrophie der Ulna im Röntgenbilde auf Rechnung einer optischen Täuschung fällt.

b) Ganz anders verhält sich der Radius. Das wesentlichste des Prozesses besteht darin, daß dessen Gelenkfläche den rechten Winkel zur Ebene des Vorderarms verläßt und sich volarwärts neigt. Diese Volarneigung der Radiusgelenkfläche um eine quere Achse ist die Hauptursache der sich im Gelenk selbst abspielenden Veränderungen. Sie kann auf zweierlei Weise entstehen: entweder durch Verkrimmung des ganzen Radius, oder aber durch ungleiches Wachstum in der Epiphysenlinie, d. h. dorsal stärkeres, volar geringeres Wachstum bei wenig verkrümmter oder normaler Diaphyse. Die Formveränderung des Radiusschaftes entsteht infolge des Muskelzuges der Flexoren, auch in den Fällen, wo nicht spezielle professionelle Bewegungen ausgeführt werden. Wie schon Madelung ausführte, werden ja die meisten Arbeiten des täglichen Lebens durch die Beugemuskulatur verrichtet, die durch die Masse ihrer kontraktilen Substanz die Streckmuskulatur um ein Bedeutendes überwiegt. Der Muskelzug kamn, unter Voraussetzmng eines nachgiebigen Knochens, in doppelter Weise die Form des Radius verändern: erstens durch Hervorrufung einer Krümmung in der Diaphyse, zweitens durch Schiefstellung der Epiphyse. In beiden Fällen resultiert als erstes eine Volarneigung der Radiusgelenkfläche um eine quere Achse. Beide Möglichkeiten haben wir in unsern eigenen Beobachtungen gesehen; bei Fall 1 lag die Krümmnng in der ganzen Diaphyse, bei 2 mehr in der Epiphyse. bei 3 wiederum in der ganzen Diaphyse.

Zu dieser ersten Krümmung nach der Volarseite kommt, wie aus Röntgenbitdem ersichtich ist, als zweites Noment eine abnorme Ulnarneigung der Gelenkfläche des Radius. Eine solche Neigung besteht in geringem Grade schon normal, und es ist schwierig, wenn nicht unmöglich, zwischen normalem und pathologischem Befunde eine scharfe Grenze zu ziehen (s. Figuren 7, 8, 16-18). Gesteigert wird sie durch zwei Momente: erstlich

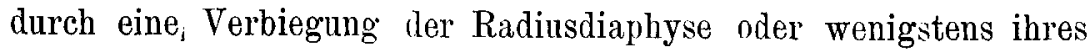
juxtaepiphysären Abschnittes mit Konkavität nach der Ulna hin, und ferner durch ein stärkeres Wachstum der Epiphyse selbst auf der Radialseite. 
Über Manus valga oder sogen. Madelungsche Deformität d. Handgelenks. 581

Vergleicht man bei unsern 3 Fällen den Grad der Ulnarneigung der Gelenkfläche mit demjenigen der ulnarkonkaven Krümmung der Diaphyse, so kommt man zum Schlusse, daß sowohl die Diaphysenkrümmung, als auch ungleiches Epiphysenwachstum mitgewirkt haben mußten. Bemerkenswert ist endlich die ulnare Ansladung der Epiphyse bei der einen Tochter von Fall 3 (s. Fig. 12).

Hier, d. h. bei der individuell verschiedenen Stellung der Radiusgelenkfläche setzt wohl hauptsächlich der Einfluß der Heredität ein. In Familien mit stark ulnar und vieleicht auch etwas volar geneigter Gelenkfläche des Radius wird sich, unter im übrigen gleichen Verhältnisse, $d . \mathrm{h}$. bei gleichem Grade von rachitischer Knochenerkrankung, die Deformität leichter entwickehn. als bei mehr quer gestellter. nach vorn gerichteter Gelenkfläche.

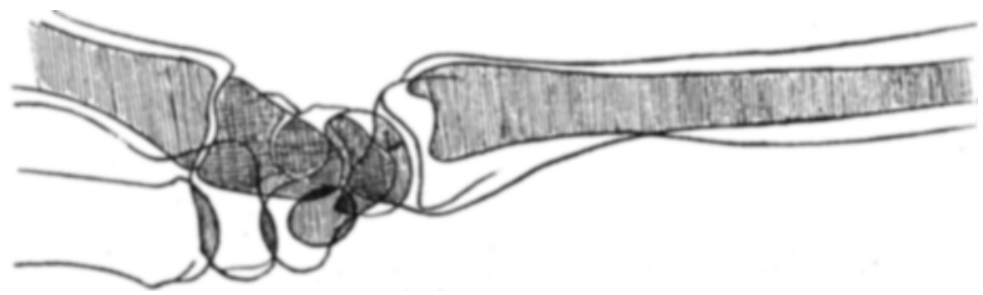

Fig. 19.

Normale Hand. Radio-uInare Aufnahme. $\mathrm{I}_{s}=$ Lunatum.

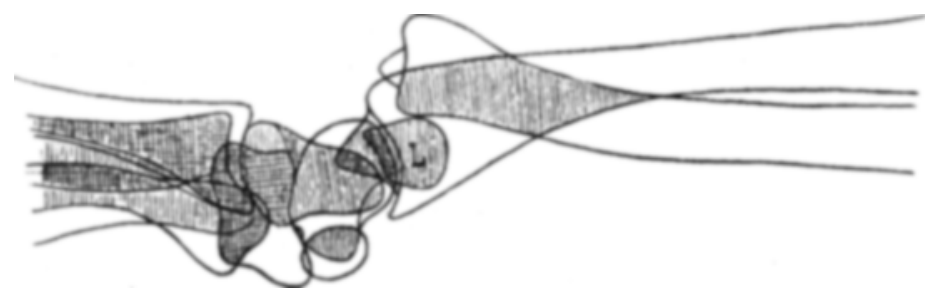

Fig. 20. Fall 1.

Iinke Hand. Kadio-ulnare Aufnahme. $\mathrm{L}=$ Lunatum.

c) Als drittes Moment beim ganzen Prozeß kommt hinzu eine Verlagerung der Handwurzel volar- und proximalwärts (siehe schematische Skizze. Fig. 19 u. 20). Der Muskelzug der Flexoren übt vor allem einen $\mathrm{Zug}$ anf das Handwurzelskelett aus, und erst durch Vermittelung desselben auch einen Druck auf den Radius. Je mehr sich der Radius verbiegt und sich seine Gelenkfläche volarwärts und ulnarwärts neigt, um so mehr verliert der Carpus seine normale 
Stätze und um so mehr wird er schließlich selbst durch den Muskelzug verlagert. Die Verschiebung äußert sich vor allem darin, daß der ganze Carpus etwas volarwärts gezogen wird, und zwar besonders die Knochenteile, die den Sehnenansätzen zunächst liegen, also die distalen Teile des Carpus. Die Folge davon ist eine leichte Einknickung zwischen der proximalen und distalen Reihe der Carpalknochen. Je mehr sich der Radius radialwärts ausbuchtet und je mehr die beschriebene uinare Neigung seiner Gelenkfläche eintritt, um so mehr werden endlich die Carpalknoclien durch den Muskelzug direkt auf die Volarseite von Radius und Ulna gezerrt, so daß z. B. die distale Gelenkfläche des os lunatum proximaler zu liegen kommt, als die Gelenkfläche der Ulna, wie wir dies bei unsern sämtlichen Fällen sehen. Das Lunatum selbst nimmt dabei die Form eines Keiles mit proximal gerichteter Spitze an (Fig. 4, 11). Ja sogar der ganze proximale Teil des Carpus, bestehend aus den Ossa naviculare, Lunatum und Triquetrum gleitet schließlich keilförmig auf die Volarseite der Vorderarmknochen und bildet statt eines Halbkreises einen Winkel, dessen Scheitel das Os lunatum bildet, wie dies bei Fall 1 beschrieben wurde und im Radiogramm leicht ersichtlich ist (s. auch Tafel XIII). Durch dieses Hinaufrücken des Carpus vor die Vorderarmknochen, in Verbindung mit der gleichzeitigen Knickung zwischen proximaler und distaler Reihe der Carpalknochen wird natürlich der ganze Carpus verkürzt. Geht der ganze Prozeß noch weiter, so muß es schließlich zu scheinbarer Luxation des Carpus nach der Volarseite kommen, wie wir den Beginn einer solchen bei Fall 1 kennen lernten. Von einer wirklichen Luxation ist nach dem Gesagten auch bei den schwersten Fällen nicht die Rede.

Aus der oben beschriebenen Art und dem Intensitätsgrade der stattgehabten Umformung des Handgelenks erklären sich unmittelbar die verschiedenen Bewegungsstörungen, an denen die mit Manus valga behafteten Patienten leiden. Es ist einleuchtend, daß bei der vorhandenen Volameigung der Radiusgelenkfäche die Volarflexion am wenigsten, die Dorsalflexion am meisten behindert sein muß. Erstere ist inden meisten Fällen sogar gegenüber der Norm vermehrt. Aber auch die Dorsalflexion ist trotz vorhandener Volarneigung der Gelenkfläche nicht in allen Fällen beschränkt; dies erklärt sich vielleicht dalurch, $d a$ l' durch fortwährend wiederholte starke Extensionsbewegungen die Articulatio intercarpea unterstützend für die Articulatio radiocarpea eintritt. Die Vermehrung der Ulnarabduktion, die auch ein fast konstantes Vorkommen hat, ist die natürliche 
Folge der Ulnarneigung der Radiusgelenkfläche. Pro- und Supination, als Bewegungen, die mit dem Handgelenk nichts zu tun haben, bleiben bei der Manus valga intakt.

Bevor wir die Besprechung der Pathogenese verlassen, soll noch eines einzig dastehenden Falles von Kirmisson Erwähnung geschehen. bei dem wir alle Charaktere der Madelungschen Deformität genau entgegengesetzt finden: Stellung der Hand in Dorsalflexion, Luxation der Ulna nach der Vola, Krümmung des untern Radiusendes nach dem Dorsum und dementsprechend vermehrte Kxtension und verminderte Flexion. Die Deformität bestand in gleicher Weise beidseitig und war von andern rachitischen Affektionen, - plattem Thorax, Skoliose - begleitet. Wieso sich in diesem Ausnahmefall die Deformität in der beschriebenen Weise entwickelte ist schwer zu sagen. Kirm is son selbst kann keine Erklärung dafür abgeben. Möglicherweise ist daran eine besondere Art der Beschäftigung schuld. Im Übrigen sei darauf hingewiesen, daß sich bei rachitischen Individuen auch das eine Mal Genua valga, das andere Mal Genua vara entwickeln, ja daß beide Deformitäten bei demselben Individuum vorkommen können.

3. Symptome und Diagnose.

Da sich dieselbe aus der Beschreibung des Krankheitsverlanfes und des objektiven Befundes von selber ergeben, halte ich eine Aufzählung der objektiven Symptome für überflüssig. - Betreffend die subjektiven Symptome, welche die Entstehung der Deformation begleiten, finden wir eine große Ähnlichkeit mit den andern verwandten spätrachitischen Deformitäten. Wie beim. Pes valgus adolescentium („entzündlicher Plattfuß") und der Coxa vara können wir zwei Stadien unterscheiden, ein schmerzhaftes erstes und ein schmerzfreies zweites. Nur selten freilich erreichen die Schmerzen des ersten Stadiums einen höhern Grad. Die Deformität wird deshalb in der Regel bloß zufällig entdeckt, wenn niçht kosmetische Gründe der Patientinnen zum Arzte führen.

Die Diagnose ist so einfach, dals von einer Differentialdiagnose meist nicht die Rede sein kann. Höchstens kämen in ungewöhnlicher Stellung geheilte Radiusbrüche, bezw. Epiphyseolysen und deformierende Arthritis in Frage. In beiden Fällen werden uns aber schon die Anamnese und der Befund am übrigen Körper anfklären, so daß das Röntgenbild zur Diagnosenstellung kaum nötig ist. Daß es dagegen für die Erkennung der Pathogenese von grundlegender Bedeutung ist, das haben wir oben gesehen. 


\section{Therapie.}

Wie ans den Arbeiten von Poulsen u. a. ersichtlich ist, hat die Therapie im Lanfe der Zeit je nach der pathogenetischen Erklärung, die sich die Autoren von dem Leiden machten, viele Wandlungen erfahren.

Da die Schmerzen vorübergehend sind, hätte ein operativer Eingriff, der in der Osteotomie des Radins zu bestehen hätte, nur kosmetischen Wert. Es waren ja auch nirgends die Funktionsstörungen so bedeutend, daß es zu ihrer Hebung einer operativen Hülfeleistung bedurfte. Nach dem Berichte von Poulsen, der wie Duplay die lineäre Osteotomie des Radius ausführte, waren allerdings die Resultate befriedigende. Was aber wenig dazu aufmuntert, das ist die Tatsache, daß durch die Osteotomie die sekundären Veränderungen an Handwurzelskelett in keiner Weise beeinflußt werden und daß eine solche sogar auf die Funktion des den abnormen Verhältnissen angepaßten Gelenkes nachteilig wirken könnte.

Bei dem ersten unserer drei Fälle, der allein nach ausgebildeter Deformität ärztliche Hülfe aufsuchte, haben wir uns mit der Applikation eines orthopädischen Apparates nach Art des von Redard, Hoffa u. a. angegebenen begnügt, der während mehrerer Monate ohne nennenswerten Erfolg getragen wurde. Ein besseres Resultat. ließe sich natürlich bei Anwendung desselben Apparates schon in der Zeit der Entwicklung des Leidens erwarten.

Nach Abschluß unserer Arbeit erschien eine Mitteilung von Dr. P. Ewald (Arch. f. klin. Chirurgie, Bd. 84, Heft 4), in welcher die Bedeutung einer Wachstumsstörung im Epiphysenknorpel hervorgehoben und auf Grund eines bei Vulpius beobachteten Falles die Möglichkeit einer traumatischen Entstehung dieser Störung angenommen wird, ähnlich wie in der Arbeit von Abadie.

Läßt sich anch dieser Fall, wie der Verfasser selbst zugibt, nicht ohne weiteres unter die Madelungsche Deformität einreihen, so zeigt er doch, daß, wie es auch in unserer Arbeit mehrfach betont worden ist, von den Wachstumsverhältnissen an der Epiphysenlinie eine nicht geringe Bedentung für die Schrägstellung der Gelenkflächen des Radius und damit für die Entstehung der wirklichen Manus valga zukommt. 
Über Manus valga oder sogen. Madelungsche Deformität d. Handgelenks. 585

\section{Literaturverzeichnis.}

1. 1832. Dupuytren, Leçons orales de elinique chirurgicale, T. I, S. 164. (Paris 1832.)

2. 1841. Bégin, Dictionnaire abrégé des sciences médicales, T. XIII, S. 493.

Art. Radiocarpien, et Bull. de l'Acad, de Méd. de Paris, 20 juin 1841. (Nach Abadie zit.).

3. 185. Malgaigne, Traité des fractures et des luxations, 1855, T. II. S. 711 .

4. 1859. Weber, C. O., Chirurg. Erfahrungen und Untersuchungen. Berlin 1859, S. 231. (Abschn. Verrenkungen des Handgelenks.)

5. 1864. Busch, W., Lehrbuch der Chirnrgie. Berlin 1864, Bd. II, 3. Abt., S. 111. (Nach Madelung zit.).

6. 1874. Nélaton, A., Eléments de pathologie chirurgicale. Paris 1874, T. III, S. 195.

7. 1875. Jean, Luxation incomplète congénitale du poignet. Bull. de la soc. anat., 23. mai 1875. (Nach Delbet zit.).

8. 18i9. Madelung, Die spontane Subluxation der Hand nach vorne. Arch. f. klin. Chir. 1879, Bd. 23.

9. 1884. Félix, Étude sur la subluxation spontanée du poignet en avant. Thèse de Lyon 1884-85, No. 246. (Nach Malfuson zit.).

10. 1885. Duplay, S., De l'ostéotomie linéaire du radius pour remédier aux difformités du poignet soit spontanées, soit traumatiques. Arch. générales de méd. 1885 , S. 385 .

11. 1891. Duplay, S., Un cas de rachitisme tardif des poignets. Gaz. des hôp., 31 déc. 1891, No. 152. (Nach Malfuson zit.).

12. 1892. Redard, Sur une déformation rare du poignet. Arch. gén. de méd. 1892, T. II, S. 651 .

13. 1892. Guépin, A., Laxité congénitale de l'articulation radio-cubitale inférieure et subluxation consécutive de la tête du cubitus en arrière: C. R. de la soc. de Biologie, 2 juillet 1892, S. 627.

14. 1888. v. Bergmann, Deutsche med. Wochenschr. 1888, S. 8 ti1. (Freie Vereinigung d. Chirurgen Berlins.)

15. 1894. Malfuson, Déformation du poignet d'origine probablement rachitique. Thèse de Paris 1894, No. 543.

16. 1894. Hoffa, A., Lehrbuch der orthopäd. Chirurgie, 2. Aufl. 1894, S. 477.

17. 1896. Cahier, L., Art. Luxations in Traite de Chirurgie von Le Dentu et Delbet. (Paris 1896.)

18. 1896. Féré, Ch., Note sur les difformités de développement du cubitus et de la clavicule. Revue de Chir. 1896, 5. 398.

19. 1897. Jagot, Sur un vice héréditaire de conformation des deux poignets. Arch. méd. d'Angers 1897, No. 4, S. 159. (Nach Abadie zit.).

20. 1891 u. 1897. Nélaton, Ch., Art. Luxations in Traité de Chir. de D uplay et Reclus. 1891 и. 1897, T. II, S. 124.

21. 1895. Guéry, A., Un cas de luxation progressive du poignet (subluxation spontanée de Madelung). Revue d'orthopédie, 1 juillet 1898, No. 4, S. 277 . 
586 XXII. Siftrist, Üb. Manus valga od. sog. Madelungssche Deform. d. Handgel.

22. 1899. Delbet, Carpus curvus. Leçons de Clinique chirurgicale. Paris 1899, S. 161. (Nach Abadie zit.).

23. 1899. Cabeça, Custodio, Sub-luxaçao espontanea del punho. Carpus curvus. Rev. port. méd. et chir. prat. 30 mai 1899, S. 51.

24. 1911. Dekeyser, A., Subluxation spontanée du poignet. (Subluxation de Madelung). Journal médical de Bruxelles 1901, No. 42. S. 593.

25. 1902. Kirmisson, E., Les difformités acquises de l'appareil locomoteur pendant l'enfance et l'adolescence. Paris 1902, S. 363.

26. 1902. Gevaert, Un cas de subluxation du poignet de Madelung. Luxation progressive des adolescents (Kirmisson). Revue d'orthopédie, 1 sept. 1902 , S. $33 \overline{5}$.

27. 1902. Ardouin, Un cas de luxation congénitale incomplete du poignet. Revue d'orthopédie, 1 sept. 1902, S. 351. (Nach Abadie et Poulsen zitiert).

28. 1903. Abadie, J., De la luxation progressive du poignet chez l'adolescent. Revue d'orthopédie 1 nov. 1903, S. 481.

29. 1903. Cnopf, Über Madelungs spontane Subluxation des Handgelenks nach vorne. Festschrift für Hofrat Göschel; zit. in Zentralbl. f. Chirurgie, Nr. 21, 1903.

30. 1904. Barthès, L., Ch., De la luxation progressive du poignet chez l'adolescent et chez l'adulte. Thèse de Paris 1904, Nr. 495.

31. 1904. Poulsen, Kr., Über die Madelungsche Deformität der Hand. Arch. f. klin. Chir., Bd. 75, H. 2, S. 506 . (Berlin 1904.)

32. 1905. Schulze, H., Ein Fall von spontaner Subluxation der Hand nach unten (Dupuytren-Madelungscher Subluxation). Münchner med. Wochenschrift $190 \overline{5}, \mathrm{Nr} .30$.

33. 1905. Volkmann, Th., Über Madelungsche Subluxation nach vorne. Diss., Leipzig 1905.

34. 1906. Putti, V., La deformita de Madelung. Arch. internat. de Chir. Vol. III, fasc. 1.

35. 1906. Schade, A., Kasuistischer Beitrag zu ken Luxationen im Handgelenk auf Grund patholog. Zustände. Diss., Kiel 1906.

36. 1906. Sauer, F., Die Madelungsche Deformität des Handgelenks. Beitr. z. klin. Chir., 48. Bd., 1. H., S. 179. 

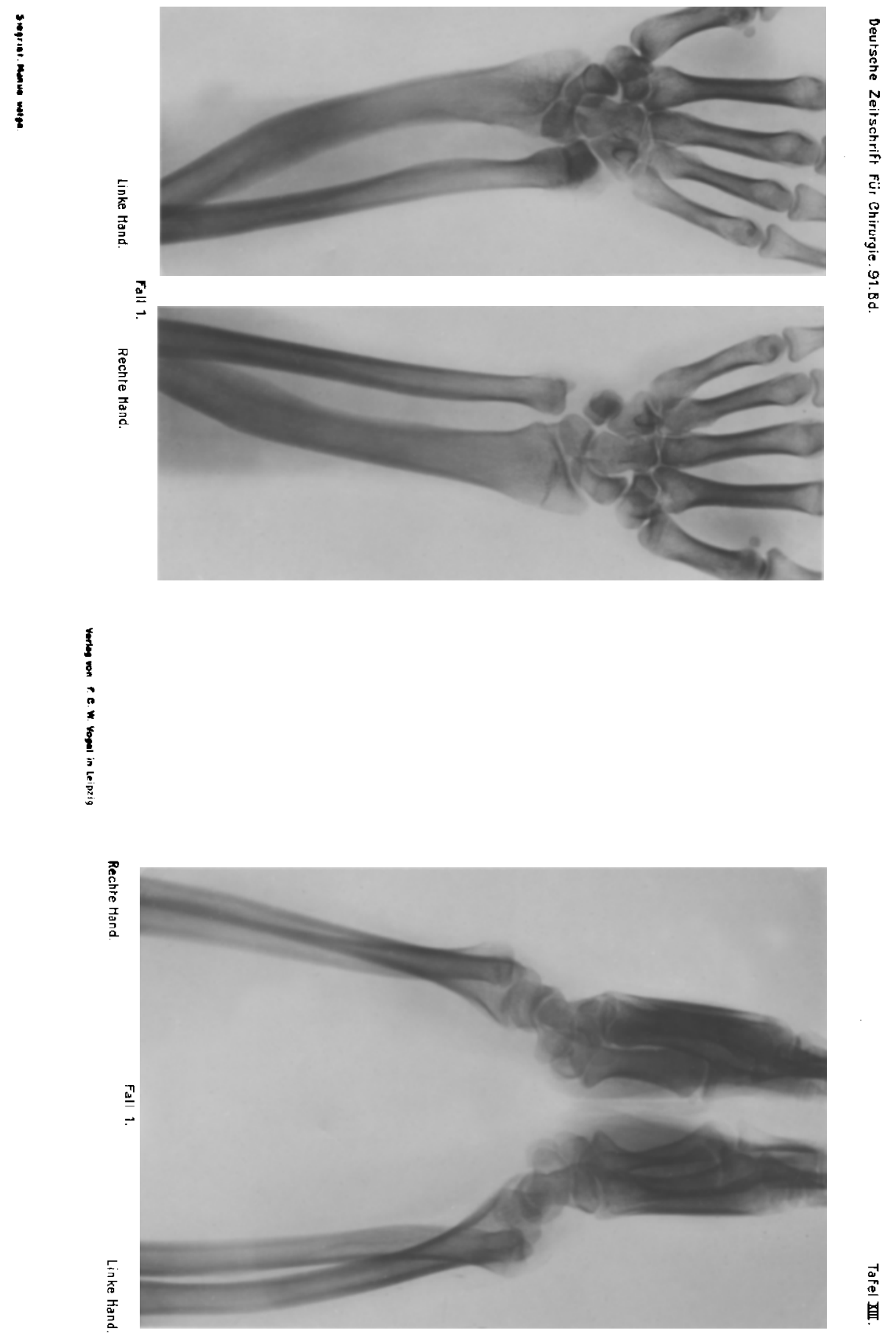